Portland State University

PDXScholar

6-2-2021

\title{
The Digital Divide and Health: Examining Digital Access as a Social Determinant of Health
}

Elizabeth Melissa Withers

Portland State University

Follow this and additional works at: https://pdxscholar.library.pdx.edu/open_access_etds

Part of the Community Health and Preventive Medicine Commons, and the Sociology Commons Let us know how access to this document benefits you.

Recommended Citation

Withers, Elizabeth Melissa, "The Digital Divide and Health: Examining Digital Access as a Social Determinant of Health" (2021). Dissertations and Theses. Paper 5705.

https://doi.org/10.15760/etd.7577

This Dissertation is brought to you for free and open access. It has been accepted for inclusion in Dissertations and Theses by an authorized administrator of PDXScholar. Please contact us if we can make this document more accessible: pdxscholar@pdx.edu. 
The Digital Divide and Health:

Examining Digital Access as a Social Determinant of Health

by

Elizabeth Melissa Withers

A dissertation submitted in partial fulfillment of the requirements for the degree of

Doctor of Philosophy

in

Sociology

Dissertation Committee:

Hyeyoung Woo, Chair

Matthew Carlson

Lindsey Wilkinson

Jill Castek

Portland State University

2021 
(C) 2021 Elizabeth Melissa Withers 


\begin{abstract}
This dissertation is comprised of three papers that consider ways in which one's level of digital access may impact self-rated health. Data are from multiple years of three separate nationally representative cross-sectional surveys: National Health Interview Survey, General Social Survey, and Health Information National Trends Survey to address the primary overarching research question: Is there an association between digital access and health? The examination of the relationship between digital access and health is situated within a social determinants of health perspective and draws on van Dijk's (2005) causal and sequential model of digital access. Education, income, race and ethnicity, work status, job satisfaction, occupation, and eHealth activities are all considered as possible moderators/mediators of the relationship between digital access and health. The findings of this dissertation suggest that digital access is an emerging social determinant of health. This may have important implications for existing health disparities as evidence of persistent socioeconomic and demographic disparities in digital access was also shown in this study.
\end{abstract}


Dedicated to the Digital Information and Communication Technologies that cared for my children while I completed this dissertation research. 


\section{ACKNOWLEDGEMENTS}

I am deeply grateful for all of the mentoring I have received from my committee members throughout my academic career thus far. Thank you to Matthew Carlson, Lindsey Wilkinson, and Jill Castek for their thoughtful, honest, and encouraging feedback. I have learned so much from each of them and truly appreciate their insight and expert advice. A very special thank you to my committee chair Hyeyoung Woo for the unwavering academic and professional support spanning over a decade. I cannot adequately express my appreciation for her guidance in this dissertation research, her generosity as an advisor, and general support throughout my time in the doctoral program.

A warm thank you as well to my friends and family for always believing in me and for supporting me in so many ways along this journey. To my creative, loving, adventurous, curious, and absolutely hilarious kids, Sienna Esmonde and Forrest Esmonde, thank you for making focusing on this research just challenging enough that I really had to push myself and grow immensely along the way. To my mom, Julie Scofield, dad, George Withers, stepmom, Donna Martin, brother, Sam Withers and sisterin-law, Marie Bourgeais, I am so grateful for the encouragement and love, the childcare and meals provided, and of course for being my role models in life. Thank you to all of my friends who are really more than friends and especially to Haley Throckmorton, who has always been my number one cheerleader and has been there to catch me every time I fall. And my eternal gratitude to my husband Nick Esmonde for having all of the patience that I am lacking and for loving me unconditionally. 
TABLE OF CONTENTS

ABSTRACT i

DEDICATION

ACKNOWLEDGEMENTS

LIST OF TABLES $\quad$ v

INTRODUCTION

INTRODUCTION REFERENCES

PAPER ONE

IS DIGITAL ACCESS SHAPING OR SHAPED BY SOCIAL DETERMINANTS OF HEALTH? CONSIDERING THE MEDIATION AND MODERATION EFFECTS OF EDUCATION, INCOME, AND RACE AND ETHNICITY 9

PAPER ONE REFERENCES 49

PAPER TWO

DIGITAL ACCESS TO WORK, JOB SATISFACTION, AND OCCUPATION:

EMERGING SOCIAL DETERMINANT OF HEALTH 56

PAPER TWO REFERENCES

PAPER THREE

ACCESS IN THE DIGITAL FIELD, EHEALTH BEHAVIORS AND HEALTH 93

PAPER THREE REFERENCES 134

$\begin{array}{ll}\text { CONCLUSION } & 139\end{array}$

CONCLUSION REFERENCES 149 


\section{LIST OF TABLES}

\section{PAPER ONE TABLES}

TABLE 1. DESCRIPTIVE STATISTICS BY LEVEL OF DIGITAL ACCESS 42

TABLE 2. T-TEST COMPARING ANALYTIC SAMPLE TO EXCLUDED CASES 43

TABLE 3. T-TEST COMPARING ANALYTIC SAMPLE TO EXCLUDED CASES (DIGITAL ACCESS MISSING) 44

TABLE 4. ORDERED LOGISTIC REGRESSION PREDICTING DIGITAL ACCESS 45

TABLE 5. ORDERED LOGISTIC REGRESSION PREDICTING SELF-RATED HEALTH 46

TABLE 6. ORDERED LOGISTIC REGRESSION PREDICTING SELF-RATED HEALTH WITH INTERACTIONS

TABLE7. DIRECT AND INDIRECT EFFECT OF EDUCATION (MODEL A), INCOME (MODEL B), RACE \& ETHNICITY (MODEL C)

AND MEDIATOR, DIGITAL ACCESS, ON HEALTH

\section{PAPER TWO TABLES}

TABLE 1. DESCRIPTIVE STATISTICS BY LEVEL OF DIGITAL ACCESS 82

TABLE 2. DESCRIPTIVE STATISTICS BY LEVEL OF DIGITAL ACCESS 83

TABLE 3. MEDIATION ANALYSES

\section{PAPER THREE TABLES}

TABLE 1. DESCRIPTIVE STATISTICS BY LEVEL OF DIGITAL ACCESS 126

TABLE 2. DESCRIPTIVE STATISTICS BY AGE

TABLE 3. ORDERED LOGISTIC REGRESSION PREDICTING

LEVEL OF MOTIVATION/MATERIAL DIGITAL ACCESS

TABLE 4. BINARY LOGISTIC REGRESSION PREDICTING SEARCHING FOR HEALTH INFORMATION ONLINE

TABLE 5. BINARY LOGISTIC REGRESSION PREDICTING CORRESPONDING WITH A DOCTOR ONLINE

TABLE 6. BINARY LOGISTIC REGRESSION PREDICTING SHARING HEALTH INFORMATION ON A SOCIAL NETWORKING SITE

TABLE 7. BINARY LOGISTIC REGRESSION PREDICTING PARTICIPATION IN ONLINE SUPPORT GROUP

TABLE 8. ORDERED LOGISTIC REGRESSION PREDICTING SELF-RATED HEALTH 


\section{INTRODUCTION}

Innovations in digital information and communication technologies (ICTs) continue to transform the social world in ways that expand well past the sharing of information. Practically every social institution from education to the labor market, media and entertainment to government participation, have been dramatically altered by technological innovations, making access to and the use of digital ICTs of growing importance for full participation in society.

The global flows of data, services and people that characterize the global knowledge economy have been underpinned by information and communications technology. From e-commerce to e-government, ICTs such as the internet and other global telecommunications systems are major conduits through which contemporary society is acted out (Selwyn and Facer 2007:2).

Given the extent to which digital access has become a necessary precursor to participation in much of the social world, it will likely affect the conditions which shape health outcomes.

Despite the proliferation of and growing reliance on digital ICTs, there remains a persistent gap, to varying degrees, along socioeconomic and demographic lines such as income, education, and race and ethnicity (Pew Research Center Internet/Broadband Fact Sheet 2021). For example, over 21 million individuals in the U.S. do not have broadband Internet access (Federal Communications Commission 2019). Some suggest increasing mobile phone access as a solution to the low penetration rates of home-based Internet connection in underserved and rural areas where fixed-line infrastructure is often absent (Nandi et al. 2016). It is true that ownership of smartphones and other mobile devices have increased in the U.S. for all adults, including among lower income Americans who 
tend to have much lower levels of technology adoption (Anderson and Kumar 2017). However, research has shown that mobile dependent users do not have the same level of access in terms of the development of digital literacy skills and confidence (Katz et al. 2019; Kumar et al. 2019; Puspitasari and Ishii 2016) or the activities they can perform (Dunaway et al. 2018; Mascheroni and Olafsson 2016; Park 2015; Wijetunga 2014). This is important because being smartphone dependent is especially common for adults belonging to racially marginalized groups and those with lower levels of education and income (Pew Research Center Mobile Fact Sheet 2019).

Understanding these nuances in the ongoing digital divide is of particular significance in terms of the effects on health outcomes as in many cases the populations being most negatively affected by digital inequality are the same marginalized populations who are already more likely to experience poor health. As such, the technological transformation of society into one where people are ever more reliant on digital ICTs could exacerbate existing health inequalities as digital inequality and health disparities occur along similar axes and are both rooted in an unequal distribution of resources.

This dissertation aims to explore the relationship between digital access and health outcomes. While the importance of digital access cannot be overstated in current society, empirical studies examining the influence of digital access on health are limited. This study is important and timely because as digital ICTs are becoming increasingly necessary for accessing important resources, digital access will likely have an increasing effect on the social health gradient. Much of the existing literature regarding issues of 
inequality and access to digital ICTs has focused on the consequences of limited access in terms of general participation in various fields of society. In terms of research regarding the relationship between digital ICTs and health, many have discussed what has been termed "eHealth" which can be understood as access to digital health resources such as electronic health records, online health and disease management information, and virtual healthcare. However, given the extent to which digital access has become so embedded in the conditions in which people live and work, one's level of access to digital ICTs will likely have impacts on health beyond utilization of healthcare and online health information searches.

Little research has examined the association between access to digital ICTs and health outcomes in terms of the role the digital field plays as a point of access to many important social determinants of health such as employment, income and education. This is particularly important because patterns of digital access may both reflect and exacerbate existing health inequalities. This research adds to the literature by focusing on the question of what are the rewards on health associated with digital access and what are the disadvantages of not having digital access?

\section{Structure of this Dissertation}

This dissertation is comprised of three papers that consider interrelated ways in which one's level of digital access may impact self-rated health. The social determinants of health are the conditions in which we live, which also shape our health. Rapid technological innovations and spread mean that those conditions are increasingly shaped 
by digital ICTs. Each paper utilizes data from a separate nationally representative crosssectional survey to address the primary overarching research question: is there an association between digital access and health?

Paper One: Is Digital Access Shaping or Shaped by Social Determinants of Health? Considering the Mediation and Moderation Effects of Education, Income, and Race and Ethnicity

Paper one of this dissertation explores the effects of the digital divide on health outcomes by examining whether the association varies by education, income, or race and ethnicity, as well as whether the relationship between these socioeconomic and demographic characteristics and health are mediated by levels of digital access. Using pooled data from six waves of the United States National Health Interview Survey (NHIS), this paper offers descriptive analyses of levels of digital access by important socioeconomic and demographic characteristics. This research explored first, the possibility that health returns on level of digital access might vary by education, income, and race and ethnicity and second, whether the relationship between digital access and health is mediated by education, income, and race and ethnicity.

Paper Two: Digital Access to Work, Occupation, Job Satisfaction: Emerging Social Determinant of Health

Paper two examines the relationship between digital access and health outcomes as it is shaped by access to the labor market related resources: work status, occupation, 
and job satisfaction. This research used pooled data from five cross-sectional waves of the General Social Survey (GSS) conducted by the National Opinion Research Center (NORC) at the University of Chicago. This paper addressed the fact that social inequalities, which ultimately determine disparities in health and which operate via mechanisms such as employment opportunities, are occurring increasingly in terms of one's material access, ability to use, and form of engagement with, digital ICTs. More specifically, this paper addresses questions regarding access to work-related resources such as employment, occupation, and job satisfaction and whether, as the digital economy has grown, access to these resources is now being structured by one's digital access.

Paper Three: Access in The Digital Field, eHealth Behaviors and Health

The third paper considers the relationship between digital access and health outcomes focusing on the role of eHealth behaviors. This paper uses pooled data from six cycles of the nationally representative cross sectional Health Information National Trends Survey (HINTS) conducted by the National Cancer Institute. This particular aspect of the relationship has received the attention of previous research. However, this study contributes to the literature by situating the examination of the relationship between eHealth activities and self-rated health within a theoretical framing of the digital field as a site for the reproduction of existing social inequalities. The analyses for this paper were also stratified by age which has been a persistent predictor of digital access and is important to consider in terms of the effects on health, as aging has compounding effects 
on health. Furthermore, this paper offers an empirical examination of some aspects of van Dijk's sequential model of digital access by analyzing whether higher levels of resources such as income, or categorical inequalities such as level of education, are associated with different levels of digital access. Additionally, the paper addresses the sequential nature of his perspective by examining whether digital access in terms of mode of connection is associated with what is considered the subsequent stages of access in terms of engaging with eHealth activities.

\section{Conclusion}

I conclude with a summary of the findings from this dissertation research. Each paper examines the overarching question of whether or not there is an association between digital access and health. Using data from three nationally representative data sets and examining the relationship between digital access and health using different measures and in terms of different possible mechanisms, these three papers offer important findings individually and taken together. I discuss implications of these findings as well as limitations of the studies. 


\section{REFERENCES}

Anderson, Monica, and Madhumitha Kumar. 2017. "Digital Divide Persists Even as Lower-Income Americans Make Gains in Tech Adoption." Pew research center 22 (2017).

Dunaway, Johanna, Kathleen Searles, Mingxiao Sui, and Newly Paul. 2018. "News Attention in a Mobile Era." Journal of Computer Mediated Communication, 23(2), 107-124.

Federal Communications Commission 2019 Broadband Deployment Report 2019:331. https://docs.fcc.gov/public/attachments/FCC-19-44A1.pdf. Accessed March 30, 2021.

Katz, Vikki. S., Meghan B. Moran, and Katherine Ognyanova. 2019. "Contextualizing Connectivity: How Internet Connection Type and Parental Factors Influence Technology Use Among Lower-Income Children". Information, Communication \& Society, 22(3), 313-335.

Mascheroni, Giovanna and Kjartan Ólafsson. 2016. "The Mobile Internet: Access, Use, Opportunities and Divides Among European Children." New Media \& Society 18(8): 1657-1679.

Nandi, Somen, Saigopal Thota, Avishek Nag, Sw Divyasukhananda, Partha Goswami, Ashwin Aravindakshan, Raymond Rodriguez, and Biswanath Mukherjee. 2016. "Computing for Rural Empowerment: Enabled by Last-Mile Telecommunications." IEEE Communications Magazine 54(6): 102-109. 
Park, Yong Jin. 2015. "My Whole World's in My Palm! The Second-Level Divide of Teenagers' Mobile Use and Skill." New Media \& Society 17(6): 977-995.

Pew Research Center. 2019. “Mobile Fact Sheet.” Internet and Technology https://www.pewresearch.org/internet/fact-sheet/mobile/

Puspitasari, Lia and Kenichi Ishii. 2016. "Digital divides and mobile Internet in Indonesia: Impact of smartphones." Telematics and Informatics 33(2): 472-483.

Selwyn, Neil and Keri Facer. 2007. "Beyond the Digital Divide." Opening Education Reports. Bristol: Futurelab. https://www.igiglobal.com/viewtitlesample.aspx?id=38308\&ptid=495\&t=beyond+digital+divide: +toward+an+agenda+for+change Retrieved March 30, 2021

Wijetunga, Dinuka. 2014. "The Digital Divide Objectified in The Design: Use of The Mobile Telephone by Underprivileged Youth in Sri Lanka." Journal of ComputerMediated Communication 19(3): 712-726. 


\section{Paper one}

Is Digital Access Shaping or Shaped by Social Determinants of Health? Considering the Mediation and Moderation Effects of Education, Income, and Race and Ethnicity

Over the past few decades, some demographic gaps in digital access have nearly closed altogether. Disparities in access between some groups such as men and women, have been significantly reduced and in many cases disappear altogether when other factors are controlled for (Zickuhr and Smith 2012). However, despite recent gains in digital access among the US population in general, there remains a persistent gap to varying degrees, along socioeconomic and demographic lines such as income, education, and race and ethnicity (Pew Research Center Internet/Broadband Fact Sheet 2021). These forms of digital inequality may have detrimental effects on existing health inequalities because the patterns are closely related to other forms of social exclusion, which have significant effects on health outcomes. In other words, the populations being most negatively affected by digital inequality are in many cases the same marginalized populations who are already more likely to experience poor health.

The purpose of this study is to examine the relationship between digital access and health outcomes. Patterns of digital access may impact health outcomes as both are shaped by existing patterns of social inequalities, and barriers in access to the social determinants of health available via digital information and communication technologies (ICTs) may reproduce and even exacerbate existing health disparities. More specifically, socioeconomic disparities in digital access patterned by level of education and income 
may exacerbate existing health disparities patterned by these same socioeconomic determinants. Additionally, racial and ethnic disparities in health persist alongside of racial and ethnic disparities in digital access. This research explores the effects of the digital divide on health outcomes by examining the association between level of access and self-rated health, whether the association varies by education, income, or race and ethnicity, as well as whether the relationship between these socioeconomic and demographic characteristics and health are mediated by level of digital access.

The American Medical Association defines the six social determinants of health domains as economic stability, neighborhood, education, food, community/social support, and health care system (Bennett et al. 2018). These are the domains of life within which social forces shape the conditions of daily life that impact a wide range of health outcomes and life chances. While digital divide scholars have certainly focused much attention on the effects of digital access on economic stability, social support, and education, research has rarely been in terms of the relationship to health outcomes. Much of the research regarding the impacts of the digital divide on health has been investigating the relationship in terms of either the last social determinants domain listed, interacting with and accessing health care systems, or the use of digital health applications. This research contributes to the existing digital divide literature as well as the research on social determinants of health, by examining the effects of digital access as a potential social determinant of health. 


\section{THEORETICAL BACKGROUND AND LITERATURE REVIEW}

This research draws on the theoretical frameworks developed and empirical research conducted by digital divide scholars as well as those from within the field of medical sociology. In the following section, I provide a brief overview of these perspectives and the ways in which they will work together to inform the analyses for this study as well as a review of the literature pertaining to the digital divide and persistent socially patterned health disparities.

\section{Social Determinants of Health and Fundamental Cause Theory}

A social determinants of health perspective is a useful framing for understanding how health outcomes might be shaped by level of digital access. In general, a social determinants of health perspective aims to examine the ways in which health inequalities within and between countries, are not 'natural' but rather the result of social factors (Marmot et al. 2008). The unequal distribution of access to important resources directly impacts the conditions in which one lives in terms of access to things like education, housing, or healthcare, as examples, and ultimately shape experiences of morbidity and mortality as a result of these conditions (Marmot et al. 2008). Put in terms of digital access, the social determinants of health are the ways in which the above circumstances are shaped by one's level of digital access. In other words, because access to the basic goods and services, opportunities for education and employment, as well as political and social participation, which are key drivers of morbidity and mortality, are increasingly 
accessed via digital ICTs, digital access itself should be considered a social determinant of health.

Furthermore, by employing a social determinants of health perspective, the focus of this research is aimed at understanding how social structures may affect health outcomes as opposed to limiting analyses to more proximal and individually-based risk factors. Without this broader understanding, research on health disparities runs the risk of employing "approaches to managing race, class and sex/gender [that] distill the effects of social and relational ideologies, structures and practices organized around such differences into characteristics of discrete and self-contained individuals" (Shim 2002:134). In other words, by incorporating a more structure-oriented approach to understanding health disparities, socioeconomic or demographic differences in health are understood in terms of the role of historically constructed relations of power rather than individuals' characteristics or behaviors (Williams 2003).

According to fundamental cause theory, some social conditions should be considered fundamental causes of disease as they cannot be explained solely in terms of how they shape more proximal risk factors. Rather, some social conditions shape an individual's access to vital resources that are essential for avoiding risks for morbidity and mortality or minimizing the consequences of illness should it occur (Link and Phelan 1995). Resources that help individuals avoid risks for disease include, but are not limited to, knowledge, power, prestige as well as more interpersonal properties such as social connectedness. A close relationship to such resources is the essential feature of a fundamental social cause. Working within a framework informed by fundamental cause 
theory, an individual's access to vital resources should be understood as essential for promoting and maintaining good health. Put in terms of the digital divide, because access to so many resources has become largely, and in some cases entirely, available via digital ICTs, digital access will affect health outcomes. These resources can be understood as the mechanisms which link digital access to health outcomes.

\section{Digital Access: A Sequential Model}

For the purposes of this research, digital access can be understood in terms of van Dijk's (2005) multiple access model of digital inequality. Within this framework digital access occurs sequentially in terms of four types of successive stages and kinds of access: (1) motivational access, (2) material or physical access, (3) skills access, and (4) usage access. Here, problems of accessing digital technologies gradually shift from the first two stages and kinds, if and when motivation and material access have been achieved, to the second two stages and kinds of access, skills and usage. Although there are a number of theoretical perspectives for understanding the digital divide, van Dijk's sequential model is particularly useful for understanding the multiple points at which level of digital access may be either restricted or advanced by their access to resources. Furthermore, by incorporating the ability to use digital ICTs in ways that reap offline rewards for the user into the concept of digital access, this perspective is also useful for understanding how health outcomes might be shaped by one's level of digital access.

First, motivational access, the first phase and kind of access, can be understood as the motivation on the part of the potential user to use digital ICTs (van Dijk 2005:27). 
Many people lack the motivation either because they perceive digital ICTs to be irrelevant to their lives (Stanley 2003) or because they are skeptical and have anxiety about or distrust for digital ICTs (Harrington, Mcelroy and Morrow 1990; Stanley 2003; Torkzadeh and Angulo 1992; Weil, Rosen, and Wugalter 1990). Once someone has overcome the barriers to motivational access, their access is shaped by the second stage and kind of access. Material and physical access is generally understood as being able to access a computer with Internet connection. However, the diffusion of smart phones and other forms of technology such as tablets, has expanded this type of access. According to Van Dijk's theoretical framework, this stage and type of access is differentiated as physical access and conditional access (2005: 48). Here, physical access refers to the hardware of computers and other digital ICTs, as well as the network connection. Conditional access, on the other hand, refers to the applications, programs, and other digital content that often requires an additional fee. Increasingly, physical access is only as useful as the level of conditional access available.

The third type and stage of access is skills access which refers to the different kinds of skills necessary for utilizing digital ICTs. Which leads to the final stage and type of digital access having to do with the actual use of digital ICTs. Usage access can be understood in terms of the frequency and duration of use, the types of activities performed and content accessed using digital ICTs (van Deursen and van Dijk 2014). This disparity in usage behaviors is important because not all digital ICT activities provide users with the same benefits (Zillien and Hargittai 2009). As van Dijk notes, while the first three stages and types of digital access are necessary preconditions to 
usage access, they are not sufficient conditions (2005). As such, among those who have achieved motivational, physical and material, and skills access there remains disparities in how people use the Internet and as a result their Internet use returns. In other words, the benefits of using digital ICTs are not uniformly distributed among people who have attained the first three levels of access, because what an individual does with the Internet, for example passive consumption uses vs. active and creative uses, remains critical.

Having considered the ways in which a social determinants and fundamental cause perspective in conjunction with van Dijk's sequential model for understanding digital access provide a useful framework for understanding the relationship between digital access and health, the following sections move on to consider some possible mechanisms through which the relationship might operate. More specifically, education, income, and race and ethnicity are discussed with regards to their relationship with health outcomes as well as in terms of disparities in digital access.

\section{Education}

Digital access may affect health outcomes as digital ICTs become increasingly important for accessing educational opportunities. Research has thoroughly demonstrated that education is a significant predictor of health across a variety of health outcomes (Antonovsky 1967; Crimmins and Saito 2001; Elo and Preston 1996; House et al. 1994; Kitagawa and Hauser 1973; Mirowsky and Ross 2003; Ross and Wu 1995; Schnittker 2004). Higher levels of education are associated with lower rates of morbidity, with regards to the most common acute and chronic diseases (Cutler and Lleras-Muney 2006). 
Health outcomes may be affected by levels of digital access in terms of the relationship between access to digital ICTs and education opportunities and academic achievement.

Today, digital ICTs are part of the curricula at every level of education and across the U.S. However, van Deursen and van Dijk argue, that while operational and formal digital skills may be taught in primary and secondary education, instruction on content related skills such as information, communication, and strategic skills, is largely absent from education curricula (2014). These content related skills, such as the ability to search, select, process, and evaluate information from the Internet, are necessary for academic achievement and especially for higher education. This suggests that those who have acquired these content related digital skills will have more success in attaining higher levels of education and in this sense digital skills access may impact educational attainment. In fact, some research suggests that even among elementary aged students, digital access is associated with higher academic achievement (Juang and Russel 2006; Judge 2005; Paino and Renzulli 2013).

On the other hand, formal digital literacy skills instruction as well as informal learning supported through digital ICTs have become integral to curriculum of formal education learning environments. In this sense, an individual's level of skills access may depend on the amount of formal education they have received. Research has indicated that individuals with higher levels of education have higher levels of digital skills (Hargittai 2002, 2003; Zillien and Hargittai 2009). In fact, the gap in access to digital ICTs and Internet connection by educational attainment is one of the most pronounced. While $98 \%$ of college graduates use the Internet, as of 2019 , only $84 \%$ of those who 
graduated from high school and $71 \%$ of those with less than a high school degree report use (Pew Research Center Internet/Broadband Fact Sheet 2021). Educational attainment is not only a strong predictor of Internet adoption; it is also highly related to a range of digitally mediated activities and skills (van Deursen and van Dijk 2011) as well as with ownership of digital ICT devices.

Income

Economic resources and employment directly affect an individual's ability to access material resources such as food, housing, and health care services, which are essential to health. Digital access may affect health through an income pathway both in terms of an individual's ability to find and maintain employment, and in terms of the type of employment or occupation they are qualified to do. People with low to no digital access face considerable barriers when looking for work both in terms of the kinds of jobs they are eligible for (skills access) and the way in which access to employment opportunities has become digitized with online job listings and applications.

According to a Pew Internet \& American Life report (2015), 54\% of adult Americans have used the Internet to search for information about a hob and $45 \%$ have submitted a job application online (Smith). Higher levels of digital skills benefit job seekers, as they may be faster and more efficient in their online communications and information gathering. Kuhn and Mansour (2011) found that Internet job search reduces individual workers' unemployment durations by about 25 percent. Digital skills are also viewed by employers as a desired skill set which means the higher the level of digital 
skills the more competitive an individual will be in the labor market. Additionally, some research has indicated that the expansion of personal social networks through online activity can provide an individual with access to informal information about job opportunities (Hampton and Wellman 2000; Fountain 2005). In this sense, digital access may lead to increased social capital, which is in turn vital for employment opportunities.

Access to digital ICTs may also play an important role in structuring earnings for individuals who are employed. Some research shows Internet users gain significantly more in earnings than non-users (DiMaggio and Bonikowski 2008). This may be because higher levels of digital skills mean employees have better access to labor-market information, and are possibly better and more efficient at doing their work.

Moreover, health disparities structured by economic inequalities may be impacted by digital access as level of access has been shown to vary by level of income. According to a Pew Internet \& American Life Project report, as of 2011 only $62 \%$ of low-income individuals making less than $\$ 30,000$ per year use the Internet, as compared to $90 \%$ of individuals making \$50,000-74,999 per year and 97\% of those who make more than \$75,000 annually (Zickuhr and Smith 2012).

Level of income impacts access to digital ICTs in a number of ways. For example, income may impact motivational access in terms of the equipment and connection one has available to them. The quality of the equipment available and the reliability of the connection will have an impact on how people come to the decision of whether or not they want to access digital ICTs. Leisure time may also be a mechanism at work in the relationship between income and motivational access. In the sense that economic capital 
provides the material necessities for existence, it also provides a freedom from spending time acquiring and maintaining those necessities (Bourdieu 1990:252). In turn, motivational access may be shaped by the amount of time resources an individual has at their disposal (van Dijk 2005: 39).

The relationship between income and material and physical access is somewhat straightforward in terms of the extent to which people can afford digital ICTs equipment and Internet connection. Although many Americans do have access to computers and Internet connection from their homes, many rely on gaining physical and material access at public computer labs, the homes of friends and family, and at work or school. And while material and physical access is generally understood as being able to access a computer with Internet connection, the diffusion of smart phones and other forms of technology such as tablets, has expanded this type of access. However, the device used to access the Internet may enable or limit the types of usage activities one is capable of engaging in. This is not only true in terms of whether a person accesses the Internet via computer or smartphone, but also in terms of the quality of the device and reliability of the network connection as well as the location where a person gains access.

Level of income may also impact digital skills access. For example, children who grow up with computer and Internet in their homes are at an advantage when it comes to skills access because research has shown that much of digital literacy is learned informally at home as it is embedded in one's life. Some scholars argue digital literacy skills are acquired in informal spaces (Meyers, Erickson, and Small 2013) as opposed to through formal instruction. As such, individuals who find themselves in environments 
where digital ICTs are being used fluidly and on a frequent basis may be at an advantage in their ability to develop their own skills.

Usage access is another important consideration for the mechanisms through which digital access may be shaped by level of income. Patterns of usage access can be understood as being shaped by disproportionate distribution of economic, cultural, and social capital. Similar to motivational access, economic capital may determine levels of usage access in terms of quality of the equipment available and the reliability of the connection. For example, some research suggests that the type of device used to access the Internet affects the types of activities users engage in such that those using computers are significantly more likely to participate in "capital enhancing" activities than those using mobile devices (Pearce and Rice 2013).

Time resources may also be a mechanism at work in the relationship between level of income and usage access (van Dijk 2005). In the sense that economic capital provides a freedom from spending time acquiring and maintaining the material necessities for existence (Bourdieu 1990:252), higher levels of income may also free time up for individuals to engage more deeply with digital ICTs. However, as van Dijk notes, this relationship is not a simple corollary as there are relatively high household usage rates among individuals who are unemployed, disabled, and retired suggesting that time resources are not always shaped simply by economic capital (2005). Furthermore, usage access is not a simple matter of time spent on the Internet, rather type and diversity of digital activity is a key component to usage access. Some of the digital ICT activities 
which may not provide many capital enhancing opportunities such as gaming, video and audio streaming, and social interaction, are rather time-consuming activities.

\section{Race and Ethnicity}

Racial and ethnic health disparities persist in terms of higher rates of mortality among racially marginalized populations as well as in the earlier onset and greater severity and progression of disease (Williams and Mohommed 2013). Research has documented the ways in which these inequities in morbidity and mortality are the result of social marginalization of racial and ethnic minorities and other vulnerable populations (Weinstein et al. 2017; Ford et al. 2017). Racial and ethnic health disparities are the result of racism impacting health in multiple ways. Williams and Mohammed (2013) highlight three primary pathways through which empirical evidence has shown racism to affect health. These include, the ways in which institutional racism shape socioeconomic status, cultural racism produces harmful stereotypes, prejudices and degrading images which negatively impact the health of their subjects, and lastly, interpersonal discrimination is associated with negative psychosocial stress that has harmful effects on health.

The COVID-19 pandemic has highlighted health consequences of structural racism experienced by Black, Hispanic/Latinx, and American Indian/Alaskan Natives. These groups make up a higher proportion of essential workers and therefor experience higher risk of exposure to the virus (NCSL National Conference of State Legislatures 2021). Furthermore, these groups have higher prevalence of underlying medical conditions which have been shown to increase the risk of severe reactions to the COVID- 
19 virus including hospitalization and death due to the virus (Centers for Disease Control and Prevention 2021).

As for the impact of digital access on racial and ethnic health disparities, one important area of interest is in terms of the relevancy or perceived relevancy of the materials and applications available via digital ICTs. Because materials and applications available via digital ICTs are made by and for dominant culture, those belonging to marginalized racial or ethnic groups may find the content undesirable, irrelevant, or inaccessible. In analyzing the underlying causes for racial differences in Internet adoption, Brock (2006) claims that a lack of relevant and interesting content is more likely a significant force than that of a lack of digital skills. As Daniels writes, "race and racism persist online in ways that are both new and unique to the Internet, alongside vestiges of centuries-old forms that reverberate both offline and on" (Daniels 2012:696). As such, access to the social determinants of health available via digital technologies will likely produce racially disparate returns on health as these technologies are embedded with, perpetuate, and even spark new forms of racism and racial discrimination.

Regarding the relationship between digital access and health, racial and ethnic gaps in level of digital access may have a mediation effect. Although there have been persistent gains in closing racial disparities in digital access, some gaps do remain. For example, as of 2019 , while $79 \%$ of white adults were broadband users, only $66 \%$ and $61 \%$ of their Black and Hispanic, respectively, counterparts were (Pew Research Center Internet/Broadband Fact Sheet 2021). Additionally, there are racial disparities in access in terms of adults who do not use broadband at home but own a smartphone. While only 
$12 \%$ of white adults are smartphone dependent, $23 \%$ of black adults and $25 \%$ of Hispanic adults rely solely on a smartphone for their Internet connection. As such, the relationship between race and ethnicity and health may be increasingly mediated by level of digital access as a mechanism through which social determinants of health are accessed.

\section{RESEARCH QUESTIONS}

This research aims to examine digital access from a social determinants of health perspective by asking the following research questions. (1) Whether or not, and to what extent do, socioeconomic and demographic characteristics remain salient predictors of digital access independent of control variables? (2) Is higher digital access associated with better self-rated health? (3) Does the effect of digital access on health vary by socioeconomic and demographic characteristics? (4) Is the association between socioeconomic and demographic characteristics medicated by level of digital access?

\section{METHODS}

Data

This research uses data from the United States National Health Interview Survey (NHIS). The NHIS collects information on a variety of health and sociodemographic topics and is widely used in health-related research. The NHIS is a cross-sectional household interview survey with a multistage area probability design that permits the representative sampling of households and non-institutional group quarters within the U.S. Sampling and interviewing are continuous throughout each year and the survey has been conducted every year since 1957 . The survey consists of the core questions which 
contain four major components, household, family, sample adult, and sample child. Supplements to the core are integrated into the survey as a means of responding to any new public health data needs as they develop. Beginning in 2012, a survey item asking respondents whether or not they use the Internet was included in the sample adult questionnaire. Data from the seven cross-sectional surveys between 2012-2018 were pooled for this research in order to analyze trends in digital access and association with self-rated health. Analyses were restricted to the adult sample $(\mathrm{N}=224,638)$. Cases with missing values for the primary dependent variable for this study, self-rated health $(n=96)$ were excluded from all analyses resulting in an analytic sample of $\mathrm{N}=224,542$. However, for those analyses addressing the first research question and for which digital access was the dependent variable, cases with missing values for the variables used to create that measure were also excluded $(n=10,269)$ resulting in an analytic sample of $n=214,273$. These cases were included in the subsequent analyses as a dichotomous measure for digital access unknown.

\section{Measures}

Due to the broad exploratory and descriptive aims of the research, multiple measures were used as dependent, independent, and mediating or moderating variables to assess the range of research questions each specifically. 


\section{Dependent Variables}

Health. Self-rated health, which measures general overall condition of health, is the primary outcome variable. This measure asks respondents to indicate their health status in terms of a five-point scale ranging from excellent to poor and was reverse coded (1 Poor, 2 Fair, 3 Good, 4 Very Good, 5 Excellent).

Digital Access. The digital access measure was constructed using three separate survey items related to respondents' use of the Internet. The first survey item used asks respondents a simple yes, no question, "Do you use the Internet?" Two further survey items, which when used in combination measure the frequency of use, were then asked to those respondents who answered yes indicating that they do use the Internet. The first of these questions asks for the frequency of Internet use in terms of number of units ranging from 0-995, while the second question asks for the frequency of Internet use in terms of time units which include, Day, Week, Month, and Year. Using these three measures of Internet use I constructed both a ordinal variable as well as 5 dichotomous measures of digital access. The ordinal variable which is used as the dependent variable in the regression analysis addressing the first research question, is coded 0 non-users, 1 less than daily Internet use, 2 one-time daily Internet use, 3 more than once daily Internet use. Cases with missing values for the digital access measure were excluded from the analyses employing the ordinal digital access measure $(n=10,269)$. The dichotomous digital access variables measured the same levels of access as the ordinal variable: (1) Non-users, (2) less than daily Internet use, (3) one-time daily Internet use, (4) more than once daily 
Internet use, which was the reference category, and the cases with missing values for any of the three variables used to create these measures were included in the analysis using a dummy variable (5) digital access unknown. These measures were used in analyses in which digital access was the independent or mediating variable.

\section{Independent Variables}

Education. The education variable measures highest level of education and is coded into three dichotomous variables (1) high school or less, (2) some college, and (3) college degree or higher which is the reference category. Cases with missing values for the education measure are included as level of education unknown $(n=929)$. In order to examine whether the effect of digital access on health varied by level of education six interaction terms were also created using the education and digital access variables and include, (1) high school or less * non-users (2) high school or less * less than daily Internet use (3) high school or less * once daily Internet use (4) some college * non-users, (5) some college * less than once daily Internet use, (6) some college * one-time daily Internet use. Those who use the Internet more than once daily and an education level of college or more were the reference categories.

Income. The income variable measures total family income from all sources in the previous calendar year. For this research I used an income measure provided in the public use NHIS data which includes imputed values to replace the missing data. I collapsed the 24-income bracket measure top coded at $\$ 115,000$ total family income, into 7 
dichotomous variables, (1) Income $<\$ 15 \mathrm{~K}$ (2) Income $\$ 15-\$ 30 \mathrm{~K}$, (3) Income $\$ 30-\$ 45 \mathrm{~K}$, (4) Income $\$ 45-\$ 60 \mathrm{~K}$, (5) Income $\$ 60-\$ 90 \mathrm{~K}$, (6) Income $\$ 90-\$ 115 \mathrm{~K}$, and (7) Income $\$ 115 \mathrm{~K}+$ which was used as the reference category. In order to examine whether the effect of digital access on health varied by level of income three interaction terms between an ordinal measure of income (coded $1<\$ 15 \mathrm{~K}, 2 \$ 15-\$ 30 \mathrm{~K}, 3 \$ 30-\$ 45 \mathrm{~K}, 4 \$ 45-\$ 60 \mathrm{~K}, 5$ $\$ 60-\$ 90 \mathrm{~K}, 6 \$ 90-\$ 115 \mathrm{~K}, 7>\$ 115 \mathrm{~K})$ and digital access were created and include (1) income * non-users, (2) income * less than daily Internet use, and (3) income * once daily Internet use, with those who use the Internet more than once daily as the reference categories.

Race and Ethnicity. The race and ethnicity variables were derived from two survey measures, the first of which asked respondents a yes, no question of whether or not they were of Hispanic ethnicity and the second of which measures respondents' self-reported race. These measures were used to create four dichotomous race and ethnicity variables; (1) Hispanic which includes all respondents who report being of Hispanic ethnicity, (2) non-Hispanic Black which includes all respondents who report being Black or African American and are not of Hispanic ethnicity, (3) non-Hispanic other which includes respondents who indicate that their race is American Indian / Alaskan Native, Asian, Multiple Race, Other Race, and Race group not releasable 'other' and who are not of Hispanic ethnicity, and (4) non-Hispanic white, the reference category, which includes respondents who report being White and not of Hispanic ethnicity. 
In order to examine whether or not the effects of digital access on health varied by race and ethnicity I created nine interaction terms between the digital access measures and the race and ethnicity measures. These interaction variables include (1) Hispanic * non-users, (2) Hispanic * less than daily Internet use, (3) Hispanic * once daily Internet use, (4) non-Hispanic Black * non-users (5) non-Hispanic Black * less than daily Internet use, (6) non-Hispanic Black * once daily Internet use, (7) non-Hispanic other * nonusers, (8) non-Hispanic other * less than daily Internet use, (9) non-Hispanic other * once daily Internet use. Those who use the Internet more than once daily and non-Hispanic white are the reference categories.

\section{Control Variables}

Several relevant social and demographic variables were controlled for to more accurately estimate the associations between digital access and health. First, gender is measured using the dummy variable female, with male as the reference category. Age and cohort are also controlled for. Age is included as a control variable both because it is important to consider the effects of aging on health and because research has shown persistent age disparities in access to digital ICTs (Pew Research Center Internet/Broadband Fact Sheet 2021). Age is included as a continuous measure of years old and is top coded at 85 . Additionally, cohort measures are included as a means of controlling for the historical and cultural differences in experiences with access to digital ICTs and the Internet more generally. Using the survey year and the age variable, I created four dichotomous measures: (1) Pre-Baby Boomers which includes respondents 
born in 1945 or earlier, (2) Baby Boomers which includes respondents born between 1946-1964, (3) Gen X which includes those born between 1965-1980, and (4) Millennials which is the reference category and includes those born in 1981 or after.

Poverty status is controlled for using a dichotomous measure. Poverty status is derived from total family income, including the imputed values to replace missing cases, and using the federal poverty threshold such that respondents whose total family income from all sources is less than $250 \%$ of the poverty threshold are considered to be experiencing poverty and those at or above $250 \%$ are not. Those at or above $250 \%$ of the poverty threshold are the reference category.

Employment status is controlled for using three dichotomous measures created using a survey item which asked respondents what their employment status has been for the past 1 to 2 weeks. The employed measure, which was the reference category, includes respondents who indicated they were working for pay at a job/business, working, without pay, at a job or business, or with a job but not at work. The unemployed measure includes those who indicated they were unemployed or not in the labor force. Cases with unknown or missing values were included in the employment status unknown measure.

The NHIS public use data has a measure for health insurance coverage status which was constructed by the National Center for Health Statistics (NCHS) and is derived from responses to a series of questions regarding respondent health insurance coverage. The variable was recoded into three dichotomous measures (1) has health insurance, which is the reference category, (2) does not have health insurance, and (3) health insurance status unknown. Finally, marital status was controlled for using five 
dichotomous measures (1) married, which included those who reported living with their partner and is the reference category, (2) never married, (3) divorced or separated, (4) widowed, and (5) marital status unknown.

Analytic Approach

First, T-tests were conducted in order to compare the sample characteristics between those cases included in analyses with those excluded due to missing values for the digital access variables to evaluate the possible presence of selection bias. I then conducted descriptive analysis to show socioeconomic and demographic characteristics stratified by level of digital access.

Next, ordered logistic regression analyses were used to estimate the effects of socioeconomic and demographic characteristics on level of digital access. This model was restricted to the analytic sample which excluded the cases with missing values for the digital access measures $(\mathrm{N}=214,273)$. Ordered logistic regression was conducted to estimate the effects of digital access on self-rated health. Model 1 includes just the digital access measures and Model 2 adds all other independent and control variables to Model 1. Ordered logistic regression was conducted in order to further examine the nature of this association in terms of whether or not the effects of digital access on health vary by a) level of education, b) level of income, or c) race/ethnicity. For each of these estimates, model 1 includes digital access measures along with the respective primary independent variable. In model 2 the interaction terms are added to model 1 and the control variables are included in the full $3^{\text {rd }}$ model. 
Finally, three models of mediation were conducted to determine whether the effect of digital access on health functions more as a mediator between previously studied social determinants of health level of education (Model 1), level of income (Model 2), or race/ethnicity (Model 3). These mediation analyses were conducted using the KHB method (Breen, Karlson, and Holm 2013; Kohler, Karlson, and Holm 2011). The KHB method decomposes the total effect of the independent variables on the dependent variable into direct effect of the independent variable on the dependent variable save the effects of the mediators and the indirect effect of the independent variable on the dependent variable through the mediating variables. These models were restricted to the analytic sample which excluded the cases with missing values for the digital access measures $(n=214,273)$ as the ordinal measure for digital access was used.

\section{RESULTS}

\section{Sample Demographics}

Descriptive statistics were stratified by level of digital access, non-users $(n=57,355)$, less than daily Internet use $(n=35,578)$, once daily Internet use $(n=91,767)$, more than once daily Internet use $(n=29,573)$, Internet use unknown $(n=10,269)$ as well as for the full sample $(n=224,542)$ in order to compare sample characteristics across groups. Table 1 provides the descriptive statistics stratified by level of digital access.

These results indicate that the average level of overall self-rated health is highest among respondents who report using the Internet more than once daily (3.95) and declines across digital access level: once daily use (3.87), less than once daily Internet 
use (3.70) with the lowest average health among respondents who report being nonInternet users (3.14).

The average age of the non-user group (61.07) is more than ten years older than any other group, with those in the digital access unknown (50.13) being the second oldest group on average. The more than once daily Internet users have the lowest average age (42.72) and the trend appears similarly for the other two groups with once daily users having an average age of 45.46 and less than once daily users having a slightly older average age of 49.04 .

Level of education and level of income follow similar trends across digital access level groups with higher on average education (2.25 or the equivalent of some college) and income (4.42 or the equivalent of $\$ 45,000-\$ 60,000$ annual family income) occurring among the more than once daily group. Mean education and income decline with each lower level of digital access and are the lowest among non-Internet users (education mean of 1.37 or the equivalent of high school or less, income mean of 2.66 or the equivalent of $\$ 30,000$ - $\$ 45,000$ annual family income). Similarly, the proportion of unemployed respondents and those below the poverty threshold is highest among the non-Internet user group. At the other end of the spectrum the highest proportion of employed respondents and those at or above the poverty threshold occurs within the more than once daily and once daily digital access groups respectively.

In terms of race and ethnicity, the non-Internet user group has a higher proportion of Hispanic (22.62\%) and non-Hispanic Black (17.21\%) than any other digital access level or the full sample (Hispanic 14.99\%, non-Hispanic Black 12.85\%). The more than 
once daily Internet use group has a higher proportion of non-Hispanic other $(9.61 \%)$ than any other group or the full sample $(8.10 \%)$ and the once daily group has a higher proportion of non-Hispanic white $(70.55 \%)$ than any other group and is a higher proportion than in full sample $(64.06 \%)$.

Results of the T-test examining the statistically significant difference in characteristics between the analytic sample $(n=224,542)$ and cases excluded from the sample ( $n=96$ ) due to missing values for the primary dependent variable self-rated health, are presented in Table 2 . These results indicate that the excluded cases have on average lower levels of digital access, are older, have lower levels of income, and are more likely to be unemployed. There are also differences in terms of marital status with the excluded sample being less likely to be married or never married and more likely to be separated, divorced, widowed or to have an unknown marital status. These differences may impact regression results such that associations are underreported.

Results of the T-tests examining the statistically significant difference in characteristics between cases included in the analyses $(n=214,273)$ and excluded from the analyses due to missing values for the dependent variable of digital access $(n=10,269)$, are presented in Table 3. These results indicate that the excluded sample report lower levels of self-rated health, are more likely to be female, non-Hispanic Black or nonHispanic other, have lower level of income, unemployed, below the poverty threshold, separated divorced, widowed or to have an unknown marital status. Excluded cases are less likely to be Hispanic or non-Hispanic white, or married. These statistically significant differences will only impact the results of the first ordered logistic regression 
analysis for which these cases are excluded. These differences may impact those finding such that trends are underreported. For all other analyses, these cases are included as digital access unknown.

Regression Analyses

Table 4 provides the unstandardized coefficients and $\mathrm{p}$ values for ordered logistic regression predicting level of digital access aimed at examining what socioeconomic and demographic characteristics remain salient predictors of access. These results indicate that there is a statistically significant association between each of the included predictive variables and level of access to digital ICTs. Being female is positively associated with level of digital access. In terms of race and ethnicity, Hispanic (47\% less likely), nonHispanic Black (34\% less likely) or non-Hispanic Other (22\% less likely), are less likely to have each higher level of digital access as compared to their white counterparts.

Age is negatively associated with digital access such that each year increase in age is associated with a -0.035 decrease in the log odd of having a higher level of digital access. However, the results for the cohort variables are somewhat less linear. Being among the pre-boomer cohort is negatively associated with higher levels of digital access as compared to millennials, consistent with the results for the continuous measure of age. However, both the genx and boomer cohorts are positively associated with access as compared to millennials. The genx cohort is around $6 \%$ more likely to have each higher level of digital access compared to millennials, whereas the boomer cohort is around $14 \%$ more likely. Level of education and level of income both have positive effects on level of 
digital access such that each higher level of education and income is associated with an increase in the likelihood of having the next higher level of digital access. Living below the poverty threshold, being unemployed, and not having health insurance are all negatively associated with having each higher level of digital access.

The unstandardized coefficients and $\mathrm{p}$ values for the ordered logistic regression estimating the effects of level of digital access on health are presented in Table 5. Results for both models 1 and 2 indicate that higher levels of digital access are associated with higher levels of self-rated health even when controlling for other relevant social determinants of health such as education and income. While once daily and less than once daily users are shown to be less likely than their more than once daily counterparts to have each higher level of self-rated health, the non-users appear to be much more disadvantaged. Once daily use is associated with a $3 \%$ decrease and less than once daily with a $6 \%$ decrease in likelihood of having each higher level of health as compared to the group with the highest level of digital access. However, the non-users have a $34 \%$ lower likelihood of having each higher level of health as compared to those with the highest level of digital access.

Table 6 provides the results of the ordered logistic regression estimating the moderation effects of education (column A), income (column B), and race and ethnicity (column C), on the relationship between level of digital access and health. Although some of the interaction terms are statistically significant in model 2 (not shown), when all of the controls are added in model 3 , the interaction terms between education and digital access, income and digital access, or race and digital access, are statistically insignificant. 
However, being unemployed and uninsured (not shown) were both significantly negatively associated with having each higher level of self-rated health across models for each regression.

\section{Mediation Analyses}

Table 7 provides the results of the mediation analysis estimating the effects of digital access on the relationships between education and health (Model A), income and health (Model B) and race and ethnicity (Model C). Results from Model A indicate that having a higher level of education is associated with an increase in the log odd of having a higher level of self-rated health by 0.331 . Controlling for level of digital access reduces the effect to 0.304 leaving an indirect effect of 0.028 . Model B results show that while each higher level of income is associated with a 0.174 increase in the log odds of having

a higher level of self-rated health, controlling for digital access reduces the increase to 0.167. The indirect effect of digital access is 0.007 .

These results suggest that digital access may mediate the association between both education and income with health, and that level of digital accesshas a larger effect on the relationship between of education and health. The results of Model $\mathrm{C}$ indicate that digital access may mediate the relationship between race and ethnicity and self-rated health for Hispanic, non-Hispanic Black, and non-Hispanic Other as a suppression effect as compared to non-Hispanic White. Non-Hispanic Black has the strongest total negative effect on self-rated health as compared to non-Hispanic White, followed by non-Hispanic Other and Hispanic. Level of digital access has a significant indirect effect on the relationship between race and ethnicity and health for each racial/ethnic group and has a 
suppression effect on the relationship. This is to say that the negative effect of race and ethnicity on health for those belonging to these racially oppressed groups is reduced for those with higher levels of digital access. The indirect effect of digital access here is strongest for Hispanic where the total negative effect on health, -0.080 , is reduced by 0.039 to -0.041 when digital access is controlled for. Having higher levels of digital access reduces the total negative effect of race and ethnicity on health by 0.26 for nonHispanic Black and by 0.016 for non-Hispanic Other.

\section{DISCUSSION AND CONCLUSION}

While demographic and socioeconomic disparities in access to digital information technologies have lessened over time, the pertinence of access has increased over time. As such, any existing disparities may have detrimental impacts on those who experience persistent barriers to access, regardless of an association with health outcomes. As more basic and every day resources and activities become largely accessible via digital technologies, digital access will continue to become a more important social determinant of health. This study investigated the association between digital access and health outcomes by addressing whether or not higher levels of digital access are associated with better self-rated health and to what extent this relationship is shaped by and/or contingent on demographic and socioeconomic disparities.

First, this research examined the digital divide from a social determinants of health perspective and the findings suggest that there is a stand-alone relationship between level of digital access and self-rated health. This finding may have important 
implications for existing health disparities as evidence of persistent socioeconomic and demographic disparities in digital access was also shown in this study. Compared to their non-Hispanic White counterparts, respondents who report Hispanic, non-Hispanic Black and non-Hispanic Other for race/ethnicity were significantly less likely to have higher levels of digital access. Furthermore, this research found evidence for education and income-based gradients in access to digital ICTs. Taken together, the evidence of persistent racial/ethnic, education, and income-based disparities in access to digital ICTs must be addressed to prevent the exacerbation of the ongoing parallel health disparities given the findings that level of digital access is a significant predictor of health.

Furthermore, these findings illuminate important features of the relationship between digital access and health in terms of these socioeconomic and demographic trends. This research found no evidence that the effects of digital access on health varied by level of education, level of income, or race and ethnicity. However, the mediation analyses investigating the effects of digital access on the relationships between education, income, and race and ethnicity and health found evidence that for each relationship, digital access has a significant indirect effect. More specifically, the positive effects that higher levels of education or income have on health may occur in part via higher levels of digital access. And in terms of race and ethnicity, the negative effects on health associated with belonging to a racially/ethnically oppressed group may be reduced by having higher levels of digital access. Once again, these findings support the conceptualization of digital access as a social determinant of health. 
For example, in terms of education, if there had been evidence of a moderation effect, one might conclude that given equal levels of digital access, those with higher levels of education will be better suited at using the access to acquire health promoting resources available via digital ICTs. However, instead the results of this study suggest that digital access may mediate the relationship between education and health rather than the effect of digital access being moderated by education. This suggests that one of the ways in which higher levels of education affects health in today's society may be in terms of increased access to the health promoting resources available via digital ICTs. These findings, along with those indicating that those who were uninsured and unemployed were found to be negatively associated with both higher levels of digital access and higher levels of self-rated health highlights the complicated nature of the relationship between digital access and health. More research is needed to further investigating the mechanisms through which the relationship might operate.

At the same time, this study is not without limitations. For one, the use of crosssectional data can only demonstrate associations. Future research may use longitudinal surveys or experimental methods to test causal relationships. Additionally, the measures used to operationalize the level of digital access do not capture the full range of access theorized by van Dijk's sequential model. The digital access measures for this study are primarily in terms of whether or not people use the Internet as well as frequency of use. This operationalization could pose some problems for interpreting results because how the time spent using the Internet may vary across groups. For example, some research has shown that level of education is associated with level of digital usage access such that 
people with lower levels of education use the Internet in 'less beneficial' or capital enhancing ways (Hargittai and Hinnant 2008; van Deursen and van Dijk 2014).

Although individuals with lower levels of education have been shown to use the Internet more frequently and for more hours of the day, they are also more likely to participate in online activities such as gaming and socializing (van Deursen and van Dijk 2014). On the other hand, research has also demonstrated that those with higher levels of education and more privileged social positions tend to use digital ICTs for more beneficial and capital enhancing purposes (van Deursen and van Dijk 2014; Zillien and Hargittai 2009).

In conclusion, much of the digital divide scholarship has shifted focus from what is considered the first-level digital divide shaped by one's physical or material access to digital ICTs, to the second and third level divides understood in terms of one's skills/usage access and the tangible outcomes shaped by one's access respectively (van Deursen and Helsper 2015). By examining the health returns from Internet use, this study contributes to the literature on the third-level digital divide and provides evidence supporting the claim that digital access is an emerging social determinant of health. . Once physical and material access to digital ICTs is near universal, it is likely that the disparities in returns on use will be more pronounced and research on these trends will continue to be important for mitigating inequality. However, these findings also suggest that focus and attention are still needed in terms of the first level digital divide. Socioeconomic and demographic disparities in digital access persist which is important given the evidence of health returns on Internet use this. As a potential emerging social 
determinant of health, socioeconomic and demographic disparities in digital access will likely exacerbate existing health socioeconomic and demographic health disparities. 


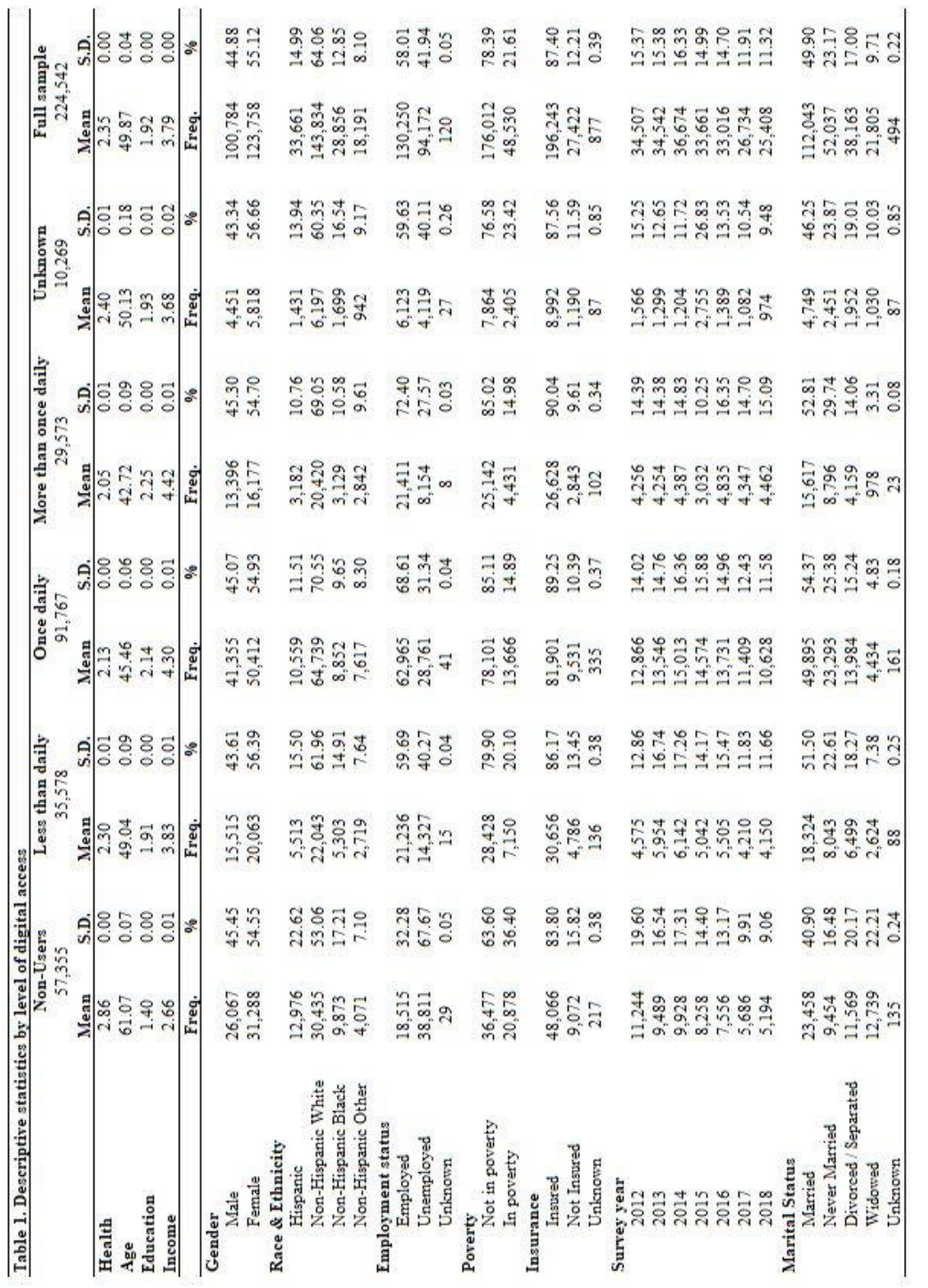


Table 2. T-test comparing analytic sample to excluded cases

\begin{tabular}{|c|c|c|}
\hline \multicolumn{3}{|c|}{ Analytic Sample $n=224,542$} \\
\hline Digital Access & * & missing have lower levels of access \\
\hline Age & * & missing are older \\
\hline \multicolumn{3}{|l|}{ Gender } \\
\hline \multicolumn{3}{|l|}{ Race \& Ethnicity } \\
\hline \multicolumn{3}{|l|}{ Education } \\
\hline Income & * & lower income \\
\hline Employment status & *** & missing more likely to be unemployed \\
\hline \multicolumn{3}{|l|}{ Poverty } \\
\hline \multicolumn{3}{|l|}{ Insurance } \\
\hline \multicolumn{3}{|l|}{ Marital Status } \\
\hline Married & * & missing less likely to be married \\
\hline Never Married & * & missing less likely to be never married \\
\hline Divorced/Separated & * & missing more likely to be separated or divorced \\
\hline Widowed & *** & missing more likely to be widowed \\
\hline Unknown & $* * *$ & missing more likely to have unknown marital status \\
\hline
\end{tabular}


Table 3. T-test comparing analytic sample to excluded cases (digital access missing)

\begin{tabular}{|c|c|c|c|}
\hline \multicolumn{3}{|c|}{ Analytic Sample $n=214273$} & Excluded Sample $n=10,269$ \\
\hline Health & & $* * *$ & missing have lower levels of health \\
\hline \multicolumn{4}{|r|}{ 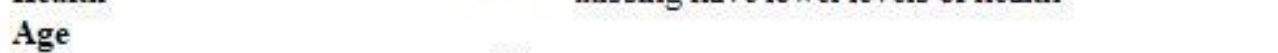 } \\
\hline Gender & & $* * *$ & missing more likely to be female \\
\hline \multicolumn{4}{|c|}{ Race \& Ethnicity } \\
\hline & Hispanic & *** & missing less likely to be Hispanic \\
\hline & Non-Hispanic White & *** & missing less likely to be NHwhite \\
\hline & Non-Hispanic Black & *** & missing more likely to be NHBlack \\
\hline & Non-Hispanic Other & ** & missing more likely to be NHother \\
\hline \multicolumn{4}{|c|}{ Education } \\
\hline Income & & *** & missing have lower levels of income \\
\hline Employm & it status & ** & missing more likely to be unemployed \\
\hline Poverty & & *** & missing more likely to be in poverty \\
\hline \multicolumn{4}{|c|}{ Insurance } \\
\hline \multicolumn{4}{|c|}{ Marital Status } \\
\hline & Married & *** & missing less likely to be married \\
\hline \multicolumn{4}{|c|}{ Never Married } \\
\hline & Divorced / Separated & $* * *$ & missing more likely to be separated or divorced \\
\hline & Widowed & *** & missing more likely to be widowed \\
\hline & Unknown & *** & missing more likely to have unknown marital status \\
\hline
\end{tabular}




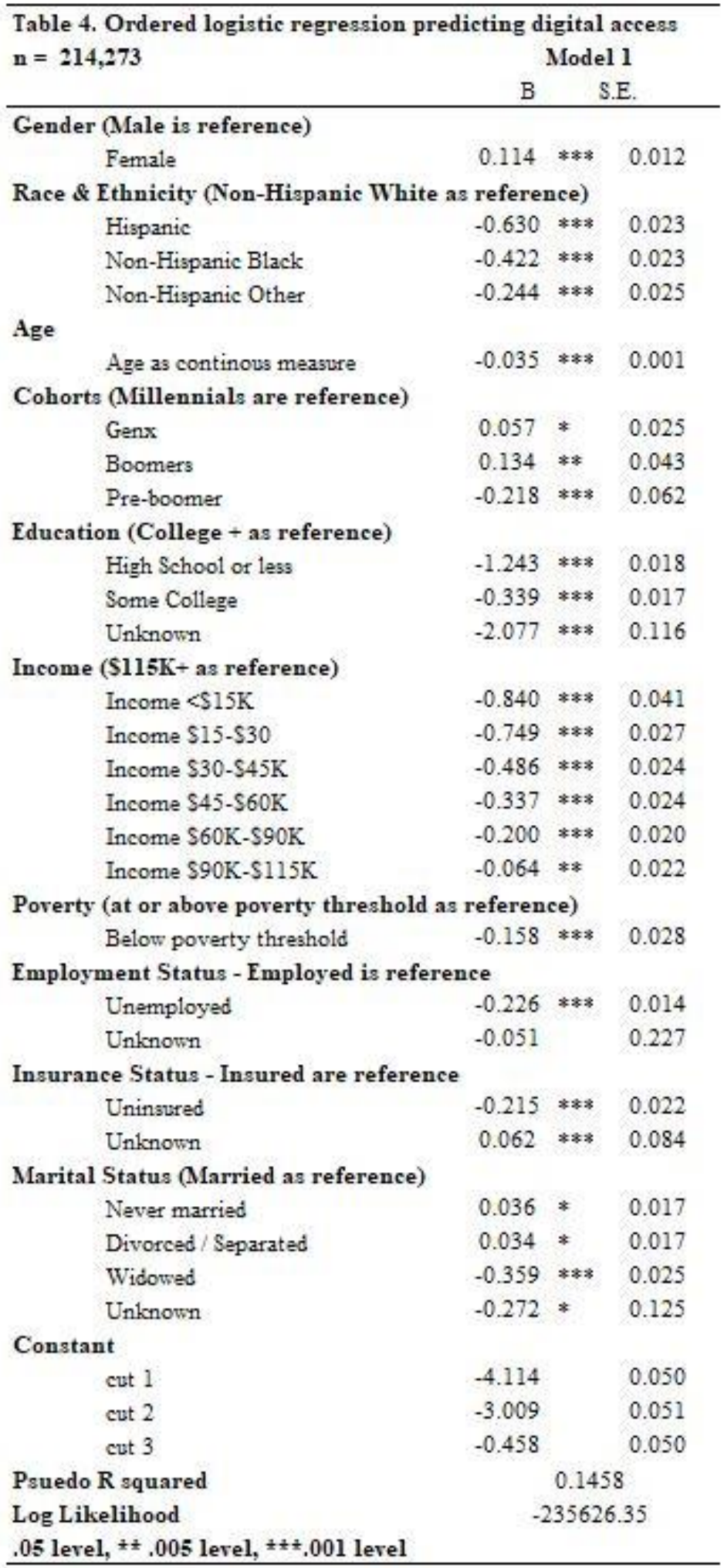




\begin{tabular}{|c|c|c|c|c|c|c|}
\hline \multirow[b]{2}{*}{$\mathrm{n}=224,542$} & \multicolumn{3}{|c|}{ Model I } & \multicolumn{3}{|c|}{ Model 2} \\
\hline & \multicolumn{3}{|c|}{ B S.E. } & \multirow[t]{2}{*}{ B } & \multicolumn{2}{|c|}{ S.E. } \\
\hline \multicolumn{6}{|c|}{ Internet Use (>once daily as reference) } & \\
\hline Non-Users & -1.361 & $* * *$ & 0.020 & -0.419 & $* * *$ & 0.021 \\
\hline <daily & -0.394 & $* * *$ & 0.020 & -0.064 & $* *$ & 0.021 \\
\hline Once daily & -0.135 & $* * *$ & 0.017 & -0.035 & $*$ & 0.017 \\
\hline Unknown & -0.530 & $* * *$ & 0.029 & -0.187 & $* * *$ & 0.029 \\
\hline \multicolumn{7}{|l|}{ Gender (Male is reference) } \\
\hline Female & & & & 0.013 & & 0.011 \\
\hline \multicolumn{7}{|c|}{ Race \& Ethnicity (Non-Hispanic White as reference) } \\
\hline Hispanic & & & & -0.030 & & 0.019 \\
\hline Non-Hispanic Black & & & & -0.183 & $* * *$ & 0.019 \\
\hline Non-Hispanic Other & & & & -0.127 & $* * *$ & 0.021 \\
\hline \multicolumn{7}{|l|}{ Age } \\
\hline Age as continous measure & & & & -0.028 & $* * *$ & 0.001 \\
\hline \multicolumn{7}{|l|}{ Cohorts (Millennials as reference) } \\
\hline Genx & & & & -0.245 & $* * *$ & 0.023 \\
\hline Boomers & & & & -0.137 & $* * *$ & 0.037 \\
\hline Pre-boomer & & & & 0.555 & $* * *$ & 0.053 \\
\hline \multicolumn{7}{|l|}{ Education (College + as reference) } \\
\hline High School or less & & & & -0.578 & $* * *$ & 0.015 \\
\hline Some College & & & & -0.382 & $* * *$ & 0.014 \\
\hline Unknown & & & & -0.792 & $* * *$ & 0.087 \\
\hline \multicolumn{7}{|l|}{ Income (\$115K + as reference) } \\
\hline Income $<\$ 15 \mathrm{~K}$ & & & & -0.977 & $* * *$ & 0.038 \\
\hline Income $\$ 15-\$ 30$ & & & & -0.826 & $* * *$ & 0.024 \\
\hline Income $\$ 30-\$ 45 \mathrm{~K}$ & & & & -0.655 & $* * *$ & 0.020 \\
\hline Income $\$ 45-\$ 60 \mathrm{~K}$ & & & & -0.586 & $* * *$ & 0.021 \\
\hline Income $\$ 60 \mathrm{~K}-\$ 90 \mathrm{~K}$ & & & & -0.418 & $* * *$ & 0.018 \\
\hline Income $\$ 90 \mathrm{~K}-\$ 115 \mathrm{~K}$ & & & & -0.235 & $* * *$ & 0.020 \\
\hline \multicolumn{7}{|c|}{ Poverty (at or above poverty threshold as reference) } \\
\hline Below poverty threshold & & & & -0.167 & $* * *$ & 0.028 \\
\hline \multicolumn{7}{|c|}{ Employment Status - Employed is reference } \\
\hline Unemployed & & & & -0.535 & $* * *$ & 0.014 \\
\hline Unknown & & & & 0.167 & & 0.178 \\
\hline \multicolumn{7}{|c|}{ Insurance Status - Insured as reference } \\
\hline Uninsured & & & & -0.118 & $* * *$ & 0.019 \\
\hline Unknown & & & & -0.058 & & 0.099 \\
\hline \multicolumn{7}{|c|}{ Marital Status (Married as reference) } \\
\hline Never Married & & & & 0.029 & & 0.017 \\
\hline Divorced / Separated & & & & -0.115 & $* * *$ & 0.017 \\
\hline Widowed & & & & 0.145 & $* * *$ & 0.023 \\
\hline Unknown & & & & 0.124 & & 0.127 \\
\hline \multicolumn{7}{|l|}{ Constant } \\
\hline $\cot 1$ & -4.043 & & 0.022 & -6.540 & & 0.044 \\
\hline $\cot 2$ & -2.433 & & 0.016 & -4.854 & & 0.043 \\
\hline $\cot 3$ & -0.865 & & 0.015 & -3.143 & & 0.042 \\
\hline $\cot 4$ & 0.565 & & 0.015 & -1.573 & & 0.042 \\
\hline Psuedo $\mathbf{R}$ squared & \multicolumn{3}{|c|}{0.028} & & 0.07 & \\
\hline Log Likelihood & & 12306 & 400 & & 29726 & .57 \\
\hline .05 level, $* * .005$ level, $* * * .001$ lev & & & & & & \\
\hline
\end{tabular}




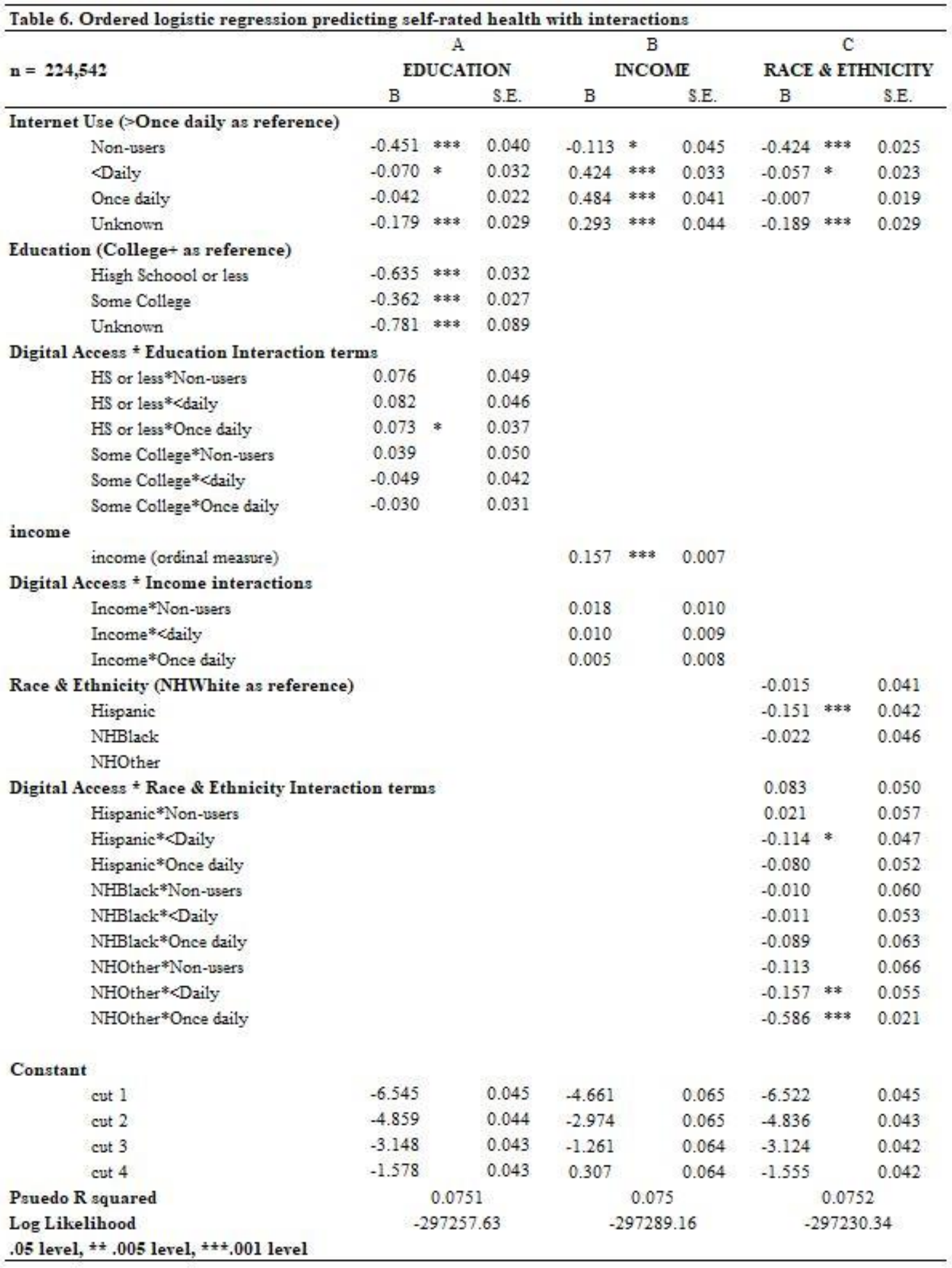


Table 7. Direct and indirect effect of education (Model A), Income (Model B), Race \& Ethnicity (Model C) and mediator, digital access, on health. $n=214,273$

\begin{tabular}{|c|c|c|c|c|c|c|}
\hline Effect & $B$ & $S E$. & $z$ & $P=\varepsilon$ & [95\% Conf. & Interval] \\
\hline \multicolumn{7}{|c|}{ Model A-Education } \\
\hline Total effect & 0.331 & 0.007 & 46.400 & 0.000 & 0.317 & 0.345 \\
\hline Direct effect & 0.304 & 0.007 & 41.670 & 0.000 & 0.290 & 0.318 \\
\hline Indirect effect & 0.028 & 0.002 & 17.740 & 0.000 & 0.025 & 0.031 \\
\hline \multicolumn{7}{|c|}{ Model B - Income } \\
\hline Total effect & 0.174 & 0.004 & 42.970 & 0.000 & 0.166 & 0.182 \\
\hline Direct effect & 0.167 & 0.004 & 41.050 & 0.000 & 0.159 & 0.175 \\
\hline Indirect effect & 0.007 & 0.000 & 16.100 & 0.000 & 0.006 & 0.008 \\
\hline \multicolumn{7}{|c|}{ Model C-Race \& Ethuicity } \\
\hline \multicolumn{7}{|c|}{ Hispanic } \\
\hline Total effect & -0.080 & 0.017 & -4.630 & 0.000 & -0.113 & -0.046 \\
\hline Direct effect & -0.041 & 0.017 & -2.340 & 0.019 & -0.075 & -0.007 \\
\hline $\begin{array}{l}\text { Indirect effect } \\
\text { non-Hispan }\end{array}$ & -0.039 & 0.002 & -18.340 & 0.000 & -0.043 & -0.035 \\
\hline Total effect & -0.204 & 0.018 & -11.360 & 0.000 & -0.239 & -0.169 \\
\hline Direct effect & -0.178 & 0.018 & -9.890 & 0.000 & -0.214 & -0.143 \\
\hline $\begin{array}{l}\text { Indirect effect } \\
\text { non-Hispan }\end{array}$ & -0.026 & 0.002 & -15.730 & 0.000 & -0.029 & -0.023 \\
\hline Total effect & -0.156 & 0.021 & -7.600 & 0.000 & -0.196 & -0.116 \\
\hline Direct effect & -0.140 & 0.021 & -6.830 & 0.000 & -0.181 & -0.100 \\
\hline Indirect effect & -0.016 & 0.001 & -10.880 & 0.000 & -0.018 & -0.013 \\
\hline
\end{tabular}




\section{REFERENCES}

Anderson, Monica and Madhumitha Kumar. 2019. "Digital Divide Persists Even as Lower-Income Americans Make Gains in Tech Adoption.” Pew Research Center https://www.pewresearch.org/fact-tank/2019/05/07/digital-divide-persists-evenas-lower-income-americans-make-gains-in-tech-adoption/

Antonovsky, Aaron. 1967. "Social Class, Life Expectancy and Overall Mortality" Milbank Memorial Fund Quarterly 45:31-73.

Bennett, Nancy M., Marie T. Brown, Theresa Green, Laura Lee Hall, and Allison M. Winkler. Addressing Social Determinants of Health (SDOH): Beyond the Clinic Walls. 2018. Available at: https://edhub.ama-assn.org/stepsforward/module/2702762. Accessed March 3 24, 2021.

Bourdieu, Pierre. 1990. In Other Words: Essays towards a Reflexive Sociology. Stanford, CA: Stanford University Press.

Breen, Richard, Kristian Bernt Karlson, and Anders Holm. 2013. "Total, Direct, And Indirect Effects in Logit and Probit Models." Sociological Methods \& Research 42(2): 164-191.

Brock, Andre. 2006. “A Belief in Humanity is a Belief in Colored Men”: Using Culture to Span the Digital Divide. Journal of Computer-Mediated Communication 11(1): $357-374$.

Centers for Disease Control and Prevention. "Covid-19: Hospitalization and Death by Race/Ethnicity.” Feb. 18, 2021. https://www.cdc.gov/coronavirus/2019- 
ncov/covid-data/investigations-discovery/hospitalization-death-by-raceethnicity.html accessed March 3, 2021.

Crimmins, Eileen M. and Yasuhiko Saito. 2001. "Trends in Healthy Life Expectancy in the United States, 1970-1990: Gender, Racial, and Educational Differences." Social Science \& Medicine 52(11): 1629-1641.

Cutler, David M. and Adriana Lleras-Muney. 2006. "Education and Health: Evaluating Theories and Evidence.” Working Paper Series 12352.

Daniels, Jessie. 2013. "Race and Racism in Internet Studies: A Review and Critique." New Media \& Society 15(5): 695-719.

DiMaggio, Paul and Bart Bonikowski. 2008. "Make Money Surfing the Web? The Impact of Internet Use on the Earnings of US Workers." American Sociological Review 73(2): 227-250.

Elo, Irma T. and Samuel H. Preston. 1996. "Educational Differentials in Mortality: United States, 1979-85.” Social Science \& Medicine 42(1): 47-57.

Ford, Chandra L. 2017. "Notions of Blackness in the Context of HIV/AIDS Disparities and Research." The Black Scholar 47(4): 18-31.

Fountain, Christine. 2005. "Finding a Job in the Internet Age." Social Forces 83:1235-62.

Hampton, Keith N. and Barry Wellman. 2000. "Examining Community in the Digital Neighborhood: Early Results from Canada's Wired Suburb.” Pp. 475-492 in Digital Cities: Experiences, Technologies and Future Perspectives, edited by T. Ishida and K. Isbister. Heidelberg, Germany: Springer-Verlag 
Hargittai, Eszter. 2002. “The Second Level Digital Divide: Differences in People's Online Skills." First Monday: Peer-Reviewed Journal on the Internet 7(4). Retrieved May 5, 2015 from http://firstmonday.org/ojs/index.php/fm/article/view/942/864.

Hargittai, Eszter. 2003. "The Digital Divide and What to Do About It." Pp. 821-839 in New Economy Handbook edited by J. C. Derek San Diego, CA: Academic Press. Hargittai, Eszter and Amanda Hinnant. 2008. "Digital Inequality - Differences in Young Adults' Use of the Internet." Communication Research 35(5): 602-621.

Harrington, Kermith V., James C. McElroy, and Paula C. Morrow. 1990. "Computer Anxiety and Computer-Based Training: A Laboratory Experiment." Journal of Educational Computing Research 6(3): 343-358.

House, James S., James M. Lepkowski, Ann M. Kinney, Richard P. Mero, Ronald C. Kessler, and A. Regula Jerzog. 1994. "The Social Stratification of Aging and Health.” Journal of Health and Social Behavior 35: 213-234.

Juang, Jie and Susan Russell. 2006. "The Digital Divide and Academic Achievement." The Electronic Library, 24(2): 160-173.

Judge, Sharon. 2005. "The Impact of Computer Technology on Academic Achievement of Young African American Children." Journal of Research in Childhood Education 20(2): 91-101.

Kitagawa, Evelyn M. and Philip M. Hauser. 1973. Differential Mortality in the United States: A Study in Socioeconomic Epidemiology. Cambridge, MA: Harvard University Press. 
Kohler, Ulrich, Kristian Bernt Karlson, and Anders Holm. 2011. "Comparing Coefficients of Nested Nonlinear Probability Models." The Stata Journal 11(3): 420-438.

Kuhn, Peter J. and Hani Mansour. 2011. "Is Internet Job Search Still Ineffective?” Discussion paper series //Forschungsinstitut zur Zukunft der Arbeit, No. 5955, http://nbn-resolving.de:101:1-201109297545.

Link, Bruce G. and Jo Phelan. 1995. "Social Conditions as Fundamental Causes of Disease." Journal of Health and Social Behavior 80-94.

Marmot, Michael. 2002. "The Influence of Income on Health: Views of an Epidemiologist: Does Money Really Matter? Or is it a Marker for Something Else?" Health Affairs 21(2): 31-46.

Marmot, Michael, Sharon Friel, Ruth Bell, Tanja AJ Houweling, Sebastian Taylor, and Commission on Social Determinants of Health. 2008. "Closing the Gap in A Generation: Health Equity Through Action on The Social Determinants of Health." The lancet 372(9650): 1661-1669.

Marmot, Michael and Richard G. Wilkinson, editors. 2006. Social Determinants of Health 2nd ed. Oxford; New York: Oxford University Press.

Meyers, Eric M., Ingrid Erickson, and Ruth V. Small. 2013. "Digital Literacy and Informal Learning Environments: An Introduction. " Learning, Media and Technology 38(4): 355-367.

Mirowsky, John and Catherine E. Ross. 2003. Education, Social Status and Health. Hawthorne, NY: Aldine de Gruyter. 
NCSL National Conference of State Legislatures. COVID- 19 Essential Workers in The States. January 11, 2021. https://www.ncsl.org/research/ labor-andemployment/covid-19-essential-workers-in-the-states. Accessed March 4, 2021.

Paino, Maria and Linda A. Renzulli. 2013. "Digital Dimension of Cultural Capital The (In) Visible Advantages for Students Who Exhibit Computer Skills." Sociology of Education 86(2): 124-138.

Pearce, Katy E. and Ronald E. Rice. 2013. "Digital Divides from Access to Activities: Comparing Mobile and Personal Computer Internet Users.” Journal of Communication 63(4): 721-744.

Pew Research Center. 2021. Internet/Broadband Fact Sheet https://www.pewresearch.org/internet/fact-sheet/internet-broadband/\#who-has$\underline{\text { home-broadband }}$

Ross, Catherine E. and Chia-ling Wu. 1995. "The Links between Education and Health." American Sociological Review 719-745.

Schnittker, Jason. 2004. "Education and the Changing Shape of the Income Gradient in Health." Journal of Health and Social Behavior 45: 286-305.

Shim, Janet K. 2002. "Understanding the Routinised Inclusion of Race, Socioeconomic Status and Sex in Epidemiology: The Utility of Concepts from Technoscience Studies." Sociology of health \& illness 24(2): 129-150.

Smith, Aaron. 2015. "Searching for Work in The Digital Era." Pew Research Center. 
Stanley, Laura D. 2003. "Beyond Access: Psychosocial Barriers to Computer Literacy Special Issue: ICTs and Community Networking." The Information Society: An International Journal 19(5): 407-416.

Torkzadeh, Gholamreza and Irma E. Angulo. 1992. "The Concept and Correlates of Computer Anxiety." Behavior and Information Technology, 11(2): 99-108.

van Deursen, Alexander J.A.M., and Ellen J. Helsper. 2015. "The Third-Level Digital Divide: Who Benefits Most from Being Online?" Communication and information technologies annual. Emerald Group Publishing Limited.

van Deursen, Alexander J.A.M. and Jan A.G.M. van Dijk. 2014. "The Digital Divide Shifts to Differences in Usage." New Media \& Society 16(3): 507-526.

van Dijk, Jan A.G.M. 2005. The Deepening Divide: Inequality in the Information Society. Thousand Oaks, CA: Sage Publications.

Weil, Michelle M., Larry D. Rosen, and Stuart E. Wugalter. 1990. "The Etiology of Computerphobia." Computers in Human Behavior 6(4): 361-379.

Weinstein, J. N., A. Geller, Y. Negussie, and A. Baciu. 2017. "National Academies of Sciences, Engineering, and Medicine Committee on Community-Based Solutions to Promote Health Equity in the United States." Communities in Action: Pathways to Health Equity. Washington, DC: National Academies Press.

Williams, Gareth H. 2003. "The Determinants of Health: Structure, Context and Agency." Sociology of Health \& Illness 25(3): 131-154.

Williams, David R., and Selina A. Mohammed. 2013."Racism and Health, I: Pathways and Scientific Evidence." American behavioral scientist 57(8): 1152-1173. 
Zickuhr, Kathryn and Aaron Smith. 2012. "Digital Differences." Pew Internet \& American Life Project April 13, 2012, http://www.pewinternet.org/2012/04/13/digital-differences/ accessed May 5, 2015 Zillien, Nicole and Eszter Hargittai. 2009. "Digital Distinction: Status Specific Types of Internet Usage." Social Science Quarterly 90 (2): 274-291. 


\section{Paper Two}

Digital Access to Work, Job Satisfaction, and Occupation: Emerging Social Determinant of Health

Innovations in digital information and communication technologies (ICTs) continue to transform the social world reinventing the ways in which people do just about everything. From interpersonal communication and information sharing to the growing importance and contribution of ICTs in areas such as health and education, in many ways one's participation in society is facilitated by and at times reliant on the use of digital ICTs. As such, those who are faced with barriers to accessing digital ICTs may experience increasingly detrimental impacts.

One area of particular concern when it comes to barriers to accessing digital ICTs, has to do with the ways limited digital access may impact one's ability to procure valuable goods and services, information, and resources that have been associated with promoting better health. Social inequalities, which ultimately determine disparities in health and which operate via mechanisms such as employment opportunities, may occur increasingly in terms of one's material access, ability to use, and form of engagement with digital ICTs. More specifically, as the digital economy grows, access to work related resources such as employment, occupation, and job satisfaction are more and more structured by one's digital access. The purpose of this study is to examine the relationship between digital access and health outcomes as it is shaped by access to the work and work-related resources: work status, occupation, and job satisfaction. 
Much of the research on the digital divide has focused on these questions of who has motivational (Helsper and Reisdorf 2017; Reisdorf and Groseli 2017), material and physical (Bauer 2018; Zhang 2013), skills (Bonfadelli 2002; Gui and Argentin 2011; Hargittai 2002, 2010; Martínez-Cantos 2017; van Deursen and van Dijk 2011), and usage access (Blank and Groselj 2014; Napoli and Obar 2014). However, the question of access in terms of its impacts on society and the individual has gained less attention. In particular, this research adds to the literature by focusing on the question of what are the benefits of digital access and the disadvantages of not having digital access?

Furthermore, in terms of the impacts that access may have on health outcomes, the digital divide literature focuses primarily and almost exclusively on eHealth or the unequal use of health applications.

\section{LITERATURE REVIEW}

For the purposes of this study, I draw on a social determinants of health perspective as a way of framing how digital access may impact health outcomes and how this relationship might operate via labor market mechanisms. In this section, I provide a brief overview of a social determinants of health perspective as well as explain what this perspective means more specifically as a framework for understanding the relationship between digital access and health. I then go on to review some of the relevant literature examining labor market transitions to a digital economy and scholarship on the digital divide. I then discuss in more detail the specific labor market mechanisms of work status, 
occupation, and job satisfaction in regards to the ways in which they might impact the relationship between digital access and health.

\section{Social Determinants of Health}

A social determinants of health perspective provides a framework for understanding health inequalities as rooted in and shaped by social inequalities. Social determinants of health are the "circumstances in which people are born, grow up, live, work and age, and the systems put in place to deal with illness" (World Health Organization 2008). Put in terms of digital access, the social determinants of health are the ways in which the above circumstances are shaped by digital access. In other words, because access to the basic goods and services, opportunities for education and employment, as well as political and social participation, which are key drivers of morbidity and mortality, are increasingly accessed via digital ICTs, digital access may be increasingly linked to social determinants of health.

Having considered what a social determinants of health perspective has to offer in terms of framing the understanding of digital access, I now move on to consider the literature regarding social determinants of health shaped by labor market participation and experiences. More specifically, this research focuses primarily on work status, occupation, and job satisfaction. For the purposes of this study, the term work status refers to whether or not a person is employed, occupation refers to the type of job they hold, and job satisfaction refers to a worker's level of satisfaction they have in the work they do (Peckham et al. 2019). 
Work status, occupation and job satisfaction all structure access to essential health promoting resources in terms of compensation and benefits and psychosocial resources like sense of control and social connectedness (Marmot 2015). Work status and occupation may also play a role in determining a worker's, and their family's, location in social hierarchies in terms of their access to power, and their prestige or status (Link and Phelan 1995). This is not to say that the relationship between work status and occupation and health are simple ones and in fact, work status and occupation may be simultaneously detrimental (hazardous conditions) and beneficial (providing financial stability) to the health of workers (Landsbergis et al. 2014; Lipscomb et al. 2006). However, some scholars argue that it is because of this complexity and the fact that participation in the labor market creates contexts which are health promoting, health damaging, structure the distribution of access to resources, and in many ways overlap with other important social determinants of health like gender and race, that it is crucial in the application of social determinants of health approach (Ahonen et al 2018).

\section{Digital Economy}

As technological advances continue to change the nature of the labor market in terms of the growing centrality of technology across many sectors and the rapid pace at which technological innovations have transformed the functions of workers in some industries, any consideration of work as a social determinant of health must consider the impact of these transformations. The Internet and the technological advancements in digital ICTs have facilitated new modes of production. However, it is unclear if these 
new forms of production of goods and services will result in job generation or if they are largely replacements for existing ones (Bauer 2016). In their examination of 702 detailed occupations in the US labor market, Frey and Osborne (2017) found that $47 \%$ were at high risk of computerization. Technology replaces humans with machines which can lead to the overall decrease of some types of employment and an increase in unemployment. This is in many ways a structural feature of capitalism such that human labor freed by increased productivity due to technological advances is not employed in other areas but rather absorbed by the capitalist class (Bauer, 2016).

Moreover, ICT does not impact occupation the same across sectors. For some sectors of the labor market, ICT may provide significant productivity enhancing tools or more resources. However, ICT has also contributed in the shift of the labor market towards a gig-economy and sharing economy composed of very low productivity activities with low pay (Bauer 2016). Furthermore, the spatial distribution of work is shifted in the digital economy such that capital and labor are much more mobile. Workers in the United State may be excluded from jobs within digital industries that have quickly migrated to lower income countries (Bauer, 2016).

Technological changes have also led to increased wage inequality because of biases against unskilled labor (Van de Klundert, 2008). According to human capital theory, a wage premium for skilled labor is a result of rapidly changing technology within a labor market when attaining higher levels of technical skills is expensive or time consuming (Mincer, 1958). As the proportion of labor requiring these skills increases within the market, the unequal distribution of income will rise (Atkinson, 2008). As such, 
changes in the technological landscape of work will impose new demands on disadvantaged groups and create new barriers (Garrido, Sullivan, and Gordon, 2010).

For example, the proliferation of digital ICTs has transformed the labor market in terms of the types of equipment, connection, and skills needed to access employment. Simply entering the labor market may be challenging for those who experience barriers to accessing digital ICTs in terms of where and how people search for work and apply for jobs. In their study examining the potential uses of digital ICTs as a tool for unemployed people accessing services and information as job seekers, McQuaid, Lindsay, and Greig (2004) found that digital inclusion results in easier job searches. Furthermore, digital skills are becoming necessary for an increasing number of jobs in the U.S. Not only do ICT-related occupations make up a large portion of the labor market, but ICT skills are increasingly important across existing sectors. Loh and Chib (2019) found a strong correlation between ICT appropriation and self-perceived employability.

\section{Digital Access}

While it is clear that access to digital ICTs is becoming an essential base requirement for many workers in the United States, digital divide scholarship offers conceptualizations of the term 'access' which provide useful frameworks for understanding the relationship. The concept of a digital divide was initially understood in terms of the inequality in access to ICT equipment and connection. However, as inequalities in skills and type of use continued to expand even once material and 
physical access were near universal, and researchers warned against technological determinism, the term "second-level digital divide" became more commonly used to describe the state of digital inequality (Hargittai 2002). Finally, the 'third level digital divide' is a term used to describe an inequality in the returns from Internet use among users and their counterparts. Here the focus is on what accounts for the differences in one's capacity to translate online activities and uses into favorable offline outcomes (van Deursen and Helsper, 2015).

However, while the nature of the digital divide has surely shifted over time as material and physical access has expanded, digital inequality continues to impact people and communities at each of the three 'levels' of the divide. As such, the framework for understanding digital inequalities put forth by van Dijk (2005) is particularly useful as it allows for an understanding of each level of the divide existing simultaneously. van Dijk's model of digital inequality frames the divide in terms of four types of successive stages and kinds of access: (1) motivational access, (2) material or physical access, (3) skills access, and (4) usage access. Here, problems of accessing digital technologies gradually shift from the first two stages and kinds, if and when mental and material access have been achieved, to the second two stages and kinds of access, skills and usage. According to van Dijk, the unequal distribution of temporal, material, mental, social, and cultural resources are of particular importance for digital ICT access.

This research focuses on the impact that these inequalities in access to digital ICTs may have on health outcomes as they shape access to the social determinants of health and in particular vital labor market related resources. Research examining how 
different job quality dimensions predict subjective well-being and the mechanisms through which the association operate has found that monetary compensation, job security, individual task discretion, work intensity, and safe working conditions were of particular significance (Horowitz, 2016). Each of these job qualities may indeed be shaped by level of digital access such that those with higher levels of skills and usage access may have more opportunities to attain work, and work with these qualities within the digital economy. In the following section I will focus specifically on the relationship between digital access and health as it may operate in terms of work status, occupation, and job satisfaction.

\section{Work status}

Some research has found that more engaged Internet users may benefit in terms of finding information regarding employment opportunities (Kuhn and Mansour, 2014) and higher earnings (DiMaggio and Bonikowski, 2008). This is important because full-time employment has been shown to be associated with better health (Ross and Mirowsky 1995) whereas being unemployed, part-time employed, or keeping house without paid work are associated with poorer health (Mirowsky and Ross, 2003). One way in which work status impacts health is in the ways it structures income and economic resources which have positive effects on health. This is because household income helps individuals meet their basic and material needs, which are essential to health. For example, economic resources shape exposure to health risks in terms of living conditions, 
neighborhood exposure to toxins and unhealthy or unsafe environments (Adler and Ostrove 1999).

Economic resources also provide the ability to purchase health insurance or health care when necessary. Some research has shown that compared to adults who were continuously insured, those with disrupted or lost coverage are less likely to access health care in terms of primary care visits, and more likely to experience unfavorable health outcomes in terms of experiencing unmet health care needs (Carlson, DeVoe, Wright 2006). Those without health insurance coverage are also less likely to receive diagnostic services and tend to be more severely ill upon diagnosis than those who have health insurance (Hadley 2003). As medical costs increase, the medical benefits provided by employers are an increasingly central mechanism through which work status and may shape health outcomes.

Work status impacts health outcomes in terms of psychosocial factors as well. Economic hardship can lead to prolonged and reoccurring physiologic and emotional stress which can have negative health consequences (Marmot 2004). Furthermore, “beyond economic livelihood, a person's work status is important for socialization. It provides opportunities for personal growth and development, including the favorable experience of self in a core social role, and allows participation in social networks beyond primary groups" (Marmot, Siegrist, and Theorell 2006). Additionally, work status influences health through healthy behavior as it helps promotes healthy behaviors such as more regular sleep or less frequent drinking. For example, some research has shown that 
as compared to permanent employees, temporary employees were found to have higher rates of drinking and smoking related mortality (Kivimäki et al. 2003)

\section{Job satisfaction}

Digital access is also likely very important in giving people access to subjectively rewarding work. One particularly important component of digital access for occupation and work performance is that of digital skills. Higher levels of operational, informational, and strategic digital skills may increase levels of job satisfaction because workers have the skills to do their jobs and to do their jobs well by utilizing digital resources available for them. Digital access has been shown to lead to higher efficiency and productivity for businesses and individuals (Morris 2009). Individuals who are productive at work, and perceive themselves as such, experience higher levels of job performance and satisfaction. People are motivated to use computers and the Internet at work both because of perceived usefulness and personal enjoyment. Anandarajan, Simmers, and Igbaria report findings which demonstrate that "as perceived usefulness increases, so do reported enhancements in job characteristics, job satisfaction, and overall productivity" (2000: 79). Fulfilling work has been shown to be associated with good health (Faragher, Cass, and Cooper 2005; Ross and Wu 1995). Individuals who have the necessary skills to do their work effectively and efficiently have lower levels of job stress and higher levels of job satisfaction (Marmot, Siegrist, and Theorell 2006). 


\section{Occupation}

Occupation impacts health in terms of the psychosocial impacts that quality of working conditions and environment have on health (Marmot, Siegrist, and Theorell 2006). Evidence suggests that lower grade of occupations are related to lower levels of control at work, a lower use of skills, and a higher level of monotony (Marmot et al. 1991). Clayton and Macdonald (2013) identified trends of more beneficial outcomes of digital inclusion among those in higher occupation roles. Respondents in the "managerial and professional' group were more likely to report having more experience of using a computer ( $88 \%$ identifying as experienced) compared to "manual and routine" group at 39\% experienced (Clayton and Macdonald 2013).

Sense of control is a mechanism through which occupation affects health. Sense of control is a valuable psychosocial resource for health as it can enhance health -related behavior, and because lack of personal control is associated with suppression of the immune system (Rodin and Timko 1992; Rowe and Kahn 1987).

People with a high sense of personal control report being effective agents in their own lives; they believe that they can master, control and effectively alter the environment. Perceived control is the cognitive awareness of a link between efforts and outcomes. On the other end of the continuum, perceived powerlessness is the belief that one's actions do not affect outcomes. It is the belief that outcomes of situations are determined by forces external to one's self such as powerful others, luck fate, or chance. People with a sense of powerlessness think that they have little control over meaningful events and circumstances in their lives (Mirowsky and Ross 2003: 60).

Occupation may impact health in terms shaping the sense of control of the worker at work. Individual task discretion or the control that a worker has over how job tasks are completed, is understood to be beneficial for workers because of the relationship with 
intrinsic rewards and self-direction and their importance to psychological functioning (Horowitz 2016).

Perhaps the most direct impact occupation may have on health is in terms of the increased exposure to health risks not evenly distributed across occupations. For example, risk of injury is higher for some occupations that others. Agriculture/forestry/fishing and mining industries and transportation and materials moving occupations have the highest rate ratios of fatal occupation injury (Steege et al. 2014). Risk of exposure to hazardous materials is similarly concentrated among some occupations. For example, research has shown that exposure to pesticides among farmworkers can lead to the development of acute and chronic illness (Thetkathuek et al. 2017).

\section{RESEARCH QUESTION}

This study examines the relationship between digital access and health outcomes by addressing the effects of labor market related resources on the relationship between digital access and health. Specific research questions are: Is the association between digital access and health mediated by (1) work status?; (2) job satisfaction?; (3) occupation? The association between level of digital access with health may be mediated by work status, job satisfaction, and occupation such that those with higher levels of digital access have higher levels of health as a means of their better access to workrelated resources via their digital access. 


\section{METHODS}

Data

Data are from the General Social Survey (GSS). The GSS is conducted by the National Opinion Research Center (NORC) at the University of Chicago and was designed to collect information regarding important American societal trends and changes in attitudes and behaviors and is generally considered a first-rate survey instrument. The GSS was conducted annually between 1972 and 1994 when it switched to a split-ballot design conducted biennially. The GSS employs a multi-stage area probability sampling design, and is nationally representative of non-institutionalized adults 18 years of age and older in the United States.

The survey instrument contains standard core questions regarding demographics and attitudinal variables as well as rotational topical modules which aim to measure trends in special interest topics. Each sample is subdivided into three ballots ( $a, b$, and $c)$ with most items appearing on two out of the three surveys which allows for the inclusion of more regular items. The survey question, "Do you personally ever use a computer at home, at work, or at some other location?" was introduced to the GSS in 2000 as part of the topical module Information Society, also conducted in 2002 and 2004. This survey question was asked again as part of the 2010 survey and has been included as a core question in every survey since.

This research used pooled cross-sectional data from the GSS 2010, 2012, 2014, 2016, and 2018 because surveys administered during these years consistently ask respondents about their computer access and Internet access through a mobile device on 
ab ballots. Because the question involving the dependent variable (self-rated health) was only included on the ac ballots during these survey years, the analyses were restricted to data collected via the a ballots only $(n=3,850)$. Cases with missing values for the dependent variable of self-rated health were excluded from the analysis $(n=9)$. Cases with missing values for the primary independent variables which ask respondents if they use a computer $(n=4)$ and if they use a mobile device to access the Internet $(n=3)$ were also excluded. The final analytic sample includes 3,834 respondents. Estimates are weighted in order to account for the sub-sampling of non-respondents, number of adults in the household, as well as the differential non-response across areas.

\section{Measures}

Dependent variable. Self-rated health, which measures general overall condition of health, is the primary outcome variable. This measure asks respondents to indicate their health status in terms of a four-point scale ranging from excellent to poor and was coded (1 Poor, 2 Fair, 3 Good, 4 Excellent).

Independent variable. The primary predictor variable for this study measures digital access in terms of access to a computer and access to the Internet via mobile device. The first survey item used for this measure is a yes or no question which asks respondents, "Do you personally ever use a computer at home, at work, or at some other location?" The GSS employs a skip pattern such that respondents who indicate yes to this question are then asked about their time spent using email. Respondents who indicate that 
they do not access a computer are first asked, "Do you have access to the Internet or World Wide Web in your home through a Internet-enabled mobile device like a smartphone, PDA, or BlackBerry?" Those who respond yes to this item are then asked about their time spent using email. However, respondents who answer no to both of these screener questions are never asked about their email use. Although having access to a computer does not equate to having access to the Internet, and surely there are plenty of respondents who utilize both a computer and a mobile device to access the Internet, these two items are mutually exclusive as those who indicate that they have access to a computer are never asked about their access to the Internet via a mobile device. Furthermore, access to the Internet via a computer does allow for higher usage access than via a mobile device.

Using these survey items, I created an ordinal measure of mobile access (coded 0 - No access, 1 - Mobile access, 2 - Computer access). First 'No access' includes respondents who indicated that they do not access a computer or the Internet via a mobile device ( $n=458)$. 'Mobile access' includes respondents who do not have access to a computer but do utilize a mobile device to access the Internet $(n=264)$. Finally, 'Computer access' includes respondents who have access to a computer $(n=3,112)$.

Mediating variables. The primary aim of this research was to examine whether and to what degree the relationship between digital access and health is mediated by work related resources. Work status and job satisfaction have been shown to be associated with health outcomes (Ross and Mirowsky 1995) and as the work-life landscape in the U.S. 
has increasingly shifted to include and even rely on digital technologies, those with lower levels of digital access may be impacted. In other words, one possible mechanism through which digital access may impact health is labor market related resources. The measures of possibly mediating labor market resources include work status, job satisfaction, and occupation.

The GSS work status survey item asks respondents, "Last week were you working full time, part time, going to school, keeping house, or what?" This variable was coded into an ordinal variable (coded 0 - not working, 1 - working part time, 2 - working full time). Here, 'not working' includes respondents who indicated that they were temporarily not working, unemployed or laid off, retired, in school, and keeping house as well as those with unknown work status which includes respondents who chose "other" or did not provide an answer.

Job satisfaction is measured with a survey question that asks respondents, "On the whole, how satisfied are you with the work you do - would you say you are very satisfied (1), moderately satisfied (2), a little dissatisfied (3), or very dissatisfied (4)?” This measure was recoded and centered at zero (very dissatisfied -2, a little dissatisfied -1, don't know, no answer and not applicable 0 , moderately satisfied 1 , very satisfied 2).

Finally, in addition to work status and job satisfaction, I consider occupation as a possible work-related mediating variable. The GSS uses the 2010 Census occupation classifications which were collapsed into the following seven top level codes for which I created mutually exclusive dichotomous occupation measures, (1) Management/professional, which was used as the reference category, (2) Service, (3) 
Sales and office, (4) Natural resources, construction, (5) Production, transportation, (6) Other / Not employed, and (7) Occupation unknown.

Control variables. I include a number of control variables in my analysis in order to discern the influence of work-related resources on the relationship between digital access and health. Gender is measured by the dummy variable female, with male as the reference category. Race and ethnicity are controlled for using the following 4 variables; (1) Hispanic which includes all respondents who report being of Hispanic ethnicity, (2) non-Hispanic Black which include all respondents who report being Black or African American and are not of Hispanic ethnicity, (3) non-Hispanic Other which includes respondents who indicate that their race is 'other' and who are not of Hispanic ethnicity, and (4) non-Hispanic Whites, the reference category, which includes respondents who report being White and not of Hispanic ethnicity.

The last sociodemographic control variables included are age and cohort. Age is included as a continuous measure of years old and is top coded at 89 . Cohort is also included which measures year of birth and was coded into four dichotomous measures: (1) Pre-Baby Boomers which includes respondents born in 1945 or earlier, (2) Baby Boomers which includes respondents born between 1946-1964, (3) Gen X which includes those born between 1965-1980, and (4) Millennials which is the reference category and includes those born in 1981 or after. Cases with missing values for the age measure are included as cohort unknown. 
Socioeconomic status continues to be an important indicator of level of digital access. The education variable measures highest level of education and is coded into three dichotomous variables (1) high school or less, (2) some college, and (3) college degree or higher, which is the reference category. Cases with missing values for the education measure are included as education unknown. The income variable measures total family annual income and is coded into 3 dichotomous variables (1) $\$ 24,999$ or less, (2) $\$ 25,000$ or more, which is the reference category, and (3) income unknown which includes those respondents who did not provide an answer, did not know, or for whom the survey question was not applicable.

Finally, an individual's home life as it might be structured by marital status or the presence of children may impact one's health and level of digital access. Marital Status is included as five dichotomous measures: (1) Married, which is the reference category, (2) Never married, (3) Separated or divorced, (4) Widowed, and (5) marital status unknown for the cases with no answer to the marital status survey item. The measure for children used is derived from GSS measures regarding cohabitation in the respondents' household and which ask about the manner of the relationship between the respondent and other people living in the household as well as the respective cohabitants age(s). I created a dichotomous measure of whether or not the respondent lived with one or more children (natural, adopted, step) who was under the age of 18. Those respondents with no children under the age of 18 living with them are included as the reference category. 


\section{Analytic Approach}

Data analysis began with T-tests performed to compare the characteristics of the excluded cases with those included in the analytic sample in order to check for selection bias. Next, descriptive analyses stratified by level of digital access were conducted in order to compare sample characteristics. In order to determine the indirect effect of the work-related mediation variables on the association between digital access with overall self-rated health, multiple mediation analyses were conducted using the Karlson/Holm/Breen (KHB) method via the Stata command, khb (Breen, Karlson, and Holm 2013; Kohler, Karlson, and Holm 2011). The KHB method decomposes the total effect into the direct effect and indirect effect while holding constant the scale and the fit of the error to the assumed logistic distribution. More specifically, the mediation analyses estimate the mediation effects of work status (Model 1), job satisfaction (Model 2), and occupation (Model 3) on the association between digital access and health. Each model includes the self-rated health dependent variables, the digital access independent variable, the mediation variable of interest, as well as each of the control variables including measurements of sex, race and ethnicity, age, cohort, education, income, marital status, and the presence of children. For Model 3, a separate mediation analysis was conducted for each of the occupation categories. For these analyses the occupation categories not being tested for mediation were included with the control variables. 


\section{RESULTS}

\section{Sample Demographics}

Results of the T-test analyses comparing the characteristic of the missing cases with those included in the analytic sample indicate that the 16 excluded respondents reported lower levels of overall health, were more likely to have a missing value for work status, level of education, level of family income, and marital status. Missing respondents were also more likely to be Hispanic, have a production or transportation occupation, be widowed, and were less likely to have an annual family income of $\$ 25,000$ or more. I will discuss what these attritions may mean for results of the current analysis later.

Tables 1 and 2 presents the results of the descriptive statistics for the analytic sample stratified by level of digital access. Average level of self-rated health is lowest among those with no digital access at 2.50 which is associated with self-rated health directly between fair and good. The mean level of health is higher among those with mobile access at 2.61 and even higher among those with computer access at 2.99 (or the equivalent to good self-rated health). The no access respondents are also the oldest on average group in the sample with a mean age of 64.57 . The respondents with mobile access have an average age of 49.37 and those with computer access are slightly younger on average with a mean age of 46.73. The full sample mean age is 49.05. Average level of education is similar among those with no access (11.06 or the equivalent of high school or less) and those with mobile access (11.50 or the equivalent of high school or less). The average level of education is much higher among those with computer access at 14.27 or the equivalent of some college. 
Average level of income is lowest among those with no digital access (9.52 or the equivalent of an annual income between $\$ 10,000-\$ 14,999)$. Those with mobile access have the next highest average level of income (10.19 or the equivalent of an annual income between $\$ 15,000-\$ 19,999)$, and those with computer access have the highest average level of income (11.18 or the equivalent of an annual income between $\$ 20,000$ 24,999).

Average level of job satisfaction is somewhat comparable across level of digital access. Average level of job satisfaction is lowest among those with no digital access (0.91), a little higher among those with computer access (1.28) and is actually highest among those with mobile access (1.31). In terms of work status, a higher proportion of those with no digital access report not working (67.90\%) and a lower proportion report working fulltime $(15.72 \%)$ than any other group. Among those with mobile access, $47.73 \%$ report not working while $34.47 \%$ report working fulltime. These trends continue with the lowest proportion of those not working (33.35\%) and the highest proportion working full time (52.99\%) among the group with computer access. As for occupation, the highest proportion of each group of respondents reported occupation other/NA - not employed (74.89\% among those with no access, $51.52 \%$ among those with mobile access, and $35.35 \%$ among those with computer access). The second highest reported occupation for each group was service (9.39\% among those with no access, $21.59 \%$ among those with mobile access, and $22.75 \%$ among those with computer access). The third highest reported occupation classification varied across groups. For those with no digital access, it was Natural resources, construction (6.11\%), Production, transportation 
for those with mobile access $(10.61 \%)$, and Sales and Office for those with computer $\operatorname{access}(15.39 \%)$.

\section{Mediation Analyses}

Table 3 shows the results of the mediation analyses. Results of the mediation

analyses indicate that in each model, level of digital access does predict level of self-rated health. In Model 1, the effect of digital access reduces from 0.265 increase in log odds of having better self-rated health with each higher level of digital access, to 0.242 increase in log odds once work status is controlled for. The indirect effect of having higher levels of employment is therefore 0.023 and is statistically significant which suggests that the relationship between digital access and health may be mediated by work status.

Results of Model 2 show that digital access is a significant predictor of health with a 0.255 increase in log odds of having better self-rated health associated with each higher level of digital access. However, the indirect effect of job satisfaction on the relationship between digital access and health is not significant, which suggests that it likely does not operate as a mediator. Finally, in Model 3, which examines the effects of occupation on the relationship between digital access and health, digital access is once again a significant predictor. In this model the indirect effect of occupation on the relationship between digital access and health is not statistically significant for all but one of the occupation categories. The Other/Not employed occupation category has a significant indirect effect of 0.010 on the relationship between digital access and health. This suggests that for the most part the relationship is likely not mediated by occupation, 
however for those in the Other/Not employed category some of the positive effects of digital access on health may occur via their occupation.

\section{DISCUSSION AND CONCLUSION}

This research sheds light on a newly developing relationship between digital access and overall health and suggests directions for further research. Higher levels of digital access, as it is measured here in terms of the physical access to a device with Internet connection as well as type of device, is positively associated with higher levels of self-rated health. These findings also suggest that work status may be an important mechanism through which the relationship is shaped. However, neither job satisfaction nor occupation were found to have statistically significant indirect effects on the relationship between digital access and health. These findings support the hypothesis that digital access may be related to health outcomes as it operates to determine one's access to work, a crucial social determinant of health. And while job satisfaction and occupation were not found to have significant indirect effects on the relationship, digital access remained a significant predictor of health which supports the hypothesis that digital access in and of itself, may be an emerging social determinant of health.

For this study I operationalized digital access using the available measures in the GSS in terms of material/physical access to Internet enabled mobile device or computer.The findings indicate that material access remains important and that device used may be of particular importance for the ways in which access to work status shapes the relationship between digital access and healthThese findings have important 
implications because as of 2015, around 9\% of smartphone owners were "smartphonedependent" users which is to say that they lack another form of high-speed access option besides their smartphone (Smith 2015). Those smartphone-dependent users are much more likely to use their phones for gathering employment opportunity information and even to apply for jobs. One Pew Research Center study found that among smartphonedependent users $65 \%$ have utilized their phone as a part of a job search and 39\% have used their smartphone for submitting a job application (Smith 2015). This dependency on a smartphone for digital access may produce barriers to accessing employment opportunities as using certain skills is more difficult on some devices than on others. For example, research indicates that doing content-rich searches can be difficult on a smartphone (Napoli and Obar 2014).

And while much of the digital divide scholarship has shifted focus away from material access, the disparity remains significant for some lower income and racial minority groups. For example, a Pew Research Center report conducted in early 2019 found that $26 \%$ of adults living in households earning less than $\$ 30,000$ a year are “smartphone-dependent" Internet users (Anderson and Kumar 2019). Furthermore, while around $12 \%$ of whites are smartphone dependent, roughly $23 \%$ of blacks and $25 \%$ of Hispanics fall into this category (Perrin and Turner 2019). This is to say that any health disadvantages related to limited digital access to employment may exacerbate racial health disparities as higher proportions of Hispanic and Black adults are smart-phone dependent than their white counterparts. 
Additionally, it is important to note that although digital access was not operationalized in a manner which captures the full range of access from motivation to usage, it remains a significant predictor of health in each model while controlling for many socioeconomic and demographic variables. This is to say that digital access seems to matter for health even in its broadest forms. This is particularly interesting as much of the digital divide literature has found that consideration of types of Internet usage and engagement is important for producing life enhancing benefits (e.g. Blank and Groselj 2014; van Deursen and van Dijk 2014; Zillien and Hargittai 2009). On the other hand, some research has shown that there are collateral benefits to Internet use across domains (van Deursen and Helsper 2018). This is to say that engagement with the Internet must not necessarily occur in one specific domain such as that of the labor market in order to reap benefits within that domain offline. For example there are collateral benefits to Internet use, or in other words engagement in one domain has benefits that extend past that domain into other domain-specific achievement outcomes (van Deursen and Helsper, 2018). This is important because, as is supported by the findings of this study, general engagement with the Internet may be an important predictor for offline benefits across a variety of domains and including health outcomes.

The digital divide literature has offered a number of important theoretical approaches to understanding digital access and the ways that inequality in access operates as a function of existing structural inequalities. However, some of the concepts used to theorize digital divide trends are challenging to operationalize. For example, although digital access may be conceptualized in terms of motivational, material/physical, skills, 
and usage access, the data used for this research do not allow for operationalizing these successive forms and stages of access. And although there are data sets which are better suited for a more nuanced measurement of digital access, they tend not to also include measurements of health and social determinants of health such as labor market related resources. Future research should continue to examine the relationship between digital access and health and in particular the possible proximal and distal pathways through which the relationship may be shaped. Further testing is needed, and in time should be conducted using longitudinal data, to investigate the causal nature of the relationship. 


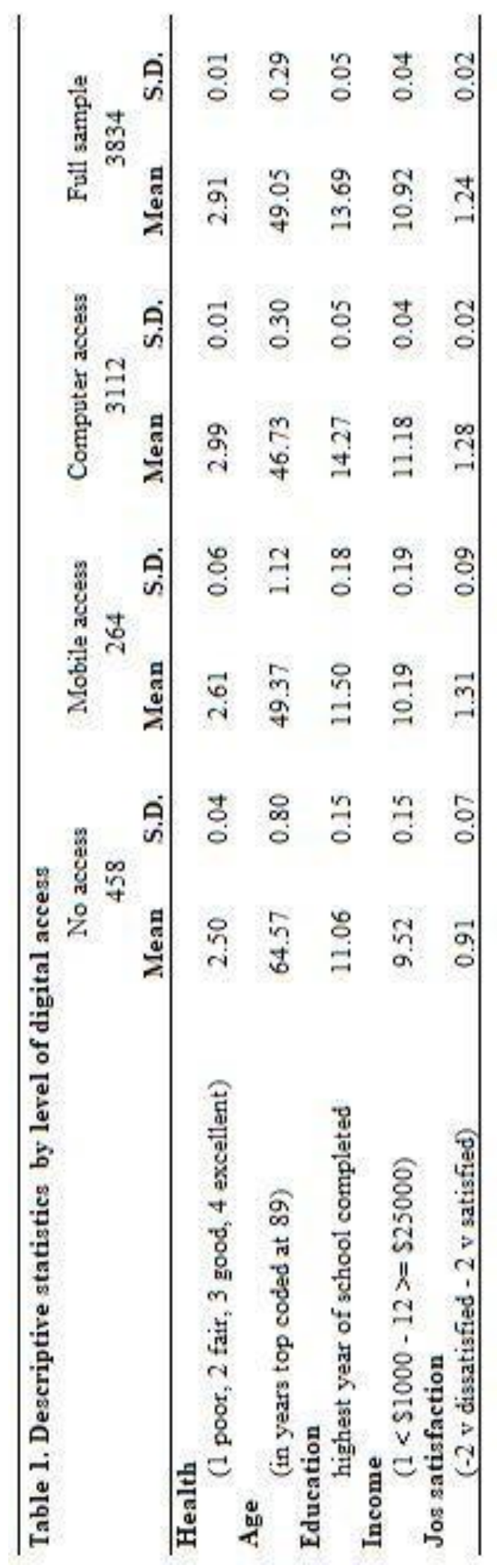




\begin{tabular}{|c|c|c|c|c|c|c|c|c|}
\hline \multicolumn{9}{|c|}{ Table 2. Descriptive statistics by level of digital access } \\
\hline & \multicolumn{2}{|c|}{ No access } & \multicolumn{2}{|c|}{ Mobile access } & \multicolumn{2}{|c|}{$\begin{array}{c}\text { Computer access } \\
3112\end{array}$} & \multicolumn{2}{|c|}{$\begin{array}{l}\text { Full sample } \\
3834\end{array}$} \\
\hline & freq. & $\%$ & freq. & $\%$ & freq. & $\%$ & freq. & $\%$ \\
\hline \multicolumn{9}{|l|}{ Work Status } \\
\hline Working fulltime & 72 & 15.72 & 91 & 34.47 & 1,649 & 52.99 & 1,812 & 47.26 \\
\hline Working parttime & 41 & 8.95 & 34 & 12.88 & 369 & 11.86 & 444 & 11.58 \\
\hline Not working & 311 & 67.90 & 126 & 47.73 & 1,038 & 33.35 & 1,475 & 38.47 \\
\hline wrk stat unknown & 34 & 7.42 & 13 & 4.92 & 56 & 1.80 & 103 & 2.69 \\
\hline \multicolumn{9}{|l|}{ Occupation } \\
\hline Management/Professional & 6 & 1.31 & 9 & 3.41 & 461 & 14.81 & 476 & 12.42 \\
\hline Service & 43 & 9.39 & 57 & 21.59 & 708 & 22.75 & 808 & 21.07 \\
\hline Sales and Office & 16 & 3.49 & 9 & 3.41 & 479 & 15.39 & 504 & 13.15 \\
\hline Natural resources, construction & 28 & 6.11 & 22 & 8.33 & 128 & 4.11 & 178 & 4.64 \\
\hline Production, transportation & 20 & 4.37 & 28 & 10.61 & 207 & 6.65 & 255 & 6.65 \\
\hline Other/NA - not employed & 343 & 74.89 & 136 & 51.52 & 1,100 & 35.35 & 1,579 & 41.18 \\
\hline Unknown & 2 & 0.44 & 3 & 1.14 & 29 & 0.93 & 34 & 0.89 \\
\hline \multicolumn{9}{|l|}{ Gender } \\
\hline Male & 196 & 42.79 & 118 & 44.70 & 1,384 & 44.47 & 1,698 & 44.29 \\
\hline Female & 262 & 57.21 & 146 & 55.30 & 1,728 & 55.53 & 2,136 & 55.71 \\
\hline Race \& Ethnicity & & & & & & & & 0.00 \\
\hline Hispanic & 93 & 20.31 & 77 & 29.17 & 369 & 11.86 & 539 & 14.06 \\
\hline Non-Hispanic White & 251 & 54.80 & 132 & 50.00 & 2,142 & 68.83 & 2,525 & 65.86 \\
\hline Non-Hispanic Black & 99 & 21.62 & 46 & 17.42 & 459 & 14.75 & 604 & 15.75 \\
\hline Non-Hispanic Other & 15 & 3.28 & 9 & 3.41 & 142 & 4.56 & 166 & 4.33 \\
\hline \multicolumn{9}{|l|}{ Cohort } \\
\hline Millennials & 25 & 5.46 & 70 & 26.52 & 842 & 27.06 & 937 & 24.44 \\
\hline Gen $X$ & 52 & 11.35 & 69 & 26.14 & 943 & 30.30 & 1,064 & 27.75 \\
\hline Baby Boomers & 169 & 36.90 & 73 & 27.65 & 988 & 31.75 & 1,230 & 32.08 \\
\hline Pre-Baby Boomers & 212 & 46.29 & 52 & 19.70 & 328 & 10.54 & 592 & 15.44 \\
\hline Unknown & 0 & 0.00 & 0 & 0.00 & 11 & 0.35 & 11 & 0.29 \\
\hline Married & 113 & 24.67 & 104 & 39.39 & 1,471 & 47.27 & 1,688 & 44.03 \\
\hline Never Married & 86 & 18.78 & 85 & 32.20 & 869 & 27.92 & 1,040 & 27.13 \\
\hline Separated/Divorced & 131 & 28.60 & 49 & 18.56 & 589 & 18.93 & 769 & 20.06 \\
\hline Widowed & 127 & 27.73 & 26 & 9.85 & 180 & 5.78 & 333 & 8.69 \\
\hline Unknown & 1 & 0.22 & 0 & 0.00 & 3 & 0.10 & 4 & 0.10 \\
\hline \multicolumn{9}{|l|}{ Children } \\
\hline no children & 51 & 11.14 & 74 & 28.03 & 776 & 24.94 & 901 & 23.50 \\
\hline children & 407 & 88.86 & 190 & 71.97 & 2,336 & 75.06 & 2,933 & 76.50 \\
\hline \multicolumn{9}{|l|}{ Survey Year } \\
\hline 2010 & 107 & 23.36 & 25 & 9.47 & 533 & 17.13 & 665 & 17.34 \\
\hline 2012 & 88 & 19.21 & 40 & 15.15 & 504 & 16.20 & 632 & 16.48 \\
\hline 2014 & 95 & 20.74 & 44 & 16.67 & 709 & 22.78 & 848 & 22.12 \\
\hline 2016 & 106 & 23.14 & 70 & 26.52 & 730 & 23.46 & 906 & 23.63 \\
\hline 2018 & 62 & 13.54 & 85 & 32.20 & 636 & 20.44 & 783 & 20.42 \\
\hline
\end{tabular}




\begin{tabular}{|c|c|c|c|c|c|c|}
\hline \multicolumn{5}{|l|}{ Table 3. Mediation Analyses } & \multirow{2}{*}{\multicolumn{2}{|c|}{$\frac{n=3,834}{95 \% \mathrm{CI}}$}} \\
\hline & \multirow[b]{2}{*}{ B } & \multirow[b]{2}{*}{ S.E. } & \multirow[b]{2}{*}{$z$} & \multirow[b]{2}{*}{$\mathrm{p}$} & & \\
\hline & & & & & \multicolumn{2}{|c|}{ lower upper } \\
\hline \multicolumn{7}{|l|}{ Model 1-Work Status } \\
\hline Total effect & 0.265 & 0.068 & 3.910 & 0.000 & 0.132 & 0.398 \\
\hline Direct effect & 0.242 & 0.068 & 3.570 & 0.000 & 0.109 & 0.375 \\
\hline Indirect effect & 0.023 & 0.008 & 2.970 & 0.003 & 0.008 & 0.038 \\
\hline \multicolumn{7}{|l|}{ Model 2 - Job Satisfaction } \\
\hline Total effect & 0.252 & 0.069 & 3.670 & 0.000 & 0.118 & 0.387 \\
\hline Direct effect & 0.255 & 0.069 & 3.720 & 0.000 & 0.121 & 0.390 \\
\hline Indirect effect & -0.003 & 0.007 & -0.450 & 0.653 & -0.016 & 0.010 \\
\hline \multicolumn{7}{|l|}{ Model 3 -Occupation } \\
\hline \multicolumn{7}{|l|}{ Senvice } \\
\hline Total effect & 0.247 & 0.068 & 3.620 & 0.000 & 0.114 & 0.381 \\
\hline Direct effect & 0.249 & 0.068 & 3.640 & 0.000 & 0.115 & 0.383 \\
\hline Indirect effect & -0.002 & 0.001 & -1.080 & 0.282 & -0.004 & 0.001 \\
\hline \multicolumn{7}{|c|}{ Sales and Office } \\
\hline Total effect & 0.247 & 0.068 & 3.620 & 0.000 & 0.114 & 0.381 \\
\hline Direct effect & 0.249 & 0.068 & 3.640 & 0.000 & 0.115 & 0.383 \\
\hline Indirect effect & -0.002 & 0.002 & -0.740 & 0.459 & -0.006 & 0.003 \\
\hline \multicolumn{7}{|l|}{ Natural resources, constructio: } \\
\hline Total effect & 0.251 & 0.068 & 3.670 & 0.000 & 0.117 & 0.385 \\
\hline Direct effect & 0.249 & 0.068 & 3.640 & 0.000 & 0.115 & 0.383 \\
\hline Indirect effect & 0.002 & 0.003 & 0.610 & 0.539 & -0.004 & 0.009 \\
\hline \multicolumn{7}{|l|}{ Production, transportation } \\
\hline Total effect & 0.249 & 0.068 & 3.640 & 0.000 & 0.115 & 0.383 \\
\hline Direct effect & 0.249 & 0.068 & 3.640 & 0.000 & 0.115 & 0.383 \\
\hline Indirect effect & 0.000 & 0.001 & -0.060 & 0.950 & -0.002 & 0.002 \\
\hline \multicolumn{7}{|l|}{ Other/Not emploved } \\
\hline Total effect & 0.259 & 0.068 & 3.780 & 0.000 & 0.125 & 0.393 \\
\hline Direct effect & 0.249 & 0.068 & 3.640 & 0.000 & 0.115 & 0.383 \\
\hline Indirect effect & 0.010 & 0.004 & 2.430 & 0.015 & 0.002 & 0.017 \\
\hline
\end{tabular}




\section{REFERENCES}

Adler, Nancy E. and Joan M. Ostrove. 1999. "Socioeconomic Status and Health: What We Know and What We Don't." Annals of the New York academy of Sciences 896(1): 3-15.

Anandarajan, Murugan, Claire Simmers, and Magid Igbaria. 2000. "An Exploratory Investigation of the Antecedents and Impact of Internet Usage: An Individual Perspective." Behavior \& Information Technology 19(1):69-85.

Anderson, Monica and Madhumitha Kumar. 2019. "Digital Divide Persists Even as Lower-Income Americans Make Gains in Tech Adoption" Pew Research Center https://www.pewresearch.org/fact-tank/2019/05/07/digital-divide-persists-evenas-lower-income-americans-make-gains-in-tech-adoption/

Ahonen, Emily Quinn, Kaori Fujishiro, Thomas Cunningham and Michael Flynn. 2018.

"Work as An Inclusive Part of Population Health Inequities Research and Prevention." American journal of public health 108(3): 306-311.

Atkinson, Anthony Barnes. 2008. The Changing Distribution of Earnings in OECD Countries. Oxford University Press on Demand

Bauer, Johannes. M. 2016. "Inequality in the Information Society". Working paper, Quello Center, Michigan State University, East Lansing, MI. doi:10.2139/ssrn.2813671.

Bauer, Johannes M. 2018. "The Internet and income Inequality: Socio-Economic Challenges in a Hyperconnected Society." Telecommunications Policy 42(4): 333-343. 
Blank, Grant, and Darja Groselj. 2014. "Dimensions of Internet Use: Amount, Variety, and Types." Information, Communication \& Society 17(4): 417-435.

Bonfadelli, Heinz. 2002. "The Internet and Knowledge Gaps: A Theoretical and Empirical Investigation." European Journal of communication 17(1): 65-84.

Breen, Richard, Kristian Bernt Karlson, and Anders Holm. 2013. "Total, Direct, And Indirect Effects in Logit and Probit Models." Sociological Methods \& Research 42(2): 164-191.

Carlson, Matthew J., Jennifer DeVoe, and Bill J. Wright. 2006. "Short-Term Impacts of Coverage Loss in A Medicaid Population: Early Results from A Prospective Cohort Study of The Oregon Health Plan." The Annals of Family Medicine 4(5): 391-398.

Clayton, John and Stephen J. Macdonald. 2013. "The Limits of Technology: Social Class, Occupation and Digital Inclusion in The City of Sunderland, England". Information, Communication \& Society 16(6): 945-966.

Czaja, Izabela, and Maria Urbaniec. 2019. "Digital Exclusion in The Labour Market in European Countries: Causes and Consequences." European Journal of Sustainable Development 8(5): 324-324.

DiMaggio, Paul, and Bart Bonikowski. 2008."Make Money Surfing the Web? The Impact of Internet Use on The Earnings of US Workers." American Sociological Review 73(2): 227-250. 
Faragher, E. Brian, Monica Cass, and Cary L. Cooper. 2005. "The Relationship between Job Satisfaction and Health: A Meta-Analysis." Occupational and Environmental Medicine 62(2):105-112.

Frey, Carl Benedikt and Michael A. Osborne. 2017. "The Future of Employment: How Susceptible Are Jobs to Computerisation?" Technological forecasting and social change $114: 254-280$.

Garrido, Maria, Joe Sullivan, and Andrew Gordon. 2010. "Understanding the Links Between ICT Skills Training and Employability: An Analytical Framework." Proceedings of the 4th ACM/IEEE International Conference on Information and Communication Technologies and Development.

Gui, Marco and Gianluca Argentin. 2011. "Digital Skills of Internet Natives: Different Forms of Digital Literacy in A Random Sample of Northern Italian High School Students." New media \& society 13(6): 963-980.

Hadley, Jack. 2003. "Sicker and Poorer-The Consequences of Being Uninsured: A Review of the Research on the Relationship Between Health Insurance, Medical Care Use, Health, Work, and Income." Medical Care Research and Review 60(2) suppl: 3S-75S.

Hargittai, Eszter. 2002. "Second-Level Digital Divide: Differences in People's Online Skills." First Monday 7(4).

Hargittai, Eszter. 2010. "Digital na (t) ives? Variation in Internet Skills and Uses Among Members of the "Net Generation"." Sociological inquiry 80(1): 92-113. 
Helsper, Ellen Johanna. 2012. "A Corresponding Fields Model for The Links Between Social and Digital Exclusion." Communication theory 22(4): 403-426.

Helsper, Ellen J. and Bianca C. Reisdorf. 2017. "The Emergence of A “Digital Underclass” In Great Britain And Sweden: Changing Reasons for Digital Exclusion." New media \& society 19(8): 1253-1270.

Horowitz, Jonathan. 2016. "Dimensions of Job Quality, Mechanisms, And Subjective Well-Being in The United States." Sociological Forum 31(2).

Jayaram, Shubha, and Michelle Engmann. 2014. "Developing Skills for Employability at The Secondary Level: Effective Models for Asia." Prospects 44(2): 221-233.

Kivimäki, Mika, Jussi Vahtera, Marianna Virtanen, Marko Elovainio, Jaana Pentti, and Jane E. Ferrie. 2003. "Temporary Employment and Risk of Overall and CauseSpecific Mortality." American journal of epidemiology 158(7): 663-668.

Kuhn, Peter, and Hani Mansour. 2014. "Is Internet Job Search Still Ineffective?" The Economic Journal 124.581: 1213-1233.

Landsbergis, Paul A., Joseph G. Grzywacz, and Anthony D. LaMontagne. 2014. "Work Organization, Job Insecurity, And Occupational Health Disparities." American journal of industrial medicine 57(5): 495-515.

Link, Bruce G. and Jo Phelan. 1995. "Social Conditions as Fundamental Causes of Disease." Journal of Health and Social Behavior, 80-94. 
Lipscomb, Hester J., Dana Loomis, Mary Anne McDonald, Robin A. Argue, and Steve Wing. 2006. "A conceptual Model of Work and Health Disparities in The United States." International Journal of Health Services 36(1): 25-50.

Loh, Yvonne Ai-Chi, and Chib, Arul. 2019. "Tackling Social Inequality in Development: Beyond Access to Appropriation of ICTs for Employability." Information Technology for Development 25(3): 532-51.

Marmot, Michael. 2004. Status Syndrome. Significance, 1(4):150-154.

Marmot, Michael. 2015. The Health Gap: The Challenge of an Unequal World. New York ; London: Bloomsbury Press.

Marmot, Michael, Johannes Siegrist, and Tores Theorell. 2006. "Health and the Psychosocial Environment at Work.” Pp. 97-130 in Social Determinants of Health 2nd ed. Edited by M. Marmot and R. G. Wilkinson. Oxford; New York: Oxford University Press.

Marmot, Michael, Stephen Stansfeld, Chandra Patel, Fiona North, Jenny Head, Ian White, Eric Brunner, Amanda Feeney, and G. Davey Smith. 1991. "Health Inequalities among British Civil Servants: The Whitehall II Study." The Lancet 337(8754): 1387-393.

Martínez-Cantos, José Luis. 2017. "Digital Skills Gaps: A Pending Subject for Gender Digital Inclusion in The European Union." European Journal of Communication 32(5): 419-438.

McQuaid, Rondald, Colin Lindsay, and Malcolm Greig. 2004. ' Reconnecting' the Unemployed: Information and Communication Technology and Services for 
Jobseekers in Rural Areas', Information, Communication \& Society, 7(3): 364388.

Mincer, Jacob. 1958. "Investment in Human Capital and Personal Income Distribution." Journal of Political Economy, 66(4): 281-301

Mirowsky, John, and Catherine E. Ross. 2003. Social Causes of Psychological Distress. Transaction Publishers.

Morris, Estelle. 2009. Independent Review of ICT User Skills, Department for Business, Innovation and Skills, London.

Napoli, Philip M., and Jonathan A. Obar. 2014. "The Emerging Mobile Internet Underclass: A Critique of Mobile Internet Access." The Information Society 30.5: $323-334$

Peckham, Trevor, Kaori Fujishiro, Anjum Hajat, Brian P. Flaherty, and Noah Seixas. 2019. "Evaluating Employment Quality as A Determinant of Health in A Changing Labor Market." RSF: The Russell Sage Foundation Journal of the Social Sciences 5(4): 258-281.

Perrin, Andrew and Erica Turner. 2019. "Smartphones Help Blacks, Hispanics Bridge Some - But Not All - Digital Gaps with Whites". Pew Research Center https://www.pewresearch.org/fact-tank/2019/08/20/smartphones-help-blackshispanics-bridge-some-but-not-all-digital-gaps-with-whites/

Phelan, Jo C., Bruce G. Link, and Parisa Tehranifar. 2010. "Social Conditions as Fundamental Causes of Health Inequalities: Theory, Evidence, And Policy Implications." Journal of health and social behavior 51(1) suppl: S28-S40. 
Reisdorf, Bianca C., and Darja Groselj. 2017. "Internet (non-) Use Types and Motivational Access: Implications for Digital Inequalities Research." New Media \& Society 19(8): 1157-1176.

Rodin, Judith and Christine Timko. 1992. "Sense of Control, Aging, Health.” Pp. 207236 in Aging, Health, and Behavior, edited by M. G. Ory, R. P. Abeles and P. D. Lipman. Newbury Park, CA: Sage.

Ross, Catherine E., and John Mirowsky. 1995. "Does Employment Affect Health?" Journal of Health and Social Behavior 36: 230-243.

Rowe, John W. and Robert L. Kahn. 1987. "Human Aging: Usual and Successful." Science 237(4811): 143-149.

Selwyn, Neil. 2003. "ICT for All? Access and Use of Public ICT Sites in the UK', Information, Communication and Society 6(3): 350-375.

Smith, Aaron. 2015. “Chapter Two: Usage and Attitudes Toward Smartphones” Pew Research Center https://www.pewresearch.org/internet/2015/04/01/chapter-twousage-and-attitudes-toward-smartphones/\#job\%20seeking

Steege, Andrea L., Sherry L. Baron, Suzanne M. Marsh, Cammie Chaumont Menéndez, and John R. Myers. 2014. "Examining Occupational Health and Safety Disparities Using National Data: A Cause for Continuing Concern." American journal of industrial medicine 57(5): 527-538.

Thetkathuek, Anamai, Pornthip Yenjai, Wanlop Jaidee, Patchana Jaidee, and Poonsak Sriprapat. 2017. "Pesticide exposure And Cholinesterase Levels in Migrant Farm Workers in Thailand." Journal of agromedicine 22(2): 118-130. 
Van de Klundert, Theo. 2008. "Looking Back, Looking Ahead: Biased Technological Change, Substitution and the Wage Gap." Journal of Macroeconomics 30(2): $707-713$.

van Deursen, Alexander J.A.M., and Ellen J. Helsper. 2015. "The Third-Level Digital Divide: Who Benefits Most from Being Online?" Communication and information technologies annual. Emerald Group Publishing Limited van Deursen, Alexander JAM, and Ellen J. Helsper. 2018. "Collateral Benefits of Internet Use: Explaining the Diverse Outcomes of Engaging with The Internet." new media \& society 20.7: 2333-2351.

van Deursen, Alexander, and Jan van Dijk. 2011. "Internet Skills and The Digital Divide." New media \& society 13(6): 893-911.

van Dijk, Jan A.G.M. 2005. The Deepening Divide: Inequality in the Information Society. Thousand Oaks, CA: Sage Publications.

World Health Organization. 2008. Commission on Social Determinants of Health. Closing the gap in a generation: health equity through action on the social determinants of health: final report of the commission on social determinants of health.

Zhang, Xiaoqun. 2013. "Income Disparity and Digital Divide: The Internet Consumption Model and Cross-Country Empirical Research." Telecommunications Policy 37.6(7): 515-529. 
Paper Three

Access in The Digital Field, eHealth Behaviors and Health

Digital information and communication technologies (ICTs) are becoming more and more essential for accessing important resources such as employment, housing, social support, and health information and services. However, many experience barriers to accessing digital ICTs which can lead to total or partial digital exclusion. This may pose a significant problem as many of these resources which are increasingly accessed (in some cases exclusively) through the digital field are closely related to health outcomes. As such, digital equity may be closely tied to health equity.

Although the Internet offers the possibility of providing opportunities for those most affected by health disparities to access information, activities, and resources with potential health promoting qualities, these digital inequalities could also exacerbate existing health inequalities as they occur along similar axes and are both rooted in an unequal distribution of resources. This is to say that digital and health inequalities may be mutually constituted such that the populations being most negatively affected by digital inequality are in many cases the same marginalized populations who are already more likely to experience poor health.

The purpose of this study is to examine the relationship between level of digital access and self-rated health with a focus on the role of eHealth activities. More specifically, this research aims to address the question of whether and to what extent motivation/material access and skills/usage access are determined by amount and composition of different forms of capital and whether or not higher levels of digital 
access reap higher rewards on health via eHealth activities. Using data from a nationally representative sample of adult population in the US, this study contributes to the literature by situating the examination of the relationship between eHealth activities and self-rated health within a theoretical framing of the digital field as a site for the reproduction of existing social inequalities.

\section{THEORETICAL BACKGROUND}

This research utilizes van Dijk's model for understanding digital access in terms of four successive stages and kinds of access. However, although van Dijk employs the term resources in his framework for understanding the forces which shape digital access, many scholars have employed Bourdieu's forms of capital along with habitus and fields as the theoretical concepts most useful for understanding the way digital access operates. In the following section I provide an overview for the ways in which this study situates van Dijk's model of digital access within a Bourdieusian perspective of social inequality.

\section{Digital Access}

van Dijk’s (2005) multiple access model of digital inequality involves four types of successive stages and kinds of access: (1) motivational access, (2) material or physical access, (3) skills access, and (4) usage access. Here, problems of accessing digital technologies gradually shift from the first two stages and kinds, if and when motivational and material access have been achieved, to the second two stages and kinds of access, 
skills and usage. According to van Dijk, the unequal distribution of temporal, material, mental, social, and cultural resources are of particular importance for digital access.

Previous digital inequality studies have employed various aspects of Bourdieu's theoretical concepts of habitus, capital, social fields, and the reproduction of social inequalities, to the analysis of access to, and the use of, digital ICTs (Baum, Newman, and Biedrzycki 2012; Calderón Gómez 2020; Gilbert 2010; Halford and Savage 2010; Levina and Arriaga 2014; Lindell 2018; Tondeur, et al. 2011). In particular, in their focus group study of access to, and use of, digital technologies as shaped by their subjects' existing capitals, Baum, Newman, and Biedrzycki (2012) employ Bourdieu to conceptualize the digital world as a field in which individuals compete for the distribution for different kinds of capital or field specific goods and resources. According to Bourdieu, competition over different types of capital between individuals and institutions occurs in different social arenas termed fields and is subsequently unevenly distributed to competitors, based on the capital they bring to the field and their ability to compete and invest. This is to say that existing forms of capital may be utilized in an effort to gain the capital at stake in the competition constantly occurring within a particular field.

In his work, van Dijk actually rejects Bourdieu's framework of capital for a couple of reasons. First, he rejects the concept of capital on the basis that it offers primarily descriptive means for understanding the relationship between inequality and digital access. Instead, van Dijk opts for the terms 'resources' to describe the items being 
unequally distributed and 'mechanisms' to explain the ways in which the distribution occurs (2005:18-19). Second, van Dijk claims,

As intermediary factors, resources should be clearly distinct from categories on the one side and kinds of access on the other. For example, having computer equipment and services should be excluded from material resources; otherwise, we would be suggesting a tautological relation with access to this technology. Further, intelligence should be kept apart from its results, the mental resources of knowledge and skills obtained. All resources should be measurable in a quantitative way in regard to individuals who have more or less access to digital technologies (2005:20).

However, for the purposes of this research, Bourdieu's theory is useful as it provides a framework for understanding digital inequality as rooted in as well as reproducing existing structural inequalities. This is to say that one's level of digital access, as understood in terms of van Dijk's multiple access model, once situated within Bourdieu's framework, may be understood as being determined by the amount and types of capital one possesses as well as working to reproduce inequality as investments of said capital in the digital field will reap higher rewards for those who have more capital to invest and more relevant skills for successful investment.

Further, once Bourdieu's perspective is employed it is no longer a tautological premise that a particular resource might both lead to higher levels of access as well as be further attained via said access. After all, capital leads to more capital and from an education background, the idea that one must separate out the initial level of intelligence as an ability to acquire skills and not something that might lead to expanded intelligence, would be questioned. For example, digital access may be determined by economic capital in terms of whether or not a person can afford a computer or reliable network connection. 
Hale (2013) found that "social and structural conditions (i.e. SES, quality of Internet access) influence Internet-related attitudes and behaviors” (Hale 2013:512).

In other words, having entered the digital field, one's digital abilities, understood as a form of cultural capital, will structure their subsequent access to digital field specific goods and resources, many of which have significant impact on health outcomes. For example, an individual's ability to compete in the digital field, for resources such as the utilization of health-related applications or other eHealth behaviors, may depend on the level of cultural capital they bring to the field in terms of their level of education. In this case, those with higher levels of cultural capital will have higher levels of the third and fourth stages and types of digital access, skills and usage, and will therefore have the means to successfully obtain health promoting resources in the digital field. That is to say, those who have higher levels of education, cultural capital, will be more likely to have both a device with Internet connection, and the ability and interest needed to search for health information or a health care provider resulting in better overall health.

Furthermore, as previously discussed, usage access is not a simple matter of time spent on the Internet, rather type and diversity of digital activity is a key component to usage access. Some of the digital ICT activities which may not provide many capital enhancing opportunities such as gaming, video and audio streaming, and social interaction, are rather time-consuming activities. Here, cultural capital may play a key role in determining usage access, as some research has demonstrated that individuals with lower levels of education use the Internet more frequently and for more hours of the day, and that they are more likely to participate in online activities such as gaming and 
socializing (van Deursen and van Dijk 2014). On the other hand, research has also demonstrated that those with higher levels of education and more privileged social positions, or in Bourdieu's terms, people who have more economic and cultural capital, tend to use digital ICTs for more beneficial purposes (van Deursen and van Dijk 2014; Zillien and Hargittai 2009).

eHealth Behaviors

eHealth activities may be understood as one possible opportunity for people to invest their capital in the digital field in the pursuit of gaining rewards on their health. While amount and composition of capital will shape the level of digital access through all four stages and kinds, having gained some level of motivational/material access, these first two stages and kinds may also be considered a form of cultural capital in and of themselves which in turn may be invested in the digital field. For example, having a faster connection or better equipment or a stronger belief that the content available online is relevant and useful to you, will shape the way one engages with digital ICTs. Higher levels of motivational/material access may lead to more time spent acquiring digital skills and may in turn determine usage behaviors while engaging in the digital field as one becomes more proficient. If we conceptualize the digital field as a place where competition over capital occurs then there are many forms of capital accessible via the digital field which may have high returns on health. eHealth activities are a useful measure because they may be conceptualized both as a form of capital available via the digital field, and as a proxy measure of skills and usage digital access as they require 
some level of both. Although eHealth activities are not competed for in the digital field as limited resources available only to the winners of the competition, they are competed over in the sense that they are only available to those who may access them which requires higher levels of digital access as well as higher levels of overall capital.

Digital access may affect health in terms of health behaviors and lifestyle. Individuals with higher levels of digital access may be more capable and more likely to use digital ICTs to better their lives as opposed to simply for enjoyment. One way in which digital ICTs can be used to better one's life is through eHealth behaviors. Using the Internet to browse for health information online, health communication and all other eHealth behaviors, including looking up healthy recipes, streaming exercise videos, using health promoting applications, belonging to health-related online communities, and accessing ones' medical charts are behaviors that may potentially increase positive health outcomes. While previous research examining the relationship between digital access and health outcomes have focused on eHealth activities as the primary/sole health related resource available via the digital field, we consider eHealth activities to be one of many possible health related resources available via the digital field.

\section{RESEARCH QUESTIONS AND HYPOTHESES}

This study investigates the association between digital access and health outcomes by addressing an overarching question of whether or not access to digital ICTs is associated with better overall self-rated health and to what extent this relationship is shaped by amount and composition of capital. More specifically, this research examines 
these relationships by asking the following research questions: (1) Do those with higher levels of capital have higher levels of motivation/material access?; (2) Do those with higher levels of motivation/material access or capital have higher levels of skills/usage access?; (3) Is there an association between motivation/material access and health?; and (4) Does participation in eHealth activities moderate the relationship between motivation/material access and health?

According to the working framework for this research, digital inequality is understood as occurring along multiple lines of access and is both shaped and reproduced in terms of an uneven distribution of capital. As such, I expect to find both that higher levels of capital will lead to greater levels of motivation/material digital access and that higher levels of motivation/material access will, in conjunction with capital, lead to higher levels of skills/usage access and determine one's ability to compete in the digital field via participation in eHealth activities.

However, eHealth activities are merely one opportunity for investing one's capital in the digital field and the eHealth activity measures included in this research do not capture all of the health promoting resources available via the digital field. As such, I expect that there will be a stand-alone relationship between motivation/material access and health. Further, I expect to find that the effects of motivation/material access on health will vary by eHealth activity such that those who participate in these activities will reap higher health benefits from their level of motivation/material access. This is expected both because participating in these activities marks a higher level of skills and usage access which may give respondents greater ability to compete in the digital field 
for the available health related resources and because the eHealth activities themselves may provide health benefits directly.

\section{METHODS}

Data

Data for this study are from the Health Information National Trends Survey (HINTS) conducted by the National Cancer Institute (http://hints.cancer.gov/). Beginning in 2003, HINTS has been used to track health communication and information technology trends in the United States. HINTS is a publicly available, nationally representative, cross-sectional survey of the non-institutionalized adults aged 18-or-older population of the US. Data for this study were pooled from the following six HINTS cycles: HINTS 4 Cycle $1(n=3,959)$, collected from October 2011 through February 2012, HINTS 4 Cycle 3 ( $n=3,185)$, collected from September 2013 to December 2013, HINTS 5 Cycle $1(n=3,285)$, collected between January and May 2017, HINTS 5 Cycle 2 $(n=3,504)$, collected between January and May 2018, HINTS 5 Cycle $3(n=5438)$, collected between January and April 2019, and HINTS 5 Cycle $4(n=3,865)$, collected between February and June 2020.

These HINTS cycles were selected for this research because they include survey questions regarding eHealth activities. HINTS 4 Cycle 1 had both a long-form and a short-form questionnaire. The short-form questionnaire $(n=443)$ did not include these eHealth measures and were excluded from the analyses leaving a total of 3,516 cases for HINTS 4 Cycle 1 and a total of 20,727 cases for the integrated data set. Cases with missing values for the primary dependent variable measuring self-rated health $(\mathrm{n}=314)$ 
and cases with missing values for the primary independent variable which asks respondents if they use the Internet $(n=58)$ were also excluded from the analytic sample. Finally, cases with missing values for age $(n=552)$ were excluded because age information is crucial in the analysis of age stratified ordered logistic regression. The final analytic sample included 19,803 cases.

\section{Measures}

Health. The primary outcome variable measures the general overall condition of health. This measure asks respondents to indicate their health status in terms of a five-point scale ranging from excellent to poor (1 Excellent, 2 Very Good, 3 Good, 4 Fair, 5 Poor). This variable was reverse coded, with higher values indicating better health conditions (1 Poor, 2 Fair, 3 Good, 4 Very Good, 5 Excellent).

Digital access: motivation and material. The first measures for digital access address the first two types and stages of access, motivational and material/physical in terms of whether or not respondents report using the Internet, as well as the quality of their connection for those who do report being Internet users.

The first survey item used for this measure is a yes or no question which asks respondents, "Do you ever go on-line to access the Internet or World Wide Web, or to send and receive e-mail?" While this question does not capture the respondents' reason for not accessing the Internet among those who answer no, it is nonetheless a good proxy of low digital access whether it be motivational access (respondent does not believe the Internet offers relevant or important content) or material access (the respondent does not 
have access to a device and/or a mode of Internet connection necessary for going online). Respondents who report not using the Internet are conceptualized as having the lowest level of motivation/material access.

Mode of Internet connection is also a crucial component of the material level of digital access and was measured using five separate survey questions regarding the mode of access respondents' use when connecting to the Internet. The survey questions ask whether respondents access the Internet through, "a dial-up telephone line," "broadband such as DSL, cable, or FiOS," “a cellular network," and "a wireless network (Wi-Fi),".

These survey items were used to operationalize level of motivation/material access in terms of three levels of access: (1) 'no access' which includes respondents who

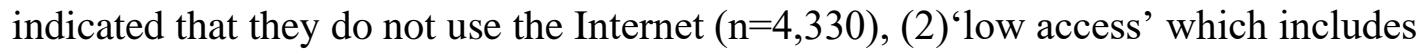
respondents who rely solely on a dial-up connection $(n=271)$, respondents who rely solely on a cellular connection ( $\mathrm{n}=704)$, and respondents who have both dial up and cell but no broadband or wifi ( $\mathrm{n}=27)$ for a total of $(\mathrm{n}=1,045)$, and (3) 'high access' which includes respondents who have any access to broadband or wifi $(n=14,005)$. Cases with missing values for the survey items measuring mode of digital connection were included in the analyses as 'digital access unknown' ( $\mathrm{n}=423)$. In the analyses conducted using level of motivation/material access as the dependent variable and to calculate averages, these three levels of access were included in one ordinal measure of digital access coded $(0-$ no access, $1-$ low access, $2-$ high access $)$ and the missing cases were excluded $(\mathrm{n}=$ 19,380). For those analyses in which level of motivation/material access was an 
independent variable it was included as 4 separate dummy variables with no access as the reference category.

Digital access: skills and usage. The third and fourth types and stages of access, skills and usage access, are operationalized in terms of the eHealth activities. Having attained the first two types and stages of digital access, one's ability to receive the rewards available via the digital field becomes a question of whether or not they have the skills required to do so as well as how they ultimately engage with online content and resources. While the following eHealth variables do not in fact measure respondents' level of digital literacy skills or capture a full range of usage access, they can act as a proxy for skills and usage as they all require some level of operation and information skills (van Dijk 2005).

eHealth activities were measured using four separate survey questions which ask respondents about different online activities in which they may have participated. These questions ask respondents who previously indicated that they do use the Internet, whether or not they have engaged in the following eHealth activities during the previous 12 months: (a) looked for health or medical information for yourself?; (b) used email or the Internet to communicate with a doctor or doctor's office?; (c) shared health information on social networking sites, such as Facebook or Twitter?; and (d) participated in an online support group for people with a similar health or medical issue? These measures are all coded as dichotomous variables ( 1 yes, 0 no). The variable, 'eHealth missing' was also created and was coded 1 for cases where there were missing values for all of the eHealth behavior variables $(n=499)$ and 0 for those who provided answers to the eHealth 
survey items. Because these questions were only asked to respondents who answered yes to the question regarding whether or not they use the Internet, non-users were excluded from the analyses which utilize eHealth activities as the dependent variable as well as the eHealth missing $(\mathrm{N}=15,050)$.

Interaction terms. In order to examine whether or not the effect of motivational and material access on health varies by respondents' level of skills and usage access, interaction terms between the different levels of motivation/material access and the 4 separate eHealth activities were created. In all, 8 interaction terms were included (for each eHealth activity one interaction term for low access and one for high access). Those respondents with no access, who by the very nature of not going online do not participate in any eHealth activities, were included in the analysis as the reference category.

Sociodemographic control variables. Sociodemographic control variables were included in the analysis in order to measure the main effects of digital access on health. Gender is measured by the variable female/other, coded $1=$ female/other which includes cases with missing values for gender and $0=$ male. Race and ethnicity was measured by the following five variables; (1) Hispanic which includes all respondents who report being of Hispanic ethnicity, (2) non-Hispanic Black which include all respondents who report being Black or African American and are not of Hispanic ethnicity, (3) non-Hispanic other which includes respondents who indicate that their race is either American Indian or Alaska native, Asian, Native Hawaiian or other Pacific Islander, or mention multiple 
races and who are not of Hispanic ethnicity, (4) non-Hispanic white, the reference category, which includes respondents who report being white and not of Hispanic ethnicity and (5) race/ethnicity unknown which includes all cases where values for race and or ethnicity were not ascertained.

Age is considered within the analyses in a couple of ways. Age remains one of the most prominent axes along which the digital divide operates. As of 2019, a Pew Research Center Internet and Technology report found that while 100\% of 18-29 year old's and $97 \%$ of $30-49$ year old's report using the Internet, only $88 \%$ of $50-64$ year old's and $73 \%$ of those 65 and older do so (Pew Research Center 2019). In order to examine the possibly age differentiated effects of digital access on health, the analyses were stratified by age using the following three groups, (1) 18-39 year old's (n=3,762), (2) 40-59 year old's $(n=7,019)$, and (3) $60+$ year old's $(n=9,022)$. Age is also included in the models as a control variable using both a continuous measure as well as the squared term in order to account for a non-linear relationship between respondent age and level of self-rated health. Average age was calculated using the continuous age measure 18 - 105 years old. Education is measured as the highest grade completed and coded as six dichotomous variables: (1) Less than high school, (2) High school graduate, (3) Some college, (4) Bachelor's degree, (5) Post Baccalaureate's, the reference category, and (6) Education unknown which includes cases with missing values for the education variable. Average education was calculated using the ordinal education variable coded (1 - Less than high school, 2 - High school graduate, 3 - Some college, 4 - Bachelor's degree, 5 Post - baccalaureate degree). Income is measured as annual income and is coded as 6 
dichotomous variables: (1) Less than $\$ 20,000$, (2) between $\$ 20,000$ and $\$ 35,000$, (3) between $\$ 35,000$ and $\$ 50,000$, (4) between $\$ 50,000$ and $\$ 75,000$, (5) $\$ 75,000$ or more, the reference category, and (6) income unknown which includes cases with missing values for income. For descriptive analyses, average income was calculated using the ordinal variable coded ( 1 - Less than $\$ 20,000,2$ - between $\$ 20,000$ and $\$ 35,000,3$ between $\$ 35,000$ and $\$ 50,000,4$ - between $\$ 50,000$ and $\$ 75,000$, and $5-\$ 75,000$ or more.

Health insurance status is measured in terms of whether or not the respondent has insurance and is coded as dichotomous measures for (1) has insurance, the reference category, (2) no insurance coverage, and (3) insurance status unknown which includes all cases with missing values for insurance status. Marital status was controlled for using five dichotomous variables: (1) married or living as married, the reference category, (2) single or never married, (3) separated or divorced, (4) widowed, and (5) marital status unknown. Finally, whether or not the responded had any children in the household was also controlled for using three dichotomous variables: (1) no children, which was the reference category, (2) children present in the household, and (3) presence of children in the household unknown. 


\section{Analytic Approach}

Analyses began with descriptive statistics stratified by level of motivation/material access comparing socioeconomic and demographic characteristics across groups. Age stratified descriptive statistics were also conducted. Next, age stratified ordered logistic regression analysis was used to estimate the effects of level of education and income on level motivational and material access. The ordinal digital access variable was used as the dependent variable. Model 1 includes just the measures for education and income conceptualized as cultural and economic capital. Model 2 adds all other control variables including, gender, race and ethnicity, age, marital status, presence of children in the household, and insurance status.

Next, in order to address the second research question regarding whether or not higher levels of capital are associated with higher levels of skills usage access, four separate age stratified binary logistic regression analyses were conducted, each predicting the odds of participating in one of the four eHealth activities. These analyses were restricted to a sample entirely made up of Internet users $(\mathrm{N}=15,050)$. Model 1 for each of the four separate binary logistic regressions included measures for motivation and material digital access, as these types and stages of access are conceptualized as necessary precursors for the second set of types and stages of access, as well as level of education, and level of income. In Model 2 all of the control variables were added to Model 1 including, gender, race and ethnicity, age, marital status, presence of children in the household, and insurance status. 
Finally, I conducted an age-stratified ordered logistic regression analysis estimating the moderation effects of eHealth activities on the association between motivation/material access and health. Model 1 examines the bivariate association between motivation/material digital access and health without any control variables for each age group. In Model 2 socioeconomic and demographic controls were added to Model 1 in order to further examine the effects of motivation/material access on health. The control variables added in Model 2 include, education, income, gender, race and ethnicity, age, marital status, presence of children in the household, and insurance status. In Model 3 the digital access interaction terms were included in order to examine whether the effects of motivation/material access on health, varied by engagement in eHealth activities.

\section{RESULTS}

\section{Sample Demographics}

Table 1 provides the descriptive statistics for the analytic sample stratified by level of motivation/material access. These results show that overall, as a group, those with no access report lower levels of self-rated health $($ mean $=3.02)$, are on average older $($ mean $=66.76)$ and have lower average levels of education $($ mean $=2.35)$ and income $($ mean $=2.15)$ than the other groups. The reverse is seen among the group of respondents with high access, as they on average report the highest levels of self-rated health (mean = $3.54)$, are the youngest (mean $=52.61)$ and have the highest average levels of both education $($ mean $=3.56)$ and income $($ mean $=3.71)$ than the other two groups. The 
groups also differ in terms of race and ethnicity. The highest proportions of non-Hispanic Black is among the group with no access and the highest proportion of Hispanic is among the low access group, whereas the high access group has the highest proportion of nonHispanic white and non-Hispanic Other.

Table 2 provides the age stratified descriptive statistics for the analytic sample. These results indicate that overall self-rated health is highest among the youngest age group $($ mean $=3.66)$, followed by the middle age group $($ mean $=3.43)$, and lowest for those ages 60 and over $($ mean $=3.28)$. Similarly, average levels of motivation $/$ material digital access very by age. The average level of access is highest among the youngest group $($ mean $=1.84)$, followed by the middle age group $($ mean $=1.65)$ and the oldest age group $($ mean $=1.24)$. In more detail, the frequency and percentages show that while only $5.32 \%$ of the youngest age group report having no access, $14.67 \%$ of the middle-aged group and $34.36 \%$ of the oldest group do not use the Internet. This trend is also demonstrated in terms of the higher levels of motivational/material access with $88.60 \%$ of the youngest group reporting the highest level of access while only $78.05 \%$ of the middle age group and $57.57 \%$ of the oldest age group have high access. However, the proportion with low access is very similar across groups with $4.68 \%$ among the youngest, $5.07 \%$ among the middle age group, and 5.69\% among the oldest age group falling into this level of access. This is to say that the differences seen across age groups occur largely in terms of the proportion who have no access as opposed to high access.

In terms of skills/usage access, descriptive statistics indicate that participation in the eHealth activities does vary by age. A higher proportion of the youngest group has 
engaged in each of the four activities (83.76\% search for health information, $41.23 \%$ correspond with doctor, $23.15 \%$ social network, $10.87 \%$ support group) followed by the middle age group $(72.05 \%$ search for health information, $36.60 \%$ correspond with doctor, 15.37\% social network, 7.57\% support group), and lowest proportions of engagement are seen among the oldest group (52.64\% search for health information, $27.94 \%$ correspond with doctor, social network, $6.14 \%$ support group). Furthermore, while only $9.33 \%$ of the youngest group report engaging in none of the eHealth activities, $15.40 \%$ of the middle age group and $27.52 \%$ of the oldest group do so. However, among each group exists the same pattern in terms of which eHealth activities respondents engage with more or less often. Looking for health or medical information for oneself is by far the most popular of the eHealth activities across age groups, followed by corresponding with a doctor's office, sharing health information on a social networking site and lastly, participating in an on-line support group for people with a similar health or medical issue.

As for socioeconomic and demographic characteristics, there are a number of agerelated trends. Average level of education is highest among the youngest group $($ mean $=$ $3.54)$, followed by the middle age group (mean $=3.31$ ) and then the oldest age group (mean $=3.10)$. Average level of income follows a slightly different pattern with the highest average level of income seen among the middle age group (mean $=3.56$ ), followed by the youngest age group $($ mean $=3.53)$ and then the oldest age group $($ mean $=$ 3.06). Additionally, while the majority of the sample across age groups is non-Hispanic White (57.59\%), the racial makeup of each group does vary some. The oldest group is the whitest group with 61.05\% non-Hispanic White, followed by $11.79 \%$ non-Hispanic 
Black, 9.73\% Hispanic, and 5.11\% non-Hispanic Other. The youngest and middle age groups are both a little over half non-Hispanic White, however the youngest age group has a higher proportion of Hispanic respondents (19.67\%), followed by non-Hispanic Black $(12.47 \%)$ and non-Hispanic Other $(10.85 \%)$. The middle age group has a more even percentage of Hispanic (15.52\%), non-Hispanic Black (15.37\%) and followed by non-Hispanic Other $(8.32 \%)$.

Marital status varies slightly by group. While married or living as married is the most common status for each group, a higher percentage of the youngest group is single or never married $(38.22 \%)$ than the middle $(15.22 \%)$ or oldest $(8.57 \%)$ age groups. Additionally, the oldest age group has a larger proportion of respondents who are widowed $(21.09 \%)$ than the middle $(2.96 \%)$ or youngest $(0.45 \%)$ age groups, and the middle age group has the highest proportion divorced or separated (22.64\%) compared to the youngest group (6.46\%) and to a lesser extent the oldest age group (19.95\%).

\section{Regression Analyses}

Table 3 provides the unstandardized coefficients and $\mathrm{p}$ values for age stratified ordered logistic regression predicting level of motivation/material access. These results indicate a positive association between both level of education and level of income with level of access across age groups and in both Models 1 and 2. Among the youngest group, the effects of education and income on access is not statistically significant for the highest levels. In other words, having a bachelor's degree is not significantly different from having a post baccalaureate's degree in predicting level of access for those ages 18- 
39. Likewise, for this age group having an annual income of $\$ 50,000$ to $\$ 75,000$ is not statistically different in predicting level of access than having an annual income of $\$ 75,000$ or more.

Gender and race and ethnicity are significant indicators of levels of motivation/material digital access for each age group. Female/other is associated with higher levels of access than male at every age. In terms of race and ethnicity, each racial ethnic group is associated with a lower likelihood of having a higher level of access than their non-Hispanic white counterparts for each age group. Being Hispanic is associated with the lowest likelihood of having higher access across age groups followed by nonHispanic Other and then non-Hispanic Black.

Marital status appears to only be a significant predictor for level of motivation/material access particularly for the oldest age group. Compared to respondents who are married or living as married, those who are single or never married are the least likely to have higher levels of access followed by those who report being widowed and, finally, the group who report being divorced or separated. Additionally, the presence of children in the household is negatively associated with higher levels of access among the youngest group and oldest group.

Tables 4-7 provide the unstandardized coefficients and $\mathrm{p}$ values for age stratified binary logistic regression predicting probability of having skills/usage access in terms of engaging in each of the four separate eHealth activities. First, I estimated the effects of level of motivation/material access, education, and income on the likelihood of using the Internet to look for health or medical information for oneself and the results are presented 
in Table 4. Higher levels of motivation/material access were associated with a higher likelihood of looking for health info online for the older two age groups across models 1 and 2. However, the effect of having high access is not significantly different from that of having low access on likelihood of searching for health information online for the youngest group. Overall, level of education is positively associated with the likelihood of using the Internet to look for health or medical information for oneself across age groups and models. However, in the oldest group (in Models 1 and 2) the relationship is not significantly different between the highest levels of education, having a bachelor's or post baccalaureate's degree. For the most part, the relationship operates such that each higher level of education is associated with an increased likelihood of engaging in the eHealth activity. However, among the youngest group these results indicate that having a high school degree is slightly more negatively associated with the activity than having less than a high school degree in both Models 1 and 2.

Overall, there is some evidence that level of income is also positively associated with the likelihood of using the Internet to look for health or medical information for oneself. This relationship appears to be strongest among the middle age group, however the results indicate that while each of the income levels included in the analysis are significantly less likely than their counterparts making $\$ 75,000$ or more to engage in the eHealth behavior, the relationship is not linear and the coefficients are all relatively similar in size. Among the youngest age group, although the association between income and using the Internet to search for health information is somewhat unclear in the first Model, it is strong and clear in the second Model with each higher level of income 
associated with higher likelihood of doing so through the first three income brackets. For this group the effect of making $\$ 50,000$ to $\$ 75,000$ is not significantly different from making $\$ 75,000$ or more on participation in this eHealth activity. Finally, the association between level of income and searching online for health information is weakest for the oldest age group and once the control variables are added in Model 2 there is no clear relationship between income and this eHealth activity for those ages 60 and older.

Next, I estimated the effects of level of motivation/material access, education, and income on the use of email or the Internet to communicate with a doctor or doctor's office and the results are presented in Table 5. These results indicate that having high access is only a significant predictor of engaging in this eHealth activity among those in the two older age groups or ages 40 and over. Among all three age groups, education is positively associated with using the Internet to correspond with a doctor and remains so when the controls are added in Model 2. However, the relationship is not linear for the middle age group in either model. For this age group, having a high school degree is the most negatively associated with the outcome, even more so than having less than a high school degree.

Income is a significant predictor of engaging in this eHealth activity at every income level across age groups and in both Models 1 and 2. However, the relationship varies somewhat between age groups. For the middle age group, the relationship operates such that each higher level of income is associated with a higher likelihood of corresponding with a doctor online. Among the youngest group however, the second income bracket ( $\$ 20,000$ to $\$ 35,000$ per year) is the most negatively associated with the 
eHealth activity, more so even than those making less than $\$ 20,000$ a year. And among those ages 60 and older, it appears that each level of income below $\$ 50,000$ or less annually is similarly negatively associated with engaging with the eHealth activity. For those in this age group, an annual income of $\$ 50,000$ - $\$ 75,000$ is significantly less likely than those making $\$ 75,000$ or more each year to engage in this eHealth activity of corresponding with a doctor online, but to a much lesser extent than the lower income brackets. Additionally, insurance status is a significant predictor with those who have no health insurance being significantly less likely to use the Internet to correspond with a doctor at every age.

Regression results predicting the two remaining eHealth activities, sharing health information on social networking sites, such as Facebook or Twitter, and participating in an on-line support group for people with a similar health or medical issue, are provided in tables 6 and 7 respectively. These results do indicate a relationship between level of motivation/material access with both eHealth activity but to a much lesser extent than the first two activities. In terms of one's likelihood of sharing health information on a social networking site, high access is positively associated with the activity for the older two age groups. However, in terms of one's likelihood of participating in an online support group for people with similar health or medical issues, the effect of having high access is only significant for the middle age group.

For the most part these results do not indicate much of a relationship between education and either eHealth activity with two exceptions. First, among the oldest age group, as compared to those with a post baccalaureate's degree, those who have a college 
degree and those who have some college, are more likely to share health information on social networking sites. And as for participation in a support group, having a high school degree is negatively associated with the likelihood of participating in this eHealth activity at every age.

In terms of the effects of income on sharing health information on social networking sites, results of Model 1 show that making the lowest level of annual income is actually positively associated with participating in the eHealth activity, in particular for the older two age groups. For the middle-aged group making the second lowest level of income $(\$ 20,000$ to $\$ 35,000$ per year) is also a significant predictor of this eHealth activity. As for participation in an online support group, there does not appear to be much of an effect from level of income. However, among the middle and older age groups, these results show that the lowest level of income is again positively associated with this eHealth activity.

Lastly, across each of the four regressions estimating the effects on participation in the eHealth activities, the most consistent predictor at every age is in terms of gender. Those respondents who report their gender as either female or other are significantly more likely to engage with each of the activities at every age. The only exception to this finding is seen among the oldest group in the regression, predicting the use of the Internet to correspond with a doctor or doctor's office. For those 60 years and older, there is no significant gender difference found in the likelihood of engaging in that particular eHealth activity. 
Table 8 presents unstandardized coefficients and $p$ values for the age stratified ordered logistic regression analysis estimating the moderation effects of eHealth activities on the association between motivation/material access and health. Overall, the age stratified regression Models indicate that in general having higher levels of motivation/material digital access are associated with higher likelihood of having better self-rated health. Furthermore, the results do indicate that the effect of the level of motivation/material access on health varies by age. Among the youngest age group, Model 1 indicates that although low access is not significantly different from no access, high access is positively associated with higher levels of health. However, in Model 2 once control variables are added, low access, and to a lesser extent high access are actually negatively associated with better health. And once the interaction terms are added, level of access is no longer significant. For the middle and older group, it appears that while having high access is a significant predictor of having a higher level of selfrated health, the effect of having low access on health is not significantly different from having no access when socioeconomic and demographic variables are controlled for.

In terms of the interaction effects between level of access and eHealth behaviors, there are no significant effects for the youngest group. Among both the older two groups there are some mixed results. According to the results of Model 3, for those ages 40-59, high access is associated with a $31.39 \%$ increase in the odds of reporting better health for those who use the Internet to search for health information online for themselves. Additionally, for the middle age group high access is associated with a $25.23 \%$ increase in having better self-rated health for those who participate in online support groups for 
others with similar health or medical issues. For those ages 60 and older, high access interacts with using email or the Internet to talk to a doctor or doctor's office, such that the effect on the odds of having better health are increased by $58.57 \%$ compared to those with no access.

On the other hand, for both of the older two age groups there is also some evidence in Model 3 that the interaction between access and eHealth activities decrease the odds of better health. Low access is associated with a 5.82\% decrease for the middle age group and a 5.26\% decrease for the older age group in the odds of having better health for those who search for health info online.

\section{DISCUSSION AND CONCLUSIONS}

This study investigated the relationship between access in the digital field and health by examining: (1) the extent to which motivation/material and skills/usage access are determined by level of education and income; (2) whether or not higher levels of motivation/material access are associated with skills/usage access; and (3) whether or not higher levels of digital access reap higher rewards on health via eHealth activities. While the importance of digital access cannot be overstated in current society, empirical studies examining the influence of digital access on health are limited. This study contributes to the literature by framing the potential health impacts of eHealth activities in terms of digital access and the existing unequal distribution of capital.

More specifically, I addressed four research questions using data from a nationally representative sample of the adult population in the US. For the first research question addressing whether those with higher levels of capital have higher levels of 
motivation/material access, results support the hypothesis that higher levels of capital will lead to greater levels of motivation/material access. Each higher level of education and income are associated with higher odds of having a higher level of motivation/material access in terms of whether or not one uses the Internet at all and if so, the available options and quality of mode of connection one uses. However, these results also showed that the association operates slightly differently for younger people such that the relationship is strongest for those with lower levels of education and income. These results suggest that compared to the older groups, education and income affect the level of access more in terms of the disadvantages associated with lower levels of each. This is not surprising considering how ubiquitous high levels of motivation/material access are for the youngest group. In other words, for younger folks who have largely grown up in a world saturated with digital ICTs, access is shaped less by capital at higher levels of capital because at those levels of capital most young people have similar levels of access. For this group the effects on access occur in terms of the disadvantages of having lower levels of capital.

For the second research question, the results of this study provide evidence that those with higher levels of the first two kinds and stages of digital access, motivation and material, will have higher levels of the second two kinds and stages of digital access, skills and usage. In fact, this relationship was seen across age groups and for all four eHealth activities with the singular exception of sharing health information on a social networking site among the youngest group which was not significantly predicted by level of motivation/material access. These results provide empirical evidence supporting van 
Dijk's (2005) framework for understanding digital access in terms of the first two stages and kinds of access acting as necessary precursors to the second two stages and kinds of access. Furthermore, digital access is shown to shape one's access to the eHealth activities themselves, not just in terms of whether someone can or does use the Internet, but also in terms of the way in which they connect. This is important because, consistent with previous research which has found evidence that the digital divide shapes outcomes in a much more multifaceted manner than a framework presenting the inequality in terms of the haves vs. the have-nots allows for (Lee, Park, and Hwang 2015; Reisdorf et al. 2020), here we see more gradation in terms of access to eHealth activities. This is to say that while having an Internet connection is a necessary condition to accessing available eHealth resources it may not be a sufficient condition, and that mode of connection must also be considered.

Regarding whether or not level of capital, in terms of income and education, shapes one's level of skills/usage access, in terms of engagement with eHealth activities, results varied by activity and by age. For the first two activities, searching for health information and corresponding with a doctor, both education and income do appear to shape one's level of engagement. The most robust relationship appears between income and corresponding with a doctor online which is likely, at least in part, due to the higher likelihood of people with higher income having a relationship with a doctor in general. This is further supported by the fact that having health insurance is a significant predictor for this eHealth activity more so than any other, indicating that those with health insurance are probably more likely to have a doctor to correspond with. 
Sharing health information on a social networking site along with participating in a support group online, did not have a clear relationship with level of education. The relationship between income and these two eHealth activities showed some evidence that having lower levels of income actually increased one's likelihood of using digital ICTs in this manner. Furthermore, these activities for the most part did not moderate the relationship between access and health. These findings suggest that although eHealth activities were used as proxy measures for skills/usage access it may be that some of these activities are less useful measures of skills access and more so of usage.

Previous research examining status-specific types of Internet usage has shown that there are different forms of "Internet-in-practice" such that high status users are much more likely to engage in what can be considered capital-enhancing activities online (Zillien and Hargittai 2009). This is to say that what the digital field has to offer in terms of rewards on health available via eHealth activities, may vary by activity, and for that matter, by age. For example, participation in a support group did increase the odds of better health among those with high access for those ages 40-59. And while searching for health information and corresponding with a doctor may be more in line with what others have called "capital enhancing" activities, sharing health information on a social networking site and participating in an online support group may not. Here it's important to remember that the usage gap exists not solely in terms of whether or not people who have achieved the three former phases of access go on to actually use digital ICTs or not, but also in terms of how they use them (van Dijk 2004, 2005, 2020). 
Finally, this research did find evidence of a stand-alone relationship between motivation/material access and self-rated health. However, the relationship was only significant for the older groups and only at the high level of access. The age difference may in part be due to the overall better self-rated health and higher levels of access seen amongst the younger group. Regardless, this is important because it suggests that while for younger people, type of connection may not be playing much of a role in shaping their ability to compete in the digital field, for middle and older-aged folks it does, and that having low access is ultimately the same as having no access at all. Furthermore, while searching for health information was health-promoting for those with high access for the older two groups, the same activity had a negative effect on health for the same groups with low access as compared to no access. Again, this suggests that level of motivation/material access do matter in terms of shaping one's ability to benefit from the health resources available in the digital field.

There are several limitations in this study. First, the use of cross-sectional data can only demonstrate associations between digital access and health. Future research can use longitudinal surveys or experimental methods to test causal relationships. Second, the measures used to operationalize the different stages and kinds of access might not fully or in very precise detail gauge an individual's level of digital access. For one, motivation access can only be assumed as there is no information which actually speaks to why respondents abstain from using the Internet. As for material physical access, there are disagreements among digital divide scholars regarding how to measure access across modes particularly when it comes to comparisons between smartphone connections and 
fixed-line broadband Internet access. Some evidence suggests that cellular connections provide ease of use and as a result promote engagement with eHealth activities (Jiang and Liu 2020; Jiang and Street 2017).

However, there is also evidence that a reliance on a smartphone is actually limiting to one's ability to engage with online materials in capital enhancing manners (Napoli and Obar, 2014) and that smartphone dependent users experience more prolonged periods of disconnection as maintaining the equipment produces barriers to connect (Gonzales, Ems, and Suri 2016). There is also research suggesting that no single mode of access is a better predictor of usage access, rather that having a wide range of modes of access expands usage access and supports user autonomy (Reisdorf et al 2020). For this study, broadband and wifi connections were considered optimal and folks with these modes were considered to have high access, many of whom reported having multiple modes. The decision to consider cellular access low was made because of the focus on usage access and effect on health outcomes but I acknowledge that access could be further differentiated. Similarly, the operationalization of skills and usage access is somewhat crude, particularly in terms of skills access. While other researchers working with the HINTS data have utilized the same eHealth activities as measures of usage access (Jiang and Liu 2020), they do not necessarily capture any detail regarding respondents' digital skills.

In conclusion, these findings indicate that there does exist a relationship between digital access and self-rated health and that access in the digital field is shaped to some extent by amount and composition of capital. This has policy implications as digital and 
health inequalities may be mutually constituted such that the populations being most negatively affected by digital inequality are in many cases the same marginalized populations who are already more likely to experience poor health. Moreover, the vast majority of literature examining the effects of digital access on health have focused primarily on the role of eHealth activities.

However, given the limited moderation effects found in this study and the evidence that first, digital access in all of its phases continues to be shaped by existing social inequalities and second, there exists a stand-alone relationship between access and health, future research should expand to include consideration of the access that the digital field may provide to other possible health-promoting resources. This is to say that policies addressed at reducing barriers to access will likely have more health impacts than those that focus on increasing engagement with eHealth activities or online health lifestyles. Lupton (2014) for one has been critical of understanding the use of digital technologies as health promotion tools and argues we need to "investigate and identify the social and political issues that emerge, including the ramifications for social groups who are already socioeconomically disadvantaged, have disabilities or suffer poor health" (2014:178). Rather, it is important that research does not draw attention even more away from the social determinants of health through emphasis on self-management and selfresponsibility while at the same time addressing the inequalities that are reproduced via the digital field. 
Table 1. Descriptive statistics by level of access

\begin{tabular}{|c|c|c|c|c|c|c|c|c|c|c|}
\hline & \multicolumn{2}{|c|}{$\begin{array}{c}\text { No Access } \\
4330\end{array}$} & \multicolumn{2}{|c|}{$\begin{array}{c}\text { Low Access } \\
1,045\end{array}$} & \multicolumn{2}{|c|}{$\begin{array}{c}\text { High Access } \\
14,005\end{array}$} & \multicolumn{2}{|c|}{$\begin{array}{c}\text { Access Unknown } \\
423\end{array}$} & \multicolumn{2}{|c|}{$\begin{array}{c}\text { Full Sample } \\
19,803\end{array}$} \\
\hline & Mean & (S.D.) & Mean & (S.D.) & Mean & (S.D.) & Mean & (S.D.) & Mean & (S.D.) \\
\hline Health & 3.02 & 0.01 & 3.21 & 0.03 & 3.54 & 0.01 & 3.36 & 0.05 & 3.40 & 0.01 \\
\hline Age & 66.76 & 0.22 & 57.11 & 0.50 & 52.61 & 0.13 & 58.74 & 0.77 & 56.07 & 0.12 \\
\hline Education & 2.35 & 0.02 & 2.96 & 0.03 & 3.56 & 0.01 & 3.10 & 0.06 & 3.26 & 0.01 \\
\hline \multirow{2}{*}{ Income } & 2.15 & 0.02 & 2.74 & 0.05 & 3.71 & 0.01 & 3.03 & 0.08 & 3.34 & 0.01 \\
\hline & Freq. & $\%$ & Freq. & $\%$ & Freq. & $\%$ & Freq. & $\%$ & Freq. & $\%$ \\
\hline \multicolumn{11}{|l|}{ Health } \\
\hline Excellent & 259 & 5.98 & 71 & 6.79 & 1953 & 13.95 & 52 & 12.29 & 2335 & 11.79 \\
\hline Very Good & 1081 & 24.97 & 330 & 31.58 & 5595 & 39.95 & 139 & 32.86 & 7145 & 36.08 \\
\hline Good & 1728 & 39.91 & 431 & 41.24 & 4749 & 33.91 & 159 & 37.59 & 7067 & 35.69 \\
\hline Fair & 1006 & 23.23 & 177 & 16.94 & 1473 & 10.52 & 57 & 13.48 & 2713 & 13.70 \\
\hline Poor & 256 & 5.91 & 36 & 3.44 & 235 & 1.68 & 16 & 3.78 & 543 & 2.74 \\
\hline \multicolumn{11}{|l|}{ Age } \\
\hline $18-39$ & 200 & 4.62 & 176 & 16.84 & 3333 & 23.80 & 53 & 12.53 & 3762 & 19.00 \\
\hline $40-59$ & 1030 & 23.79 & 356 & 34.07 & 5478 & 39.11 & 155 & 36.64 & 7019 & 35.44 \\
\hline $60+$ & 3100 & 71.59 & 513 & 49.09 & 5194 & 37.09 & 215 & 50.83 & 9022 & 45.56 \\
\hline \multicolumn{11}{|l|}{ Gender } \\
\hline Male & 1788 & 41.29 & 432 & 41.34 & 5793 & 41.36 & 157 & 37.12 & 8170 & 41.26 \\
\hline Female Other & 2542 & 58.71 & 613 & 58.66 & 8212 & 58.64 & 266 & 62.88 & 11633 & 58.74 \\
\hline \multicolumn{11}{|l|}{ Race \& Ethnicity } \\
\hline Hispanic & 782 & 18.06 & 206 & 19.71 & 1660 & 11.85 & 59 & 13.95 & 2707 & 13.67 \\
\hline Non-Hispanic White & 1725 & 39.84 & 528 & 50.53 & 8944 & 63.86 & 208 & 49.17 & 11405 & 57.59 \\
\hline Non-Hispanic Black & 737 & 17.02 & 163 & 15.60 & 1629 & 11.63 & 83 & 19.62 & 2612 & 13.19 \\
\hline Non-Hispanic Other & 283 & 6.54 & 63 & 6.03 & 1078 & 7.70 & 29 & 6.86 & 1453 & 7.34 \\
\hline Unknown & 803 & 18.55 & 85 & 8.13 & 694 & 4.96 & 44 & 10.40 & 1626 & 8.21 \\
\hline \multicolumn{11}{|l|}{ Insurance } \\
\hline Insured & 3876 & 89.52 & 930 & 89.00 & 13065 & 93.29 & 376 & 88.89 & 18247 & 92.14 \\
\hline Uninsured & 370 & 8.55 & 99 & 9.47 & 822 & 5.87 & 40 & 9.46 & 1331 & 6.72 \\
\hline Unknown & 84 & 1.94 & 16 & 1.53 & 118 & 0.84 & 7 & 1.65 & 225 & 1.14 \\
\hline \multicolumn{11}{|l|}{ Marital Status } \\
\hline Married & 1553 & 35.87 & 477 & 45.65 & 8272 & 59.06 & 189 & 44.68 & 10491 & 52.98 \\
\hline Divorced Separated & 940 & 21.71 & 252 & 24.11 & 2346 & 16.75 & 94 & 22.22 & 3632 & 18.34 \\
\hline Widowed & 1077 & 24.87 & 130 & 12.44 & 872 & 6.23 & 49 & 11.58 & 2128 & 10.75 \\
\hline Single / Other & 642 & 14.83 & 167 & 15.98 & 2390 & 17.07 & 80 & 18.91 & 3279 & 16.56 \\
\hline Unknown & 118 & 2.73 & 19 & 1.82 & 125 & 0.89 & 11 & 2.60 & 273 & 1.38 \\
\hline \multicolumn{11}{|l|}{ Children } \\
\hline Yes & 596 & 13.76 & 246 & 23.54 & 3857 & 27.54 & 95 & 22.46 & 4794 & 24.21 \\
\hline No & 2976 & 68.73 & 710 & 67.94 & 9551 & 68.20 & 279 & 65.96 & 13516 & 68.25 \\
\hline Unknown & 758 & 17.51 & 89 & 8.52 & 597 & 4.26 & 49 & 11.58 & 1493 & 7.54 \\
\hline
\end{tabular}




\begin{tabular}{|c|c|c|c|c|c|c|c|c|}
\hline \multicolumn{7}{|c|}{ Table 2. Descriptive statistics by age group } & \multicolumn{2}{|c|}{$\begin{array}{l}\text { full sample } \\
(n=19,803)\end{array}$} \\
\hline & Mean & (S.D.) & Mean & (S.D.) & Mean & (S.D.) & Mean & (S.D.) \\
\hline Health & 3.66 & 0.01 & 3.43 & 0.01 & 3.28 & 0.01 & 3.40 & 0.01 \\
\hline Education & 3.54 & 0.02 & 3.31 & 0.01 & 3.10 & 0.01 & 3.26 & 0.01 \\
\hline \multirow[t]{2}{*}{ Income } & 3.53 & 0.03 & 3.56 & 0.02 & 3.06 & 0.02 & 3.34 & 0.01 \\
\hline & Freq. & $\%$ & Freq. & $\%$ & Freq. & $\%$ & Freq. & $\%$ \\
\hline \multicolumn{9}{|l|}{ Health } \\
\hline Excellent & 651 & 17.30 & 904 & 12.88 & 780 & 8.65 & 2335 & 11.79 \\
\hline Very Good & 1572 & 41.79 & 2555 & 36.40 & 3018 & 33.45 & 7145 & 36.08 \\
\hline Good & 1180 & 31.37 & 2446 & 34.85 & 3441 & 38.14 & 7067 & 35.69 \\
\hline Fair & 311 & 8.27 & 914 & 13.02 & 1488 & 16.49 & 2713 & 13.70 \\
\hline Poor & 48 & 1.28 & 200 & 2.85 & 295 & 3.27 & 543 & 2.74 \\
\hline \multicolumn{9}{|l|}{ Motivation/Material Dig. Access } \\
\hline Non-Users & 200 & 5.32 & 1030 & 14.67 & 3100 & 34.36 & 4330 & 21.87 \\
\hline Low Digital Access & 176 & 4.68 & 356 & 5.07 & 513 & 5.69 & 1045 & 5.28 \\
\hline High Digital Access & 3333 & 88.60 & 5478 & 78.05 & 5194 & 57.57 & 14005 & 70.72 \\
\hline Digital Access Unknown & 53 & 1.41 & 155 & 2.21 & 215 & 2.38 & 423 & 2.14 \\
\hline \multicolumn{9}{|l|}{ Skills/Usage dig Access } \\
\hline No activities & 351 & 9.33 & 1081 & 15.40 & 2483 & 27.52 & 3915 & 19.77 \\
\hline Info Self & 3151 & 83.76 & 5057 & 72.05 & 4749 & 52.64 & 12957 & 65.43 \\
\hline Talk Doc & 1551 & 41.23 & 2569 & 36.60 & 2521 & 27.94 & 6641 & 33.54 \\
\hline Soc Network & 871 & 23.15 & 1079 & 15.37 & 554 & 6.14 & 2504 & 12.64 \\
\hline Support Grp & 409 & 10.87 & 531 & 7.57 & 234 & 2.59 & 1174 & 5.93 \\
\hline eHealth missing & 41 & 1.09 & 109 & 1.55 & 349 & 3.87 & 499 & 2.52 \\
\hline \multicolumn{9}{|l|}{ Gender } \\
\hline Male & 1371 & 36.44 & 2820 & 40.18 & 3979 & 44.10 & 8170 & 41.26 \\
\hline Female/Other & 2391 & 63.56 & 4199 & 59.82 & 5043 & 55.90 & 11633 & 58.74 \\
\hline \multicolumn{9}{|l|}{ Race \& Ethnicity } \\
\hline Hispanic & 740 & 19.67 & 1089 & 15.52 & 878 & 9.73 & 2707 & 13.67 \\
\hline Non-Hispanic White & 2045 & 54.36 & 3852 & 54.88 & 5508 & 61.05 & 11405 & 57.59 \\
\hline Non-Hispanic Black & 469 & 12.47 & 1079 & 15.37 & 1064 & 11.79 & 2612 & 13.19 \\
\hline Non-Hispanic Other & 408 & 10.85 & 584 & 8.32 & 461 & 5.11 & 1453 & 7.34 \\
\hline Unknown & 100 & 2.66 & 415 & 5.91 & 1111 & 12.31 & 1626 & 8.21 \\
\hline \multicolumn{9}{|l|}{ Insurance } \\
\hline Insured & 3294 & 87.56 & 6288 & 89.59 & 8665 & 96.04 & 18247 & 92.14 \\
\hline Uninsured & 438 & 11.64 & 661 & 9.42 & 232 & 2.57 & 1331 & 6.72 \\
\hline Unknown & 30 & 0.80 & 70 & 1.00 & 125 & 1.39 & 225 & 1.14 \\
\hline \multicolumn{9}{|l|}{ Marital Status } \\
\hline Married & 2028 & 53.91 & 4073 & 58.03 & 4390 & 48.66 & 10491 & 52.98 \\
\hline Divorced Separated & 243 & 6.46 & 1589 & 22.64 & 1800 & 19.95 & 3632 & 18.34 \\
\hline Widowed & 17 & 0.45 & 208 & 2.96 & 1903 & 21.09 & 2128 & 10.75 \\
\hline Single/Nev. Married & 1438 & 38.22 & 1068 & 15.22 & 773 & 8.57 & 3279 & 16.56 \\
\hline Unknown & 36 & 0.96 & 81 & 1.15 & 156 & 1.73 & 273 & 1.38 \\
\hline \multicolumn{9}{|l|}{ Children } \\
\hline Yes & 1902 & 50.56 & 2425 & 34.55 & 467 & 5.18 & 4794 & 24.21 \\
\hline No & 1762 & 46.84 & 4219 & 60.11 & 7535 & 83.52 & 13516 & 68.25 \\
\hline Unknown & 98 & 2.60 & 375 & 5.34 & 1020 & 11.31 & 1493 & 7.54 \\
\hline
\end{tabular}




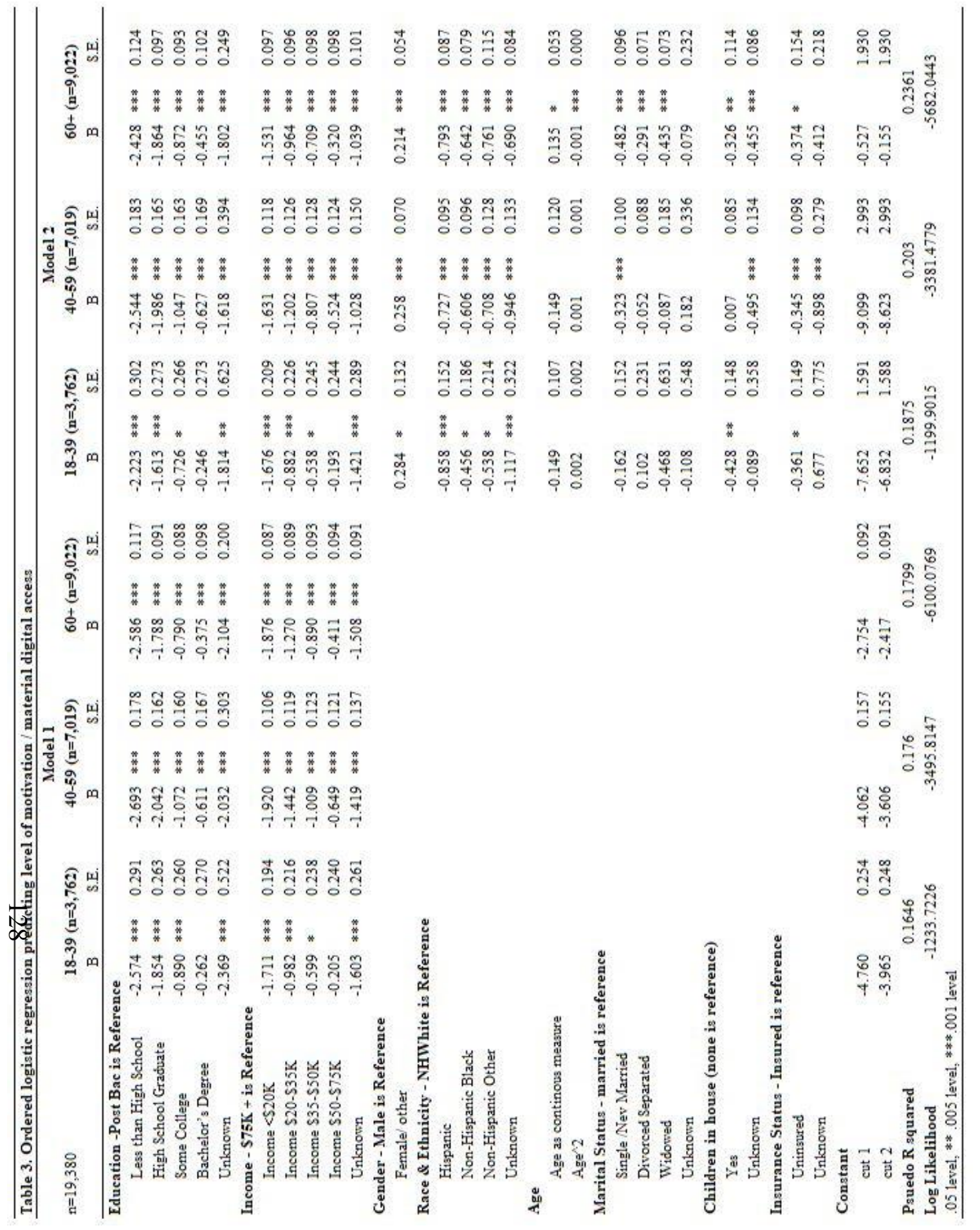




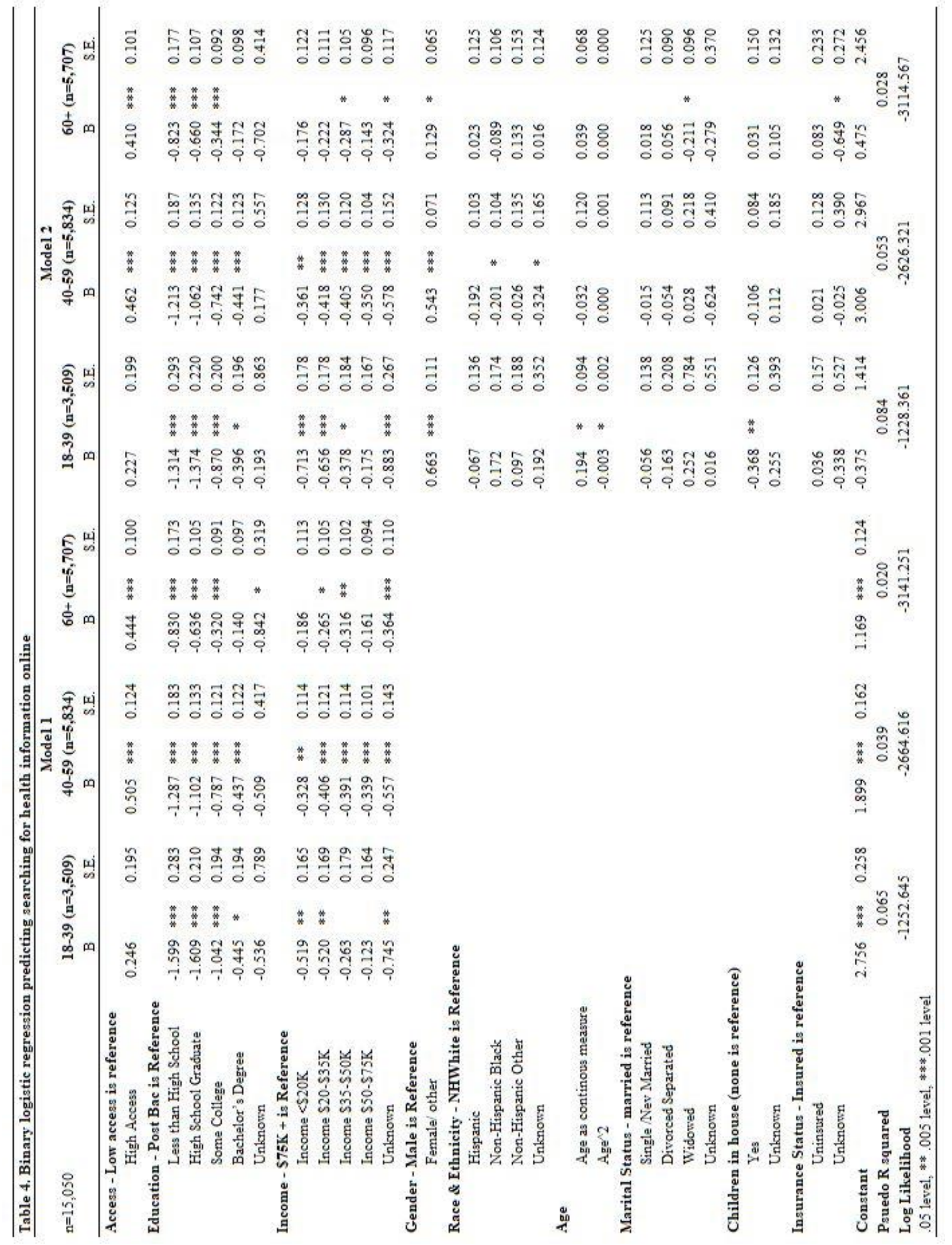




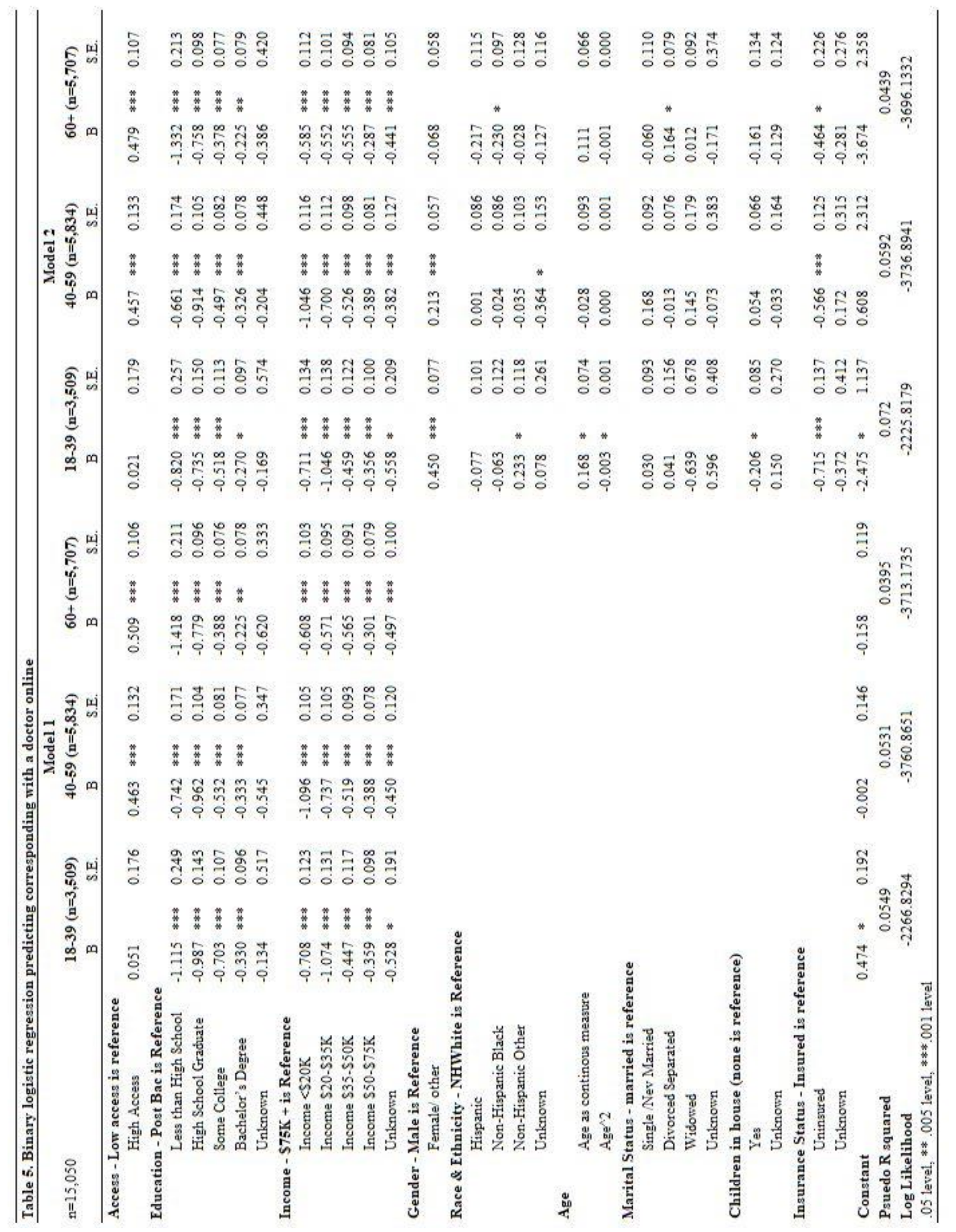




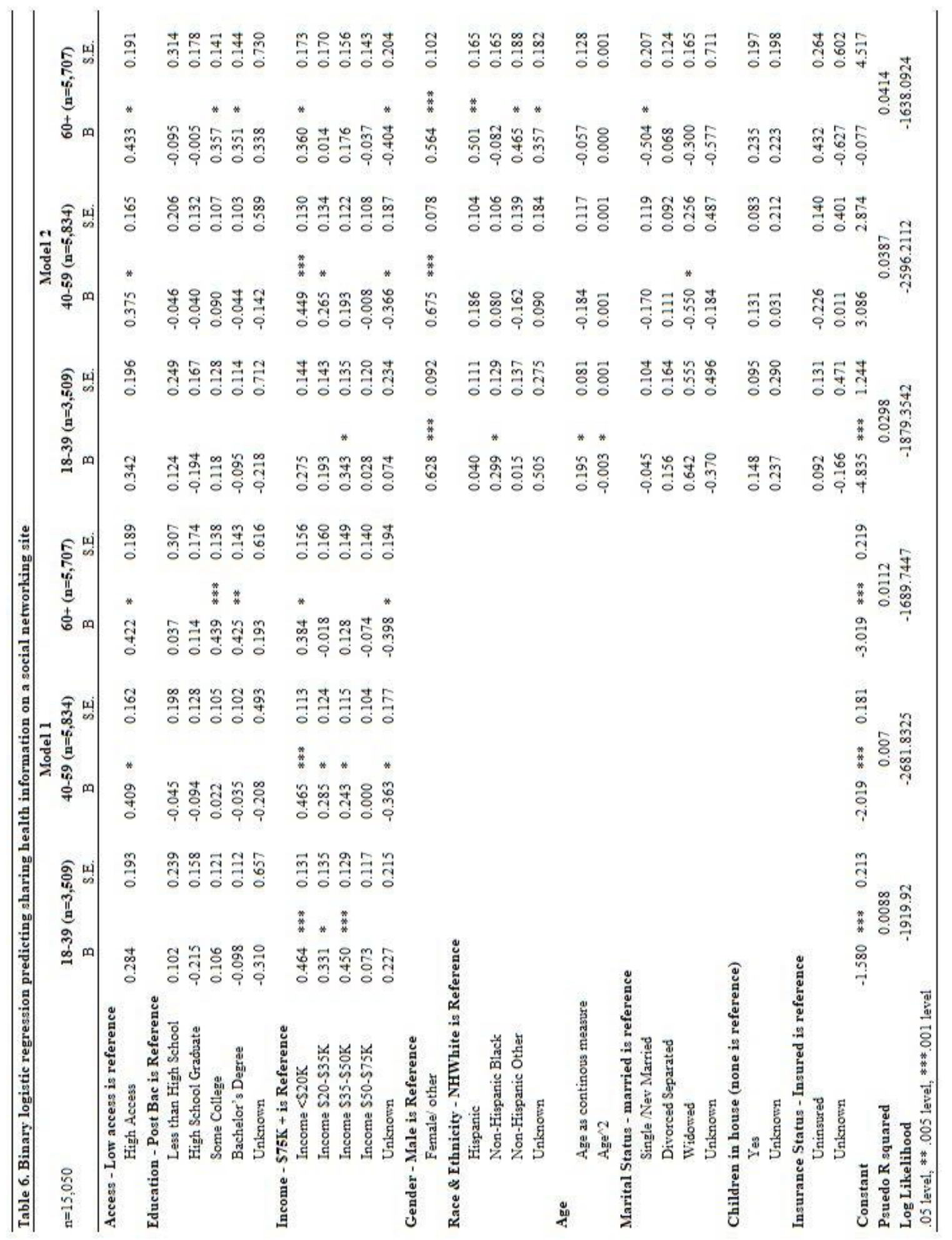




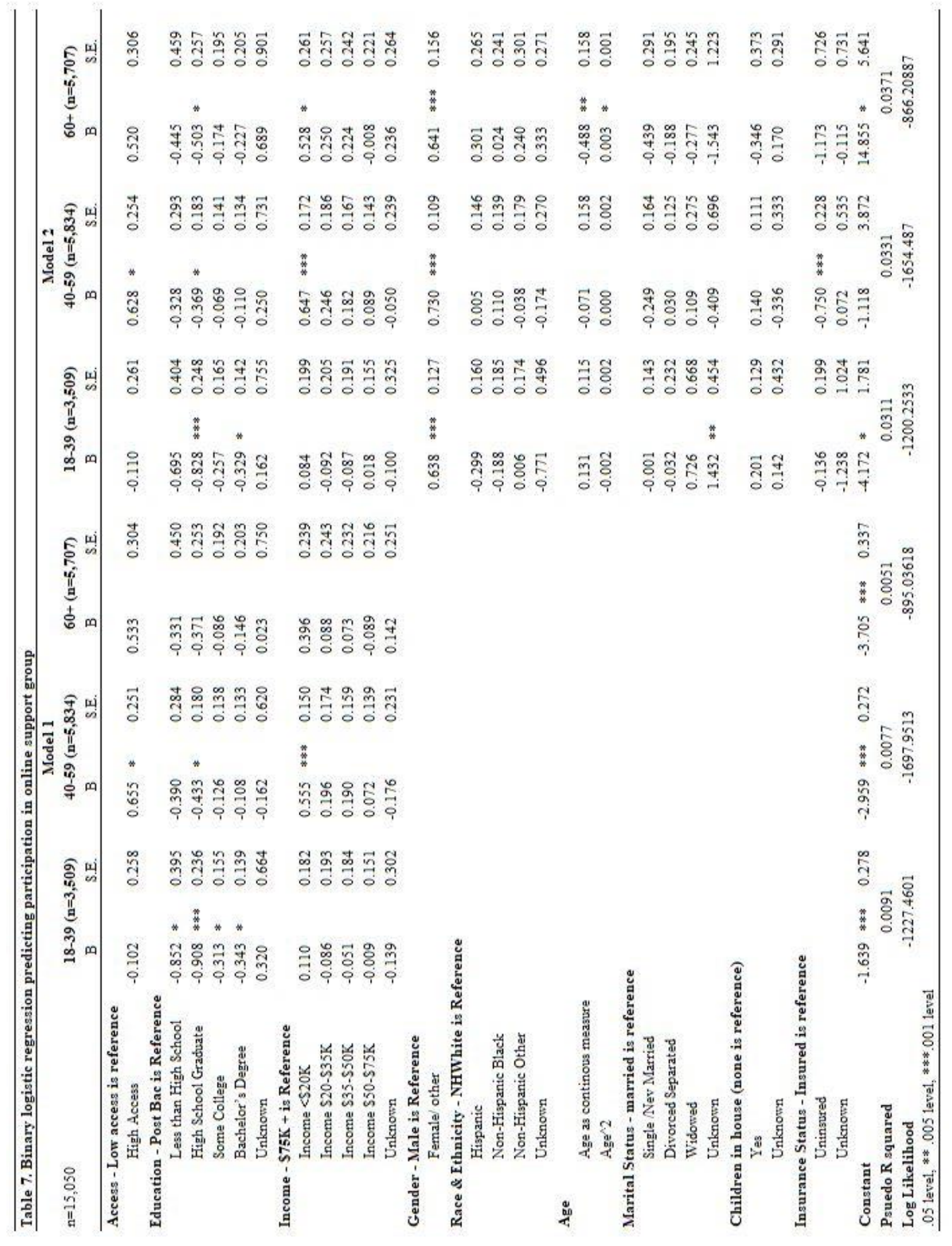




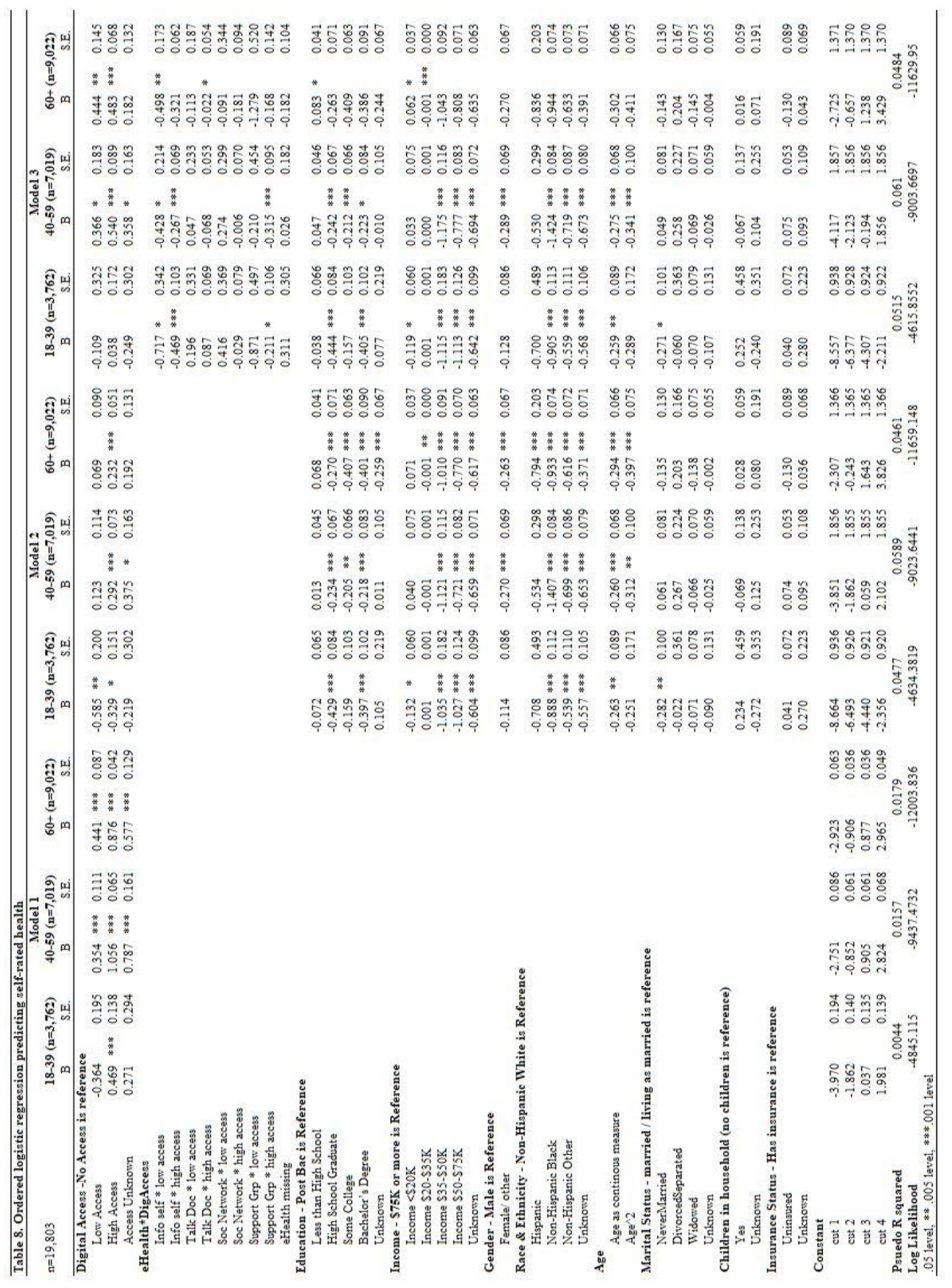




\section{REFERENCES}

Baum, Fran, Lareen Newman, and Katherine Biedrzycki. 2012."Vicious Cycles: Digital Technologies and Determinants of Health in Australia." Health promotion international 29(2): 349-360.

Breen, Richard, Kristian Bernt Karlson, and Anders Holm. 2013. "Total, Direct, And Indirect Effects in Logit and Probit Models." Sociological Methods \& Research 42(2): 164-191

Calderón Gómez, Daniel. 2020. "The Third Digital Divide and Bourdieu: Bidirectional Conversion of Economic, Cultural, And Social Capital To (And From) Digital Capital Among Young People in Madrid." New Media \& Society (2020): 1461444820933252.

Cotten, Shelia R., and Sipi S. Gupta. 2004. "Characteristics of Online and Offline Health Information Seekers and Factors That Discriminate Between Them." Social science \& medicine 59(9): 1795-1806.

Davison, Elizabeth, and Shelia Cotten. 2003. "Connection Discrepancies: Unmasking Further Layers of The Digital Divide." First Monday 8(3).

Dutton, William H., and Grant Blank. 2014. "The Emergence of Next Generation Internet Users." International Economics and Economic Policy 11(1): 29-47.

Gilbert, Melissa. 2010. "Theorizing Digital and Urban Inequalities: Critical Geographies Of 'Race', Gender and Technological Capital." Information, communication \& society 13(7): 1000-1018. 
Goldner, Melinda, Timothy M. Hale, Shelia R. Cotten, Michael J. Stern, and Patricia Drentea. 2013. "The Intersection of Gender and Place in Online Health Activities." Journal of health communication 18(10): 1235-1255.

Gonzales, Amy L., Lindsay Ems, and Venkata Ratnadeep Suri. 2016. "Cell Phone Disconnection Disrupts Access to Healthcare and Health Resources: A Technology Maintenance Perspective." New Media \& Society 18(8): 1422-1438.

Hale, Timothy M. 2011. "Health Status and Health Behavior as Factors Predicting Online Health Seeking." PhD Dissertation, The University of Alabama at Birmingham. Hale, Timothy M. 2013. "Is There Such A Thing as An Online Health Lifestyle? Examining the Relationship Between Social Status, Internet Access, And Health Behaviors." Information, Communication \& Society 16(4): 501-518.

Halford, Susan, and Mike Savage. 2010. "Reconceptualizing Digital Social Inequality." Information, Communication \& Society 13(7): 937-955.

Hassani, Sara Nephew. 2006. "Locating Digital Divides at Home, Work, And Everywhere Else." Poetics 34(4-5): 250-272.

Jiang, Shaohai, \& Liu, Piper Liping. 2020. “Digital Divide and Internet Health Information Seeking Among Cancer Survivors: A Trend Analysis From 2011 To 2017.” Psycho-Oncology 29(1), 61-67. https://doi.org/10.1002/pon.5247

Jiang, Shaohai, and Richard L. Street. 2017. "Factors Influencing Communication with Doctors Via the Internet: A Cross-Sectional Analysis Of 2014 HINTS Survey." Health Communication 32(2): 180-188. 
Kohler, Ulrich, Kristian Bernt Karlson, and Anders Holm. 2011. "Comparing Coefficients of Nested Nonlinear Probability Models." The Stata Journal 11(3): 420-438.

Lee, HyunJoo, Namsu Park, and Yongsuk Hwang. 2015. "A New Dimension of The Digital Divide: Exploring the Relationship Between Broadband Connection, Smartphone Use and Communication Competence." Telematics and Informatics 32(1): 45-56.

Levina, Natalia, and Manuel Arriaga. 2014. "Distinction and Status Production on UserGenerated Content Platforms: Using Bourdieu's Theory of Cultural Production to Understand Social Dynamics In Online Fields." Information Systems Research 25(3): 468-488.

Lindell, Johan. 2018. "Distinction Recapped: Digital News Repertoires in The Class Structure." New Media \& Society 20(8): 3029-3049.

Lupton, Deborah. 2014. "Health Promotion in The Digital Era: A Critical Commentary." Health promotion international 30(1): 174-183.

Napoli, Philip M. and Jonathan A. Obar. 2014. "The Emerging Mobile Internet Underclass: A Critique of Mobile Internet Access." The Information Society 30(5): 323-334.

Pearce, Katy E. and Ronald E. Rice. 2013. "Digital Divides from Access to Activities: Comparing Mobile and Personal Computer Internet Users." Journal of communication 63(4): 721-744. 
Pew Research Center. 2019. Internet/Broadband Fact Sheet

https://www.pewresearch.org/internet/fact-sheet/internet-broadband/\#who-hashome-broadband

Reisdorf, Bianca C., Laleah Fernandez, Keith N. Hampton, Inyoung Shin, and William H. Dutton. 2020. "Mobile Phones Will Not Eliminate Digital and Social Divides: How Variation in Internet Activities Mediates the Relationship Between Type of Internet Access and Local Social Capital in Detroit." Social Science Computer Review Advanced online publication. https://doi.org/10.1177/0894439320909446.

Tondeur, Jo, Ilse Sinnaeve, Mieke Van Houtte, and Johan van Braak. 2011. "ICT As Cultural Capital: The Relationship Between Socioeconomic Status and The Computer-Use Profile of Young People." New Media \& Society 13(1): 151-168. van Deursen, Alexander JAM, and Jan AGM van Dijk. 2014. "The Digital Divide Shifts to Differences in Usage." New media \& society 16(3): 507-526.

van Dijk, Jan AGM. 2004. "Divides in Succession: Possession, Skills and Use of New Medial for Societal Participation.” Media access: Social and psychological dimensions of new technology use 233-254.

van Dijk, Jan AGM. 2005. The deepening divide: Inequality in the information society. Sage Publications van Dijk, Jan AGM. 2020. The Digital Divide. John Wiley \& Sons. Zickuhr, Kathryn and Aaron Smith. 2012. "Digital Differences." Pew Internet \& American Life Project April 13, 2012, http://www.pewinternet.org/2012/04/13/digital-differences/ accessed May 5, 2015 
Zillien, Nicole, and Eszter Hargittai. 2009. "Digital Distinction: Status-Specific Types of Internet Usage." Social Science Quarterly 90(2): 274-291. 


\section{CONCLUSION}

This dissertation presents three papers that consider the interrelated ways in which level of digital access may affect health outcomes. In this dissertation I have situated my examination of the relationship between digital access and health within a social determinants of health perspective. By doing so, I am able to consider both a broad range of health-promoting resources available via digital ICTs as well as the possible negative health consequences that limited digital access may have on those unable to participate fully in society during the digital age. Drawing on van Dijk's (2005) causal and sequential model of digital access, I consider how the social determinants of health might interact with digital access at different levels of digital access.

\section{Summary of Findings}

In all three papers examining pooled data from three separate nationally representative cross-sectional surveys, I found evidence of a stand-alone association between digital access and health. Although digital access was operationalized differently in each paper in order to appropriately utilize the relevant survey items available from each survey, the association was evident regardless of differences in measurement. Taken together, the findings of this dissertation strongly support the hypothesis that digital access is an emerging social determinant of health. The association was consistently significant regardless of data set, operationalization, and the inclusion of different control variables. While digital access has been called a social determinant of health (Benda et al. 2020), and particularly so in the wake of the COVID-19 pandemic which put both the 
importance of and disparities in digital access in stark relief, the relationship has, until now, not been empirically studied.

Paper One: Is Digital Access Shaping or Shaped by Social Determinants of Health? Considering the Mediation and Moderation Effects of Education, Income, and Race and Ethnicity.

Paper one of this dissertation explored the effects of the digital divide on health outcomes by examining whether the association varies by education, income, or race and ethnicity, as well as whether the relationship between these socioeconomic and demographic characteristics and health are mediated by level of digital access. Findings from this paper suggest that compared to their non-Hispanic White counterparts, those who belong to racially marginalized groups, have lower levels of education or lower levels of income, are significantly less likely to have higher levels of digital access. And while there was no evidence that the effects of digital access on health varied by level of education, level of income, or race and ethnicity, findings from the mediation analyses indicate that digital access does have an indirect effect on the positive effects that higher levels of education or income have on health. In terms of race and ethnicity, the negative effects on health associated with belonging to a racially/ethnically oppressed group may be buffered by having higher levels of digital access. Once again, these findings support the conceptualization of digital access as a social determinant of health. 
Paper Two: Digital Access to Work, Occupation, Job Satisfaction: Emerging Social

\section{Determinant of Health}

Paper two examined the relationship between digital access and health outcomes in terms of the labor market related resources: work status, job satisfaction, and occupation. Findings from this paper again demonstrated that higher levels of digital access are associated with higher levels of self-rated health. In terms of labor market related resources, my findings suggest that the relationship between digital access and health may be mediated by work status. The positive effect of digital access on health may be shaped in terms of having higher levels of employment, part time or full time, as compared to not employed. These findings support the hypothesis that digital access may be related to health outcomes as it operates to determine one's work status and in particular whether or not someone is employed, a crucial social determinant of health. And while job satisfaction and occupation were not found to have significant indirect effects on the relationship, digital access remained a significant predictor of health.

While theoretically there are good reasons to believe that level of digital access will have an impact on health outcomes as they shape access to labor market resources, this relationship may be hard to detect using current survey data because technology adoption and diffusion has been a dynamic and ongoing process, where structural barriers to digital access and patterns of behavior continue to shift. Any possible effect digital access might have on health outcomes via labor market resources will likely be only now emerging as a result of the increasing shift to digital pathways of access. 


\section{Paper Three: Access in The Digital Field, eHealth Behaviors and Health.}

The third paper of this dissertation investigated the relationship between digital access and health by examining: (1) the extent to which motivation/material and skills/usage access are determined by level of education and income; (2) whether or not higher levels of motivation/material access are associated with skills/usage access; and (3) whether or not higher levels of digital access reap higher rewards on health via eHealth activities. Furthermore, the analyses for this paper were stratified by age in order to examine these associations as they were shaped by age. Results of this paper support the hypothesis that higher levels of capital lead to greater levels of motivation/material access. More specifically, each higher level of education and income were found to be associated with higher odds of having a higher level of motivation/material access.

Additionally, the results from paper three provide empirical evidence supporting van Dijk's (2005) framework for understanding digital access in terms of the first two stages and kinds of access acting as necessary conditions to the second two stages and kinds of access. This is to say that having an Internet connection may be a necessary condition for attaining skills or usage access but it is not a sufficient condition and that mode of connection must also be considered. Finally, this research added a new level of understanding regarding the effects of digital access on health, as while there was evidence suggesting a stand-alone relationship, the effects were only significant for the older two groups and only at the high level of access. 


\section{IMPLICATIONS AND LIMITATIONS}

The findings from this dissertation have important implications for understanding the effects of digital access on health. Using pooled data from multiple years of three separate cross-sectional nationally representative surveys, analyses in each paper found evidence of a stand-alone relationship between level of digital access and self-rated health. This may have important implications for existing health disparities as evidence of persistent socioeconomic and demographic disparities in digital access was also shown in this study.

Much of the digital divide scholarship has shifted focus from what is considered the first divide shaped by one's physical or material access to digital ICTs, to the second and third divides understood in terms of one's skills/usage access and the tangible outcomes shaped by one's access respectively (van Deursen and Helsper 2015). This study contributes to the literature on third-level digital divide by examining the disparities in the health returns from Internet use. Once physical and material access to digital ICTs is near universal it is likely that the disparities in returns on use will be more pronounced and research on these trends will continue to be important for mitigating inequality. However, findings from this dissertation also suggest that focus and attention are still needed in terms of the first-level digital divide and particularly in terms of the role access plays in shaping the effects of social determinants on health.

Little research has examined the association between access to digital ICTs and health outcomes in terms of the role the digital field plays as a point of access to many important social determinants of health such as employment, income and education. 
Rather, many have discussed what has been termed "eHealth" which can be understood as access to digital health resources such as electronic health records, online health and disease management information, and virtual healthcare. However, these findings suggest that that there is a broader relationship between digital access and health and that access in the digital field is shaped to some extent by amount and composition of capital. This has policy implications as digital and health inequalities may be mutually constituted such that the populations being most negatively affected by digital inequality are in many cases the same marginalized populations who are already more likely to experience poor health. Policies addressed at reducing barriers to access will likely have more health impacts than those that focus on increasing engagement with eHealth activities or online health lifestyles.

There are a number of limitations in these studies. First, the measures used in these three papers to operationalize the level of digital access do not capture the full range of access theorized by van Dijk's (2005) sequential model. Although digital access may be conceptualized in terms of motivational, material/physical, skills, and usage access, the data used for this research do not allow for operationalizing these successive forms and stages of access. The vast majority of literature examining the effects of digital access on health have focused primarily on the role of eHealth activities. However, given the limited moderation effects found in this study and the evidence that first, digital access in all of its phases continues to be shaped by existing social inequalities and second, that there exists a stand-alone relationship between access and health, future research should expand to include consideration of the access that the digital field may 
provide to other possible health-promoting resources. Surveys designed to collect data on and monitor national trends in important social determinants of health should include measures of digital access beyond equipment and mode of connection.

Additionally, the use of cross-sectional data can only demonstrate associations between digital access and health. While theoretically there are good reasons to believe that level of digital access will have an impact on health outcomes, this relationship may be hard to detect using current survey data because technology adoption and diffusion has been a dynamic and ongoing process, where structural barriers to digital access and patterns of behavior continue to shift. Any possible effect digital access might have on health outcomes via labor market resources will likely be only now emerging as a result of the increasing shift to digital pathways of access. Further testing is needed, and in time should be conducted using longitudinal data, to investigate the causal nature of the relationship. Some studies have also begun to recognize the negative effects associated with the use of digital ICTs (van Dijk 2020). Research on this topic is needed in terms of the possible ways in which the use of digital ICTs may be harmful to health in particular. While digital divide scholars have certainly focused much attention on the effects of digital access on economic stability, social support, and education, research has rarely been in terms of the relationship to health outcomes. Perhaps the most dramatic examples of this importance have emerged in the context of the COVID-19 pandemic. The social distancing orders put in place in response to the pandemic created a new heightened demand for digital access as digital ICTs were being used to work or attend school remotely and using videoconferencing and online systems including email to distribute 
and share materials. At the same time, those included in the rising number of unemployed due to the pandemic depended on online unemployment benefits filing systems. From online grocery ordering, videoconferencing with friends and families for social connection and support, to streaming workout videos from home, the COVID-19 pandemic drastically increased reliance on digital ICTs for everyday activities for many. In light of the COVID-19 pandemic, there has been an increase in attention paid to the role of digital access in shaping health outcomes by public health and medical professionals. Eruchalu et al. claim that, "the COVID-19 pandemic has highlighted that digital access is now a social determinant of health and a prerequisite for access to both COVID-related and non-COVID care" (2021:3). Digital ICTs became necessary for much of the basic healthcare delivery as the use of telemedicine and telehealth became almost ubiquitous for ambulatory care occurring primarily via videoconferencing during the pandemic (Wosik et al. 2020). Furthermore, dissemination of evidence-based safety guidelines fundamental to limiting the spread of COVID-19 required not just physical access to digital ICTs, but digital literacy skills as well, as one must be able to utilize digital ICTs to access the information in order to assess the trustworthiness of its source (Eruchalu et al. 2021). In a recent editorial in the American Journal of Public Health titled "Broadband Internet Access Is a Social Determinant of Health!” Benda et al. urge the public health community to recognize broadband Internet access as a social determinant of health. They write, "the combination of an infectious illness spreading through the populace, social distancing orders, school closures, and widespread 
unemployment form the COVID-19 pandemic has demonstrated more clearly than ever how true this is" (Benda et al. 2020:1124).

While the COVID-19 pandemic has put the relationship between digital access and health in stark relief, from a broader perspective on the social determinants of health, the relationship can be understood as having been growing for as long as the conditions of modern life have been increasingly occurring in a digital context. Here, a social determinants of health perspective provides a framework for understanding health inequalities as rooted in and shaped by social inequalities. In the 2008 World Health Organization final report of the Commission on Social Determinants of Health, Michael Marmot offered a description of how health inequalities are shaped by the conditions in which people live,

The poor health of the poor, the social gradient of health both within and between countries, and the marked health inequities between countries are caused by the unequal distribution of power, income, good and services, globally and nationally, the consequent unfairness in the immediate, visible circumstances of peoples' lives, their access to health care, schools, and education, their conditions of work and leisure, their homes, communities, towns, or cities - and their chances of leading a flourishing life. This unequal distribution of health-damaging experiences is not in any sense a 'natural' phenomenon, but is the result of a toxic combination of poor social policies and programmes, unfair economic arrangements, and bad politics (World Health Organization, 2008:1).

Put in terms of digital access, the social determinants of health are the ways in which the above circumstances are shaped by digital access. In other words, because access to the basic goods and services, opportunities for education and employment, as well as political and social participation, which are key drivers of morbidity and mortality, are increasingly accessed via digital ICTs, and as such, digital access may be increasingly linked to social determinants of health. 
This is all to say, that while the uptick in attention to digital access as a social determinant of health is incredibly important, it is perhaps equally important that the understanding of the relationship does not pertain solely to the proximal pathways through which it might operate. While healthcare delivery, access to health information and the use of online health management applications are important mechanisms, by narrowly focusing on the relationship between digital access and health in terms of these pathways, scholars may form an "incomplete understanding and underestimation of the influence of social factors on health" (Link and Phelan 1995:81). This research contributes to the existing digital divide literature as well as the research on social determinants of health, by examining the effects of digital access as a potential social determinant of health. Digital access seems to matter for health even in its broadest forms. This is to say that engagement with the Internet must not necessarily occur in one specific domain such as that of the labor market or health care in order to reap benefits within that domain offline. In other words, general engagement with the Internet may be an important predictor for offline benefits to health. 


\section{REFERENCES}

Eruchalu, Chukwuma N., Margaret S. Pichardo, Maheetha Bharadwaj, Carmen B. Rodriguez, Jorge A. Rodriguez, Regan W. Bergmark, David W. Bates, and Gezzer Ortega. 2021. "The Expanding Digital Divide: Digital Health Access Inequities during the COVID-19 Pandemic in New York City." Journal of Urban Health 1-4.

Benda, Natalie C., Tiffany C. Veinot, Cynthia J. Sieck, and Jessica S. Ancker. 2020. "Broadband Internet Access Is A Social Determinant of Health!" American Journal of Public Health 11(8):1123-1125.

Link, Bruce G. and Jo Phelan. 1995. "Social Conditions as Fundamental Causes of Disease." Journal of Health and Social Behavior 1: 80-94.

van Deursen, Alexander J.A.M., and Ellen J. Helsper. 2015. "The Third-Level Digital Divide: Who Benefits Most from Being Online?" Communication and information technologies annual. Emerald Group Publishing Limited van Dijk, Jan AGM. 2005. The Deepening Divide: Inequality in The Information Society. Sage Publications van Dijk, Jan AGM. 2020. The Digital Divide. John Wiley \& Sons. World Health Organization. 2008. Commission on Social Determinants of Health. Closing the Gap in A Generation: Health Equity Through Action on The Social Determinants of Health: Final Report of The Commission on Social Determinants of Health. 
Wosik, Jedrek, Marat Fudim, Blake Cameron, Ziad F. Gellad, Alex Cho, Donna Phinney, Simon Curtis et al. 2020. "Telehealth Transformation: COVID-19 And the Rise of Virtual Care." Journal of the American Medical Informatics Association 27(6): 957-962. 